\title{
Avaliação de Desempenho de um Sistema de Provimento de Vídeo em Ambientes Distribuídos
}

\section{Ronaldo Celso Messias Correia}

Orientador: Prof. Dr. Edson dos Santos Moreira

Dissertação apresentada ao Instituto de Ciências Matemáticas e de Computação - USP, como parte dos requisitos para obtenção do título de Mestre em Ciências Área de Ciências de Computação e Matemática Computacional. 


\section{AgRADECIMENTOS}

Ao Prof. Dr. Edson dos Santos Moreira pela orientação, apoio, incentivo, muita dedicação e ensinamentos sem os quais esse trabalho não teria sido concluído.

Aos amigos da república: André, Mário Teixeira, Mário, Milton, Robson, Rogério, Shiro e Silvio, pela amizade, companheirismo, apoio e disposição para incentivar e colaborar.

Ao amigo Shiro (Antonio Marcos), pelo grande incentivo e ajuda na realização do projeto.

A Fipp, Faculdade de Informática de Pres. Prudente, pelo apoio e compreensão no decorrer desse trabalho, em especial ao Diretor Moacir Del Trejo.

Aos colegas de mestrado do ICMC pelos momentos de estudo e alegria compartilhados.

Aos colegas do Intermidia, em especial ao Fábio, Rogério, Ciro, Roger, Pissioli, Elder, Taboca, Boni, Manzato, Rudnei; pela camaradagem, apoio e festas. trabalho.

A todos os funcionários do ICMC que direta e indiretamente contribuíram com este

A todas as pessoas que de alguma forma me incentivaram ou contribuiram com este trabalho.

Aos meus pais e irmãos Rita, Ricardo e Rejane que sempre me apoiaram e incentivaram. À familia de minha namorada pelo grande apoio e carinho.

A minha namorada Elaine Cristina pelo amor, dedicação, paciência e incentivo que venho recebendo desde que a conheci. 
Aos meus pais,

Francisco Deocciano Correia e Francisca Messias Correia.

E a minha namorada, Elaine Cristina.

Pelo seu amor, compreensão e incentivo durante todos esses anos 


\section{Referências Bibliográficas}

[Fe94] Federighi, C.; Rowe, L. A. A Distributed Hierarchical Manager for a Video-onDemand System. Anais do Symp. On Elec. Imaging Sci. \& Tech., pp. 185-197, fevereiro, 1994.

[F195] Fluckiger, F. Understanding Networked Multimedia Applications and Technology. Hemel Hempstead - UK, Prentice-Hall, 1995.

[Le94] Lee, E. K.; Chen, P. M.; Hartman, J. H.; Drapeau, A. L. C.; Miller, E. L.; Katz, R. H.; Gibson, G. A.; Patterson, D. A. RAID-II: A Scalable Storage Architecture for

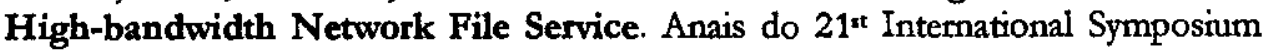
on Computer Architcture, pp. 234-244, abril, 1994.

[L093] Lougher, P.; Shepherd, D. The Design of a Storage Server for Continuous Media. The Computer Journal, vol. 36, n. 1, pp. 32-42, 1993.

[Mor97] Morandini, M.; Castro, M.A.S.; Pimentel, M.G.C. Princípios de Interação UsuárioComputador Aplicados ao Projeto de um Quiosque Hipermídia: uma Experiência. Submetido ao WoHM97 (III Workshop em Sistemas Hipermídia e Multimídia), São Carlos, 1997. 


\section{Resumo}

Um ambiente para provimento de dados multimídia sobre uma rede de computadores, apresenta vários limitantes, sendo o principal deles, a taxa de transmissão de dados na entrega de vídeo. Para contornar os problemas oriundos da precariedade dos protocolos TCP/IP e Ethernet para a transmissão de mídia contínua, nota-se o aparecimento de várias tecnologias que possibilitam o uso de um sistema de armazenamento remoto de vídeo e sua apresentação local com razoável qualidade sem a utilização de sincronismo durante o processo, através de técnicas de streaming de vídeo. Este trabalho procura avaliar como podem ser balanceados o desempenho do servidor com o desempenho das tecnologias de rede disponíveis no mercado (Ethernet, Switched-Ethernet, Fast Ethernet e FDDI) e a distribuição e apresentação de vídeos utilizando técnicas de downloading e streaming, de modo que o usuário possa ter uma idéia de como especificar seu ambiente à partir de um determinado perfil de aplicação. Os testes realizados através das aplicações desenvolvidas mostram que é perfeitamente possível a implementação de sistema de distribuição de vídeo via tecnologias padrão de rede utilizadas correntemente. A utilização das técnicas de downloading de vídeo, torna-se inviável para a distribuição de grandes arquivos ou em ambientes onde a quantidade de usuários é grande, devido ao tempo de transmissão do arquivo as estações. O trabalho quantifica estas observações e abre caminho para que avaliações mais finas de performance possam ser feitas. 


\section{Abstract}

Environments providing infrastructure for distribution of multimedia over computer networks have various limitations. One of the main problems is the video delivery. The tests made in this project have shown that it is possible to implement a video distribution system using standard network technologies. To avoid the problems which arise from the unsuitability of TCP/IP and Ethernet protocols for continuous media transmission, various technologies have been created. With these technologies, it is possible to store and provide video for remote access with reasonable quality without synchronization control during this process, using streaming video techniques. The use of video downloading techniques is not appropriated when we are dealing with large files or in a heavily loaded network due to transmission delays. This work evaluates how to balance the performance of the server in relation to the performance of the network technologies commercially available (Ethernet, Switched-Ethernet, Fast Ethernet and FDDI). It also evaluates the video distribution and presentation using downloading and streaming techniques. The results will help users to specify their network environments for specific types of applications. The work quantifies these observations and opens perspectives to do more focused evaluations of performance. 


\section{ÍNDICE}

1. INTRODUÇÃO.

2. ASPECTOS DA UTILIZAÇÃO DE MULTIMÍDIA EM SISTEMAS DISTRIBUÍDOS ................................3

2.1 - INTRODUÇÃO

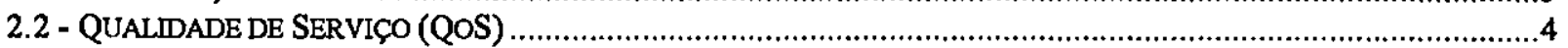

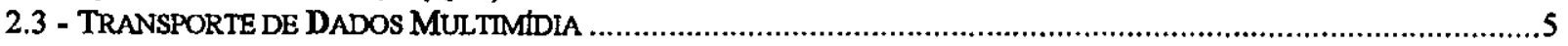

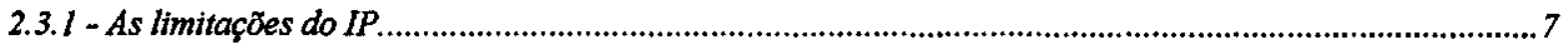

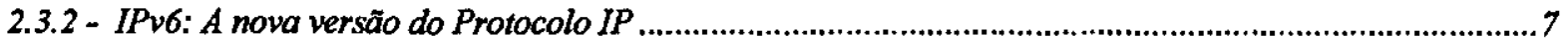

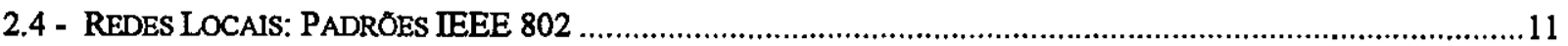

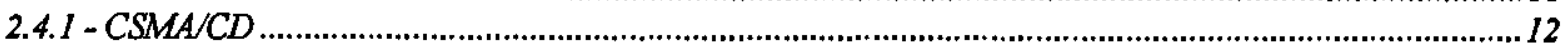

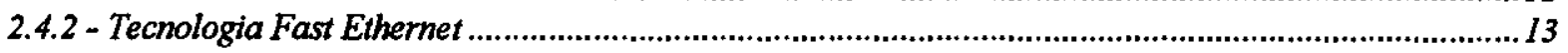

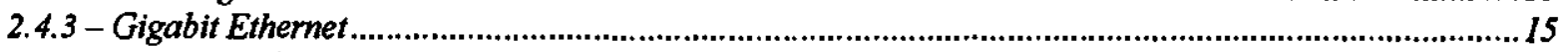

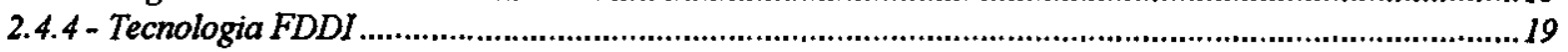

2.4.5-ATM

2.5 - PROBLEMAS COM AS PLATAFORMAS DE PROPÓSITO GERAL PARA APLICAÇÓES MULTMIDIA ..........................25

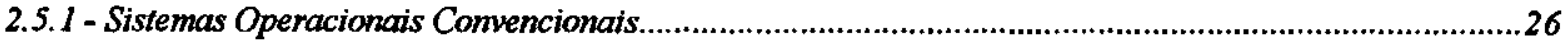

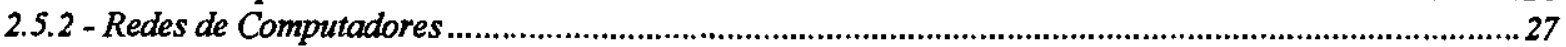

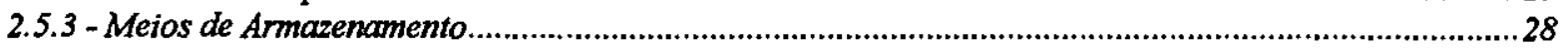

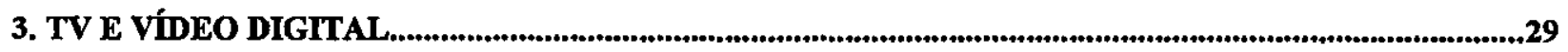

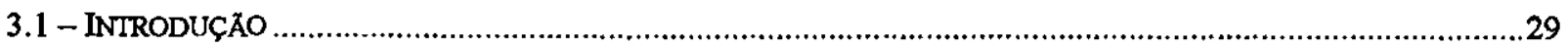

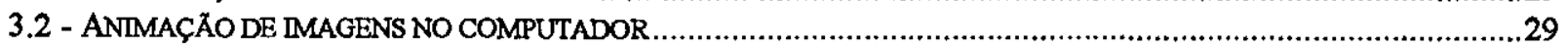

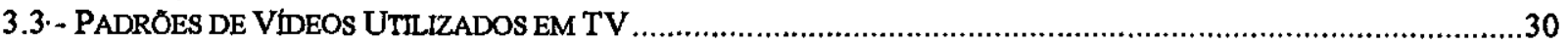

3.3.1 - Formato NTSC

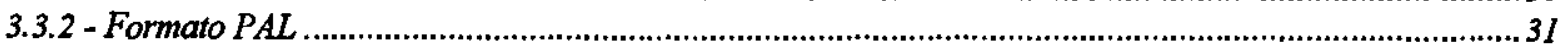

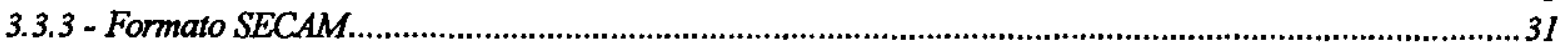

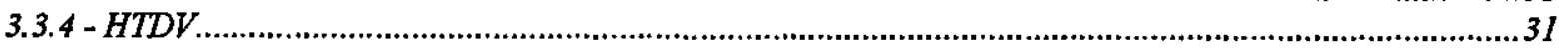

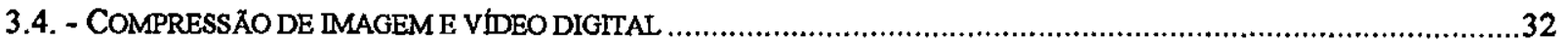

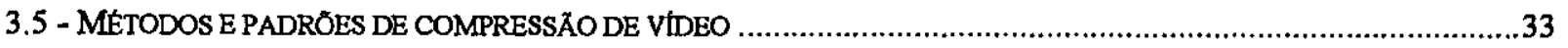

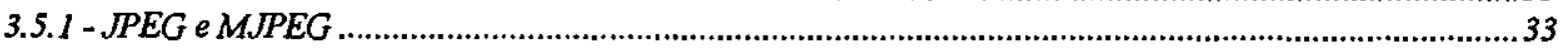

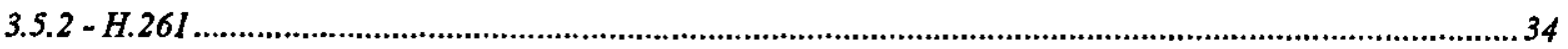

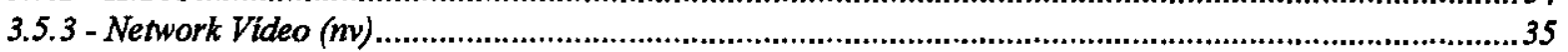

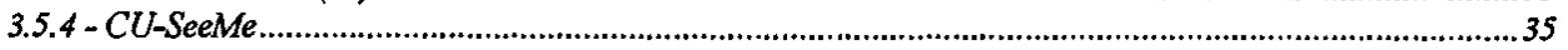

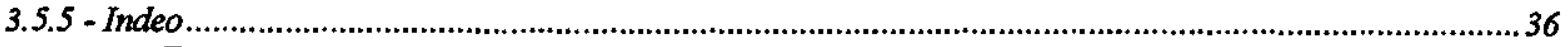

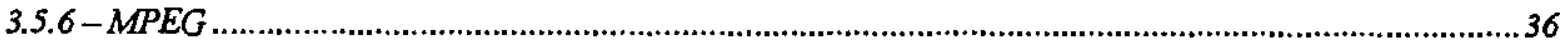

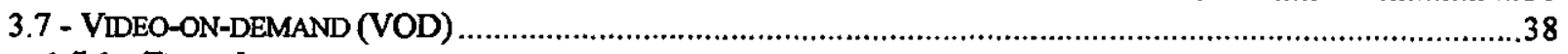

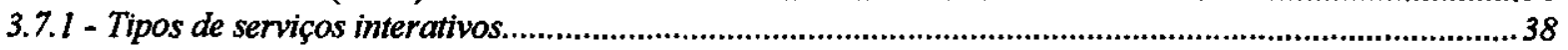

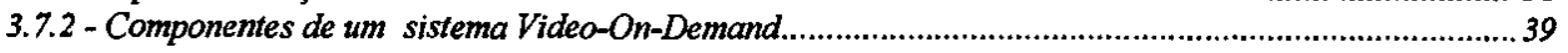

4. TECNOLOGIAS DE SUPORTE EMPREGADAS NESTE PROJETO....................................................

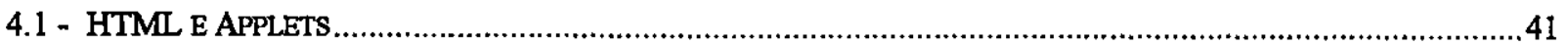

4.2 - JAVA

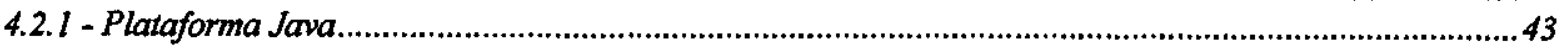

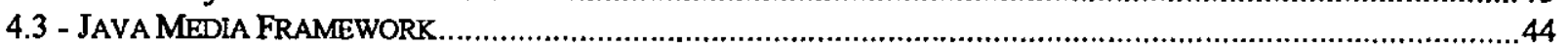

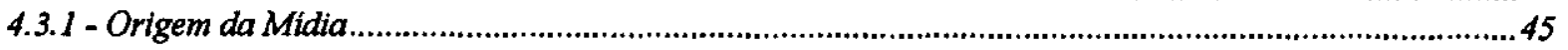

4.3.2 - Criação de um applet para executar um arquivo de midia ....................................................................46

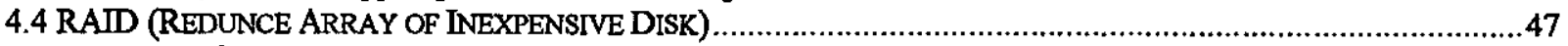

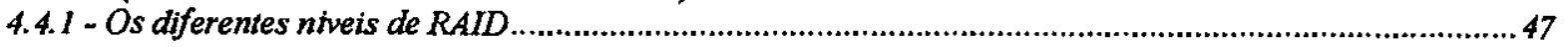

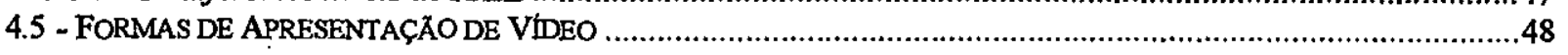

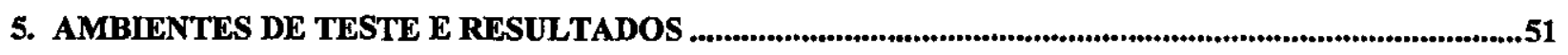

5.1 - INTRODUÇÃO 
5.2 - CONFIGURAÇÃO DO AMBIENTE.

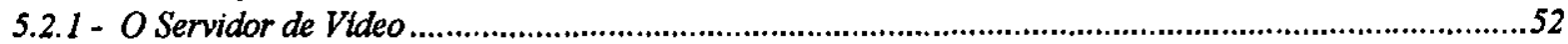

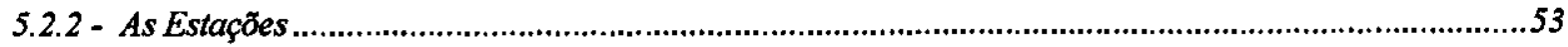

5.2.3 - Configurações de Rede Implementadas ..........................................................................................54

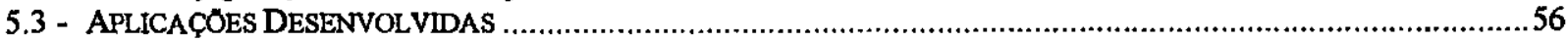

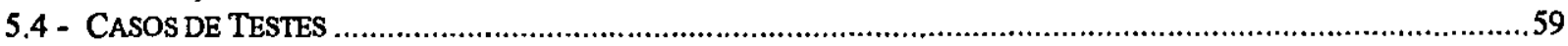

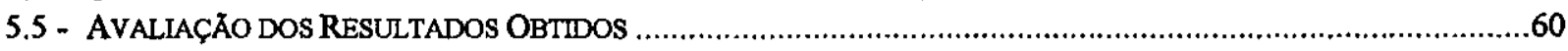

6. CONCLUSÓES

6.1- INTRODUÇÃ

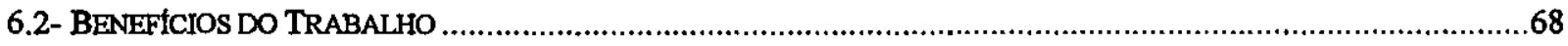

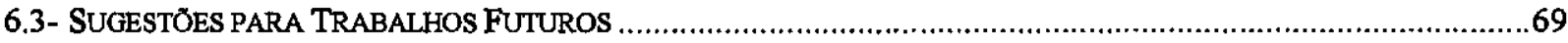

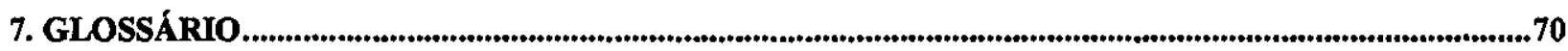

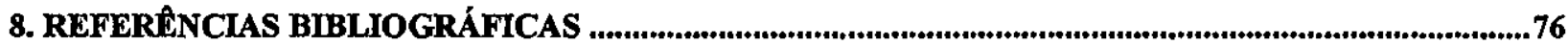




\section{LISTAS DE Figuras, TABElaS E GRÁficos}

Figura 2.1: Escopo dos padröes IEEE 802 e ANSI X3T9.5

Figura 2.2: Formato do quadro para o padräo IEEE 802.2. DSAP e SSAP identificam o destino e a origem do quadro, respectivamente.

Figura 2.3: Interface Independente do Meio

Figura 2.4: $O$ Quadro do Gigabit Ethernet

Figura 2.5: Topologia de uma rede FDDI

Figura 2.6: Quadro FDDI

Figura 2.7: Quadro FDDI para tráfego is bcrono (um quadro é gerado a cada 125 microsegundos).

Figura 2.8: Componentes da celula ATM

Figura 2.9: Classes originais de servicos suportados pelo $A A L$ (obsoletas)

Figura 2.10: $O$ modelo ATM com o AAL e suas subcamadas

Tabela 3.1: Tipos de serviços interativos [Fl95]

Figura 3.1: Componentes de um Sistema Video-on-Demand

Figura 4.1: Sintaxe de um applet

Figura 4.2 - Plataforma Java

Figura 4.3 - Criaçäo de um Applet JMF

Figura 4.4: Sistema RAID

Figura 5.1: O Ambiente Multimidia Distribuldo

Figura 5.2: Sistema de Disco do Servidor de Video

Figura 5.3: Servidor e Estaçöes em um Único Segmento

Figura 5.4: Servidor e Estaçdes em um Único Segmento Fas

Fast Ethernet

Figura 5.4: Servidor em Porta FDDI e Estaçöes em Portas Ethernet em uma Switch

Figura 5.6: Funcionamento da Ferramenta de Avaliaça de Desempenho da Rede

Figura 5. 7: Tela Principal da Ferramenta de Avaliação da Distribuiçäo de VIdeo

Gráfico 5.1: Transferência de um arquivo (81MB) do servidor para os discos das estaçóes ____ 61

Tabela 5.1: Resultados do Teste 1 (Valores em Mbytes/s)

Gráfico 5.2: Transferência de um arquivo (81MB) do servidor para a memória fisica das estaçöes____ 62

Tabela 5.2: Resultados do Teste 2 (Valores em Mbytes/s)

Gráfico 5.3: Transferência de arquivos diferentes (81MB) do servidor para os discos das estaçöes ___ 64

Tabela 5.3: Resultados do Teste 3 (Valores em Mbytes/s)

Gráfico 5.4: Teste 4- transferência de um video AVI do servidor e apresentaçäo nas estaçöes 65

Gráfico 5.5: Teste 5 - transferência de um video MPEG do servidor e apresentaçäo nas estaçöes 


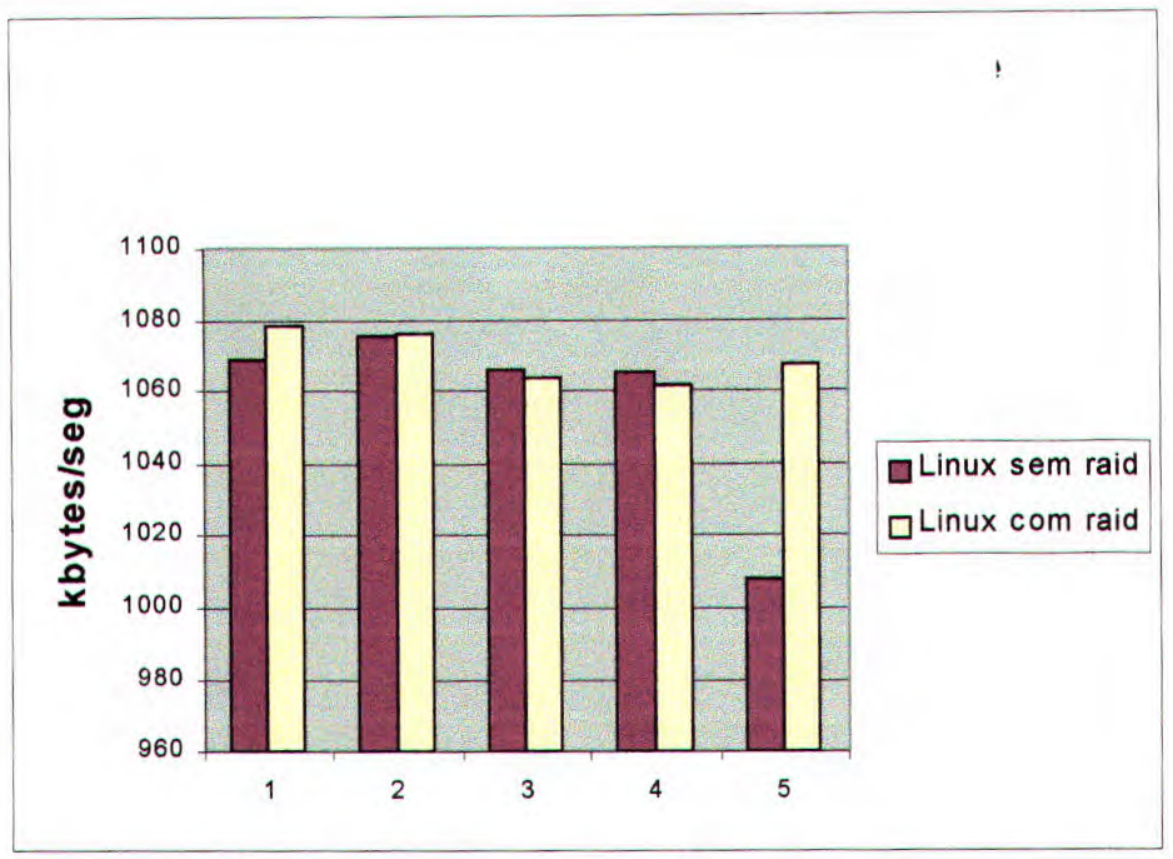

Figura 12 - Desempenho do Sistema de Arquivo sobre uma rede FDDI e switch Ethernet.

Concluímos que o gargalo do sistema inicialmente é a rede Ethernet (10Mbps), porém com um número médio de clientes, demonstrou que o sistema de arquivo tradicional se torna o gargalo, o gráfico demonstra também que o gargalo sempre é a rede no sistema de arquivo com tecnologia RAID.

\section{Estudo de Caso}

Em um ambiente educacional (Figura 13), onde o professor possui o controle total da aplicação e há necessidade de transmissão de vídeos em uma resolução de 352x240 padrão MPEG1 (1.5 Megabits por segundo), do servidor para um número elevado de clientes (20 estações), uma grande quantidade agregada de dados deverá ser transmitida pela rede (30 Megabits), mas sabemos que as redes padrões Ethernet suportam no máximo 10 Megabits tornando-se então uma aplicação inviável. 


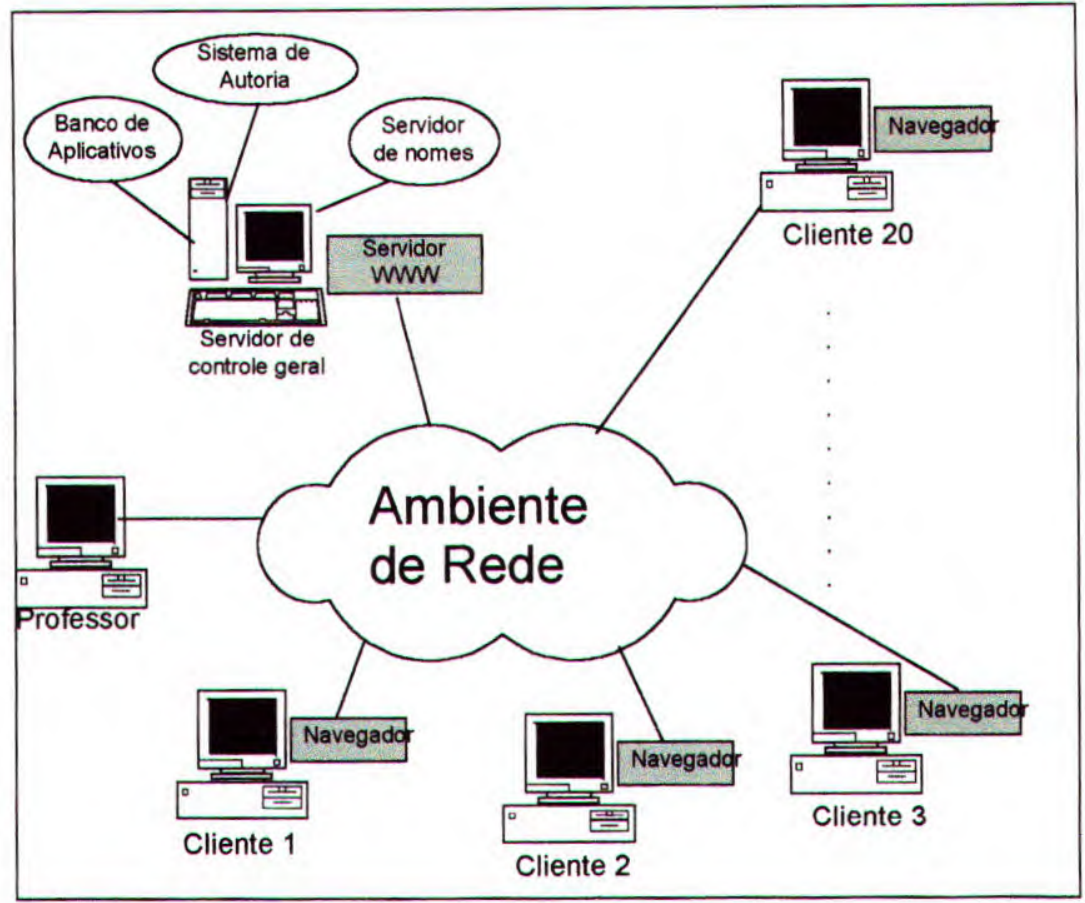

Figura 13 - Modelo de um Ambiente Educacional para Aplicações Multimídia

Problemas deste tipo são resolvidos através da utilização de tecnologias de redes de alta velocidade (Switch/ FDDI) e servidores de alto desempenho no atendimento de requisições de arquivos, conforme especificados nos testes acima (Figura 12).

\section{Conclusões}

Os testes realizados mostram que é perfeitamente possível a implementação de sistemas de distribuição de vídeo via tecnologias de rede Internet. Para contornar os problemas oriundos da precariedade dos protocolos TCP/IP e ethernet para a transmissão de mídia contínua, nota-se o aparecimento de várias tecnologias que possibilitam o uso de um sistema de armazenamento remoto de vídeo e sua apresentação local com razoável qualidade sem a utilização de sincronismo durante todo o processo (p. ex. Vxtreme, RealVideo, CU-Seeme e o padrão JMF). Desta forma, a questão principal torna-se o provimento de largura de banda necessária para a aplicação. A maioria dos problemas inseridos pela rede e pelos sistemas operacionais são resolvidos através de esquemas avançados de bufferização.

Este trabalho avaliou várias opções de tecnologias "convencionais", mostrando configurações possíveis de serem utilizadas para o serviço de armazenamento e distribuição de vídeo. Em termos gerais, a única peça não-convencional utilizada pelo sistema é uma placa especial SCSI, com 3 canais. A utilização de RAID é alcançada via software padrão embutido no Linux.

O servidor foi desenvolvido utilizando-se tecnologias de baixo custo, se comparados a sistemas semelhantes existentes no mercado. Considerando-se ainda que com o avanço tecnológico das redes, aliado com o aumento da velocidade de transmissão, acreditamos que um ambiente de provimento de vídeo como este possa ser utilizados não somente internamente a uma instituição, mas também como uma ferramenta no auxílio do ensino a distância. 


\section{INTRODUÇÃO}

A distribuição de vídeo através de redes de computadores envolve fatores como armazenamento, entrega, organização dos dados e apresentação. A questão do armazenamento e a questão da entrega de vídeos (e de dados multimídia em geral) em ambientes distribuídos (como a WWW) são pontos chave, uma vez que o fornecimento do material desejado deve atender a uma comunidade de usuários dispostos na rede em plataformas heterogêneas.

$\mathrm{O}$ grande volume dos dados multimídia e o eventual grande número de usuários realizando acessos ao sistema simultaneamente podem levar sistemas convencionais (de armazenamento e entrega) à sobrecarga, comprometendo o atendimento da demanda. [F195] [Li95]

O objetivo específico do trabalho descrito nesta dissertação é procurar avaliar como podem ser balanceados o desempenho do servidor com o desempenho das tecnologias de rede disponíveis no mercado (Ethernet, Switched-Ethernet, Fast Ethernet e FDDI) e a distribuição e apresentação de vídeos utilizando técnicas de downloading e streaming, de modo que o usuário possa ter uma idéia de como especificar seu ambiente à partị da्um determinado perfil de aplicação. Dessa forma, aplicações para transferência de arquivp̧s, distribuição e apresentação de vídeo a uma grande quantidade de estações simultaneamente foram desenvolvidas. As configurações necessárias para a implementação dos ambientes distribuidos (projetos de rede) também fazem parte do objetivo do trabalho.

Este trabalho está organizado em 6 capítulos:

- Capítulo 2: descreve os aspectos da utilização de multimídia em sistemas distribuídos, baseados na qualidade de serviço (QoS) e as características das redes tradicionais para transporte multimídia e redes ATM.

- Capítulo 3: discorre sobre as tecnologias de vídeo existentes, os métodos e padrões de compressão de vídeo, Video-On-Demand (VOD) e os tipos de serviços interativos. 
- Capitulo 4: descreve as tecnologias empregadas no desenvolvimento do projeto: HTML, Java, Java Media Framework, RAID e as formas de apresentação de vídeo.

- Capítulo 5: apresenta o projeto de mestrado desenvolvido, discutindo as implementações das ferramentas e dos projetos de rede, e os estudos de casos utilizados para a realização dos testes e a avaliação dos resultados obtidos.

- Capitulo 6: apresenta as conclusões, benefícios deste trabalho, principais dificuldades e trabalhos futuros. 


\section{ASPECTOS DA UTILIZAÇÃO DE MULTIMÍDIA EM SISTEMAS DISTRIBUÍDOS}

\section{1 - INTRODUÇÃO}

A diversidade, tanto dos dados manipulados quanto da natureza das aplicações multimídia distribuídas, reflete sobremaneira no subsistema de comunicação. Aplicaç̃os de tempo-real impõem limites no atraso a fim de garantir a naturalidade da informações (áudio e vídeo). São exemplos de tais aplicações os trabalhos cooperativos suportados por computador (Videoconferência) [Ca95] [Bo94]. Aplicações que não envolvem comunicações em tempo-real como aquelas que armazenam e recuperam documentos multimídia não impõem severas restrições no subsistema de comunicação, a maior restrição recai sobre o subsistema de apresentação. Nesta classe de aplicação os documentos são transferidos na sua totalidade antes de sua apresentação ou, se não for o caso, pode-se lançar mão de altas taxas de buferização. Aplicaç̃es como correio eletrônico multimídia e vídeo sob demanda pertencem a esta classe.

Consideraremos nesta seção apenas as aplicações que empregam comunicação em tempo-real. Estas aplicações demandam dois tipos de tráfego bastante distintos: tráfego de rajadas e tráfego com taxa constante. Tráfego de rajadas se caracterizam pela transmissão de grandes volumes de dados seguidos de perfodos de inatividade. Tanto o volume quanto o período de inatividade possuem natureza aleatória, o que torna dificil caracterizar este tipo de tráfego. Rajadas aparecem quando é necessário propagar textos ou imagens estáticas de uma estação para outra(s). Tráfego em rajadas requer apenas banda passante.

Áudio e vídeo demandam normalmente de um tráfego. Quadros de vídeo e segmentos de áudio são capturados, compactados e submetidos ao subsistema de comunicação. Entretanto, em função da técnica de compressão empregada, o volume de dados (bits) de um quadro de vídeo ou segmento de áudio pode variar. Por exemplo, pode-se propagar apenas a parcela do quadro de vídeo que sofreu variação em relação a um quadro precedente (como faz o MPEG) ou não 
propagar períodos de silêncio de áudio. Nestes casos, a taxa deixa de ser constante e o excesso de banda pode ser utilizado para outros fins. De qualquer maneira, deve-se ter uma banda permanentemente alocada ao tráfego de taxa constante, além das especificações do retardo de propagação e sua variação (jitter) possuírem valores máximos garantidos. [Ca95]

\section{2 - QUALIDADE DE SERVIÇO (QOS)}

QoS é um conjunto de parametros associados com a qualidade de um transporte de dados de uma extremidade a outra. Estes parâmetros são negociados entre as entidades comunicantes durante o estabelecimento de uma conexão. Para as aplicações multimídia distribuídas os principais parâmetros de qualidade de serviço são: [Ca95]

Taxa mínima de transferência assegurada: a quantidade de bytes que a aplicação pode transmitir em um determinado período de tempo.

Retardo máximo assegurado: o tempo máximo que o subsistema de comunicação necessita para propagar uma célula ou pacote de dados.

Jitter máximo assegurado: a variação máxima do retardo. Um jitter nulo define o tráfego como isócrono.

Taxa de perda de pacotes: média de pacotes perdidos devido aos dados ou cabeçalho serem corrompidos, ou falhas de roteamento. Presente quando o protocolo de transporte não emprega aviso de recebimento e retransmissão.

Taxa de erro de bit: média de bits incorretos no pacote.

Outros parâmetros tais como tempo máximo de abertura ou fechamento de conexões e probabilidade de resets nas conexões também podem ser considerados para fins de qualidade de serviço. 
A vasta maioria das tecnologias de redes de computadores atuais não suporta nenhum parâmetro de qualidade de serviço. Exemplo desta classe de redes são as que empregam as tecnologias Ethernet, Token Ring e FDDI para redes locais e X.25 de longo alcance. Os protocolos de transporte concebidos para operarem sobre estas redes, por conseguinte, não levam em conta qualidade de serviço durante o estabelecimento de conexões. É o caso do TPC/IP e ISO TP4, por exemplo.

Redes modernas de alto desempenho como FDDI-II e ATM permitem estipular alguns parâmetros de qualidade de serviço durante o estabelecimento de conexões, notadamente taxa mínima de transferência (garantia de banda) e tráfego isócrono.

\section{3 - Transporte de Dados Multimída}

Para sistemas multimídia distribuídos, o transporte de dados deve ter uma natureza próxima de uma transmissão contínua, para que as mídias contínuas possam fluir numa taxa ideal. Para atender este requisito os protocolos dependem da infra-estrutura de comunicação, notadamente da garantia de banda (bits/s) e tráfego isócrono. Os protocolos de transporte para aplicações multimídia devem apresentar baixo overhead. Isto é possivel atualmente graças à confiabilidade propiciada pelas redes modernas (baseadas em fibra óptica) onde a taxa de pacotes corrompidos é ínfima. Neste caso, o protocolo de transporte pode simplesmente dispensar a detecção de erros, deixando toda a confiabilidade a cargo da sub-rede de comunicação.

Atualmente, o transporte de dados de cunho geral tem a predominância dos protocolos da familia TCP/IP ( Transfer Control Protocol/Internet Protocol). Os protocolos TPC/P foram concebidos para operarem sobre sub-redes de comunicação dotadas de baixa confiabilidade onde a perda, adulteração e duplicação de pacotes de dados são freqüentes. O protocolo de rede (IP) não introduz muito overhead. O problema reside no protocolo de transporte (TCP). O protocolo TCP é orientado a conexão e é ineficaz para aplicações multimídia distribuídas pelas seguintes razões:

- nenhum parâmetro de qualidade de serviço é suportado;

- retransmissão ante a deteç̧ão de erros; 
- ausência de conexões multiponto.

Estes itens combinados tornam o protocolo inadequado para operar em tempo-real em termos de previsibilidade. Não há limite máximo garantido para o atraso e jitter, além do atraso ser considerável para grandes massas de dados devido ao cômputo do checksum por software. Outra deficiência situa-se no tipo de conexão (ponto a ponto). Conexões multiponto são estabelecidas através de conexão ponto a ponto emanando de cada nó para todos os demais.

A familia TCP/IP dispõe de um protocolo de transporte denominado UDP (User Datagram Protocol) onde a comunicação se dá sem conexão. Neste caso, a aplicação é responsável pelo gerenciamento de perda e duplicação de pacotes de dados. Como o TCP, o UDP não provê nenhum parâmetro de qualidade de serviço.

O uso da família de protocolos TPC/IP é viável para aplicações multimídia distribuídas quando a tecnologia da sub-rede de comunicação e dos processadores envolvidos assegurarem alto desempenho. Taxas de transmissão superiores a $100 \mathrm{Mbits} / \mathrm{s}$ são recomendadas para redes em conjunção com processadores de 32 ou 64 bits dotados de clock na faixa de $100 \mathrm{Mhz}$. A estratégia atual é superdimensionar o subsistema de comunicação para compensar seu não determinismo. $O$ aproveitamento das redes Fast Ethernet e Gigabit Ethernet vêem nesta direção[F195]

Para aplicações distribuídas que fazem uso de mídias contínuas o subsistema de comunicação deve suportar tráfego isócrono, isto é, deve garantir o transporte de dados à uma taxa de transferência com jitter próximo de zero. $O$ atraso e o jitter devem ser limitados a um valor da ordem de poucos milisegundos. Outra característica importante é a capacidade de se estabelecer conexões multiponto dinâmicas onde podem se juntar ou abandonar a conexão em qualquer instante de tempo. O protocolo de transporte deve ser leve, isto é, não introduzir sérios overheads na comunicação. Por exemplo, com a tecnologia de fibras ópticas a sub-rede de comunicação é confiável o suficiente para eliminar do protocolo de transporte certos mecanismos de deteç̧ão e correção de erros (por exemplo, cômputo de checksum).

Infelizmente, nenhum protocolo de transporte disponível comercialmente na atualidade atende aos quesitos apresentados acima. Dada a popularidade da família de protocolos TCP/IP, se encontra em fase de proposta a especificação de novos protocolos adequados a esta nova gama de aplicações e que mantém compatibilidade com redes TCP/IP. Os protocolos ST II e RTP são bons exemplos desta categoria. [Ca95] 


\subsection{1 - AS LIMTTAÇÕES DO IP}

O IP tem sido um sucesso desde que foi estabelecido e possui memoráveis qualidades que não devem ser esquecidas, mas, como seria esperado de um protocolo com quase duas décadas de existência, está começando a se tornar ineficiente para a nova e enorme gama de aplicaçðes que estão sendo desenvolvidas para a Internet e para a previsão da quantidade de novos usuários que deverão ser conectados à rede no futuro [Fe96][Br95][0197]

Na sua versão atual (versão 4), o IP possui muito pouco suporte a aplicaçð̃es de tempo real, não implementa nenhum controle de segurança ou autenticação dos dados, não possibilita multicast, nem configuração automática, nem níveis de Qualidade de Serviço (QoS) e, principalmente, deve esgotar os seus bits de enderȩ̧o até o ano 2000.

Quando se pensa em esgotamento de um campo de endereços de 32 bits é comum nos questionarmos se $2^{32}$ endereços (mais de 4 bilhð̃es) não serão mesmo suficientes para uma rede mundial de computadores, mas o problema não é só que existem poucos bits (na verdade ainda poucos quando se pensa na possibilidade de atribuir vários endereços IP para cada pessoa no planeta, endereços IP para equipamentos domésticos como televisores, telefones), mas sim também que no IPv4 eles não são totalmente utilizados. O IPv4 possui um esquema hierárquico de alocação de endereços que prevê alguns bits dos endereços utilizados como identificadores das sub-redes (quatro níveis de rede $A, B, C, D$ ).

Algumas medidas foram tomadas com intuito de utilizar os endereços que estão sendo desperdiçados pelo esquema hierárquico, como as tomadas de acordo com a introdução do CDRR (Protocolo Comum de Roteamento Interdomínio) que dentre outras coisas permite alocar em blocos de classes B diversas redes classe C. Entretanto isso acarreta um aumento nas tabelas de roteamento e não resolve o problema permanentemente. [Hi96]

\subsection{2 - IPv6: A NOVA VERSÃo do Protocolo IP}

Mesmo com uma política de recuperação de endereços que não estão sendo utilizados, os endereços IP se esgotarão mais cedo ou mais tarde. A solução mais intuitiva é mudar a versão do protocolo e atribuir mais bits de endereço nos campos do header. Entretanto, o que se está fazendo além disso é reformular o protocolo para melhorar a performance de roteamento, permitir a inclusão de novas op̧̧̃̃es e incluir características de autenticação e segurança. [Br95] 
O IPv6 (Internet Protocolo versão 6), o protocolo que deverá substituir o IPv4 nos próximos anos, deve solucionar o problema do esgotamento de endereços e suportar as novas tecnologias que surgiram desde que o IPv4 foi estabelecido, tais como: suporte a redes ATM, transporte de dados multimídia e QoS.[Hi96].

Uma das mais importantes características é o novo formato de endereço. O IPv6 amplia o atual endereço de 32 para 128 bits, acaba definitivamente com as classes de endereços e possibilita um método mais simples de autoconfiguração.

Outra característica importante do IPv6 é o seu novo e simplificado formato de cabeçalho. O mesmo é constitufdo por um cabeçalho inicial de 64 bits, seguido dos endereços de origem e destino de 128 bits, totalizando 40 bytes. Enquanto o cabeçalho do IPv4 possui 10 campos de cabeçalho, dois endereços de 32 bits cada, e algumas opções, o cabeçalho IPv6 compđe-se apenas de 6 campos de cabeçalho e dois endereços 128 bits cada. Os seis campos de cabeçalho são: version (4 bits), priority (4 bits), flow label (28 bits) e length of the payload (16 bits). [Si97]

Ainda comparando-se o formato do IPv6 com o do IPv4, os mecanismos de opções foram completamente revisados, seis campos foram suprimidos (header length, type of service, identification, flags, fragment offset e header checksum), três foram renomeados e, em alguns casos, ligeiramente modificados (length, protocol type e time to leave), e dois foram criados (priority e flow label). As simplificações mais consideráveis do IPv6 foram a alocação de um formato fixo para todos os cabeçalhos, a remoção do checksum de cabeçalho e remoção dos procedimentos de segmentação "hup-by-hop". A remoção de todos os elementos opcionais não significa que não se possa configurar serviços especiais. Estes poderão ser obtidos através de cabeçalhos denominados "extension headers", que são anexados ao cabeçalho principal. A remoção do checksum de cabeçalho poderia gerar problemas no roteamento dos pacotes, mas o IPv6 pressupõe que as camadas inferiores são confiáveis, com seus respectivos controles de erros como, por exemplo, o 802.2 (Logical Link Control) para redes locais, o controle das camadas de adaptação dos circuitos ATM e o controle do PPP para links seriais. [Si97] 


\section{Tipos de Endereços}

No IPv6, foram especificados apenas três tipos de endereços: Unicast, Anycast e Multicast. Sendo assim, diferente do IPv4, não mais existem endereços Broadcast. Esta função passa a ser provida pelo endereço Multicast.

Endereço Unicast: Identifica apenas uma interface. Um pacote destinado a um endereço unicast é enviado diretamente para a interface associada ao endereço.

Endereço Anycast: Identifica um grupo de interfaces de nodes diferentes. Um pacote destinado a um endereço anycast é enviado para uma das interfaces identificadas pelo endereço. Especificamente, o pacote é enviado para a interface mais próxima de acordo com a medida de distancia do protocolo de roteamento.

Este tipo de endereçamento será útil na busca mais rápida de um determinado servidor ou serviço. Por exemplo, pode-se definir um grupo de servidores de nomes configurados com um endereço anycast; o host acessará o servidor de nomes mais próximo utilizando este endereço.

Endereço Multicast: Igualmente ao endereço anycast, este endereço identifica um grupo de interfaces, mas um pacote destinado a um endereço multicast é enviado para todas as interfaces do grupo. As funcionalidades de multicasting foram formalmente incorporadas ao IPv4 em 1988, com a definição dos endereços classe D e do IGMP (Internet Group Management Protocol), e ganhou força com o advento do MBONE (Multicasting Backbone) mas seu uso ainda não é universal. Desta vez, estas funcionalidades foram automaticamente incorporadas ao IPv6. Isto significa que não mais será' necessário implementar túneis MBONE, pois todos os hosts e roteadores IPv6 deverão suportar multicasting.

Além de um maior espaço de endereços e das modificações apresentadas anteriormente, o IPv6 possui varias outras características interessantes como:

\section{Autoconfiguração}

Quando se instala uma estação cliente numa rede Netware, automaticamente, é assinalado um endereço IPX para este cliente. Esta característica de autoconfiguração, 
denominada "stateless autoconfiguration", estará presente no IPv6. Isso eliminará a necessidade de se configurar manualmente as estações da rede.

Para um maior controle de redes muito grande, os administradores poderão optar por uma outra forma de autoconfiguração, conhecida como "stateful autoconfiguration". Esta opção será disponibilizada por uma nova versão do DHCP (DHCPv6).

\section{Segurança}

As especificações do IPv6 definiram dois mecanismos de segurança: a autenticação de cabeçalho (authentication header, [At95a]) ou autenticação IP, e a segurança do encapsulamento IP (encrypted security payload, [At95b]).

A autenticação de cabeçalho assegura ao destinatário que os dados IP são realmente do remetente indicado no endereço de origem, e que o conteúdo foi entregue sem modificações. [Me95].

A segurança do encapsulamento IP permite a autenticação dos dados encapsulados no pacote IP, através do algoritmo de criptografia DES (Data Encryption Standard) com chaves de 56 bits. [Ka95].

Os algoritmos de autenticação e criptografia citados acima utilizam o conceito de associação de segurança entre o transmissor e o receptor. Assim, o transmissor e o receptor devem concordar com uma chave secreta e com outros parâmetros relacionados à segurança, conhecidos apenas pelos membros da associação. Para gerenciar as chaves provavelmente será utilizado o IKMP (Internet Key Management Protocol), desenvolvido pelo grupo de trabalho em Segurança IP.

\section{Suporte a Serviços em Tempo Real}

$\mathrm{Na}$ especificação do IPv6, o termo "flow" ou fluxo pode ser definido como uma sequeência de pacotes de uma determinada origem para um determinado destino (unicast ou multicast), na qual a origem requer um tratamento especial pelos roteadores.

Os campos "priority" e "flow label" foram criados especialmente para facilitar o desenvolvimento de protocolos para controle de trafego em tempo real, como o RSVP (Resource Reservation Protocol), de forma a permitir a implementação de uma Internet com 
aplicações multimidia e com a integração de serviços de dados, voz e vídeo em tempo real. [Me96]

\section{Suporte a Multiprotocolos e Mobilidade}

Observa-se, dos tipos de endereços unicast citados anteriormente, que foi reservada parte do espaço de endereçamento para endereços NSAP e IPX. Assim, o IPv6 suportará automaticamente trafego de redes OSI (endereços NSAP) e de rede Netware/Novell (endereços IPX). Uma grande porção do espaço de endereçamento IPv6 foi reservada para uso futuro. Essa porção também poderá ser alocada para outros protocolos que se tornarem padrões de fato.

O suporte a comunicações móveis também está presente no IPv6. Encontra-se em estudo um método para que, no estabelecimento inicial de uma sessão, um host IPv6 descubra dinamicamente através de um agente central, a localização de uma estação móvel. [Si97]

Há varias outras questões e observações sobre o processo de transição que devem ser consideradas como: planejamento de alocação de endereços, requisitos de software (sistemas operacionais e aplicativos), requisitos de hardware (memória e CPU), velocidade dos links, recursos financeiros, etc. Todos estes fatores serão imprescindíveis para o êxito de um plano de transição.

\section{4 - REDES LOCAIS: PADRÕES IEEE 802}

A Figura 2.1 ilustra onde os padrões IEEE 802 se situam no modelo OSI. O padrão IEEE 802.2 define um protocolo de enlace lógico comum: o LLC (Logical Link Control). Este padrão visa propiciar à camada de rede do modelo OSI uma total transparência em relação à tecnologia empregada em termos de método de acesso ao meio e padrões da camada física. Os padrões IEEE 802.3, 802.4, 802.5 e 802.6 são padrões de acesso ao meio e da camada física para as redes conhecidas como Ethernet, Token Bus, Token Ring e DQDB (Distributed Queue Dual Bus),respectivamente. O padrão ANSI X3T9.5 normatiza a tecnologia conhecida como FDDI (Fiber Distributed Data Interface) e, por utilizar o LLC na subcamada de enlace lógico, situa-se no mesmo nível dos padrões IEEE 802.3-6. 


\section{OSI \\ IEEE}

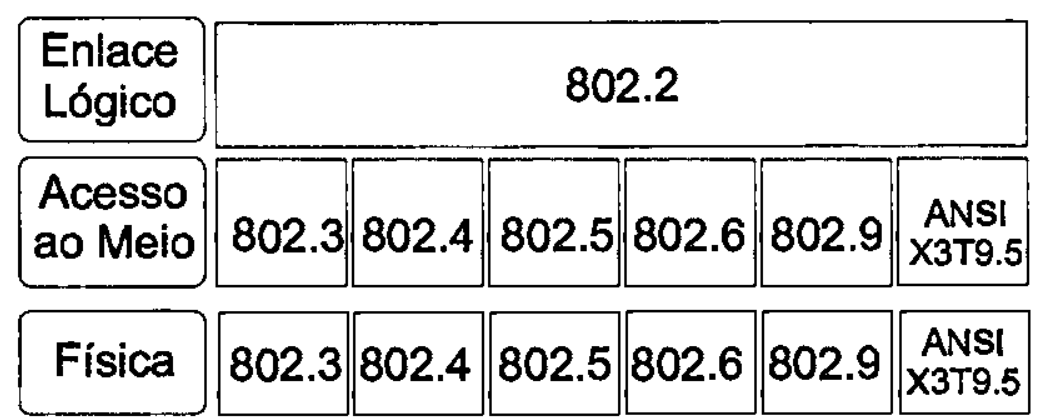

Figura 2.1: Escopo dos padrões IEEE 802 e ANSI X3T9.5

O padrão 802.2 (LLC) foi inspirado no HDLC (High-level Data Link Control), um padrão de enlace da ISO que serve de base para as redes públicas X.25 (camada 2). O LLC define o formato das unidades de dados do protocolo (PDUs, Protocol Data Units) para a camada de enlace, estabelecendo três tipos de quadros: informação, supervisão e não numerados. $O$ tipo de quadro é especificado nos dois primeiros bits do campo de controle.(Figura 2.2).

\begin{tabular}{|l|l|l|l|}
\hline $\begin{array}{l}\text { DSAP } \\
8 \text { bits }\end{array}$ & $\begin{array}{l}\text { SSAP } \\
8 \text { bits }\end{array}$ & $\begin{array}{l}\text { CONTROLE } \\
8 \text { ou } 16 \text { bits }\end{array}$ & $\begin{array}{l}\text { DADOS } \\
N \times 8 \text { bits }\end{array}$ \\
\hline
\end{tabular}

Figura 2.2: Formato do quadro para o padrăo IEEE 802.2. DSAP e SSAP identificam o destino e a origem do quadro, respectivamente.

Os quadros de informação carregam dados oriundos da camada de rede e empregam contadores nos cabeçalho para reconhecimento contínuo do fluxo de quadros. Os quadros de supervisão são empregados no controle de fluxo e como reconhecimento da recepção de quadros. Através destes o receptor informa que está pronto para receber novos quadros, ou solicita a retransmissão a partir de determinado quadro. Os quadros não numerados são utilizados para estabelecimento e térmico de conexão de enlace.

\subsection{1 - CSMA/CD}

O padrão IEEE 802.3 adota uma estratégia de acesso ao meio denominada CSMA/CD (Carrier Sense Multiple Access/Colision Detection). Nesta técnica de acesso ao meio as estações que desejarem transmitir quadros devem sensoriar o meio para detectar sua atividade. Estando o 
meio inativo, a estação inicia a transmissão, verificando se o sinal presente no meio coincide com o sinal gerado pela sua placa de rede. Se não coincidir, duas ou mais estações estão transmitindo ao mesmo tempo (colisão). Detectada uma colisão, a estação reforça a colisão injetando sinais espúrios no meio (jamming); aborta a transmissão; e volta a repetir o processo de acesso ao meio passado um período aleatório de tempo. A injeção de sinais espúrios faz com que as estações que estejam transmitindo abortem a transmissão e as estações que estejam recebendo destacarem o quadro.

Redes conhecidas comercialmente como Ethernet empregam o padrão IEEE 802.3. O meio físico é um barramento compartilhado por todas as estações. A taxa de transmissão típica é de $10 \mathrm{Mbits} / \mathrm{s}$. O meio de transmissão pode ser o cabo coaxial, par metálico trançado ou fibra ótica. Cada segmento pode se estender por 100 até 2000 metros dependendo do meio. Um máximo de cinco segmentos poderão ser conectados via repetidores. [Ca95]

\subsection{2 - TECNOLOGIA FAST ETHERNET}

O padrão 100 Base-T de Ethernet a $100 \mathrm{Mbit} / \mathrm{s}$ mantém as principais características do padrão Ethernet 10Mbit/s, tais como o formato do frame, a quantidade de dados que um frame pode carregar, e o mecanismo de controle de acesso ao meio, diferenciando do padrão original apenas na velocidade de transmissão dos pacotes, que no padrão 100 Base-T é 10 vezes maior que no original opcional. [Ot95]

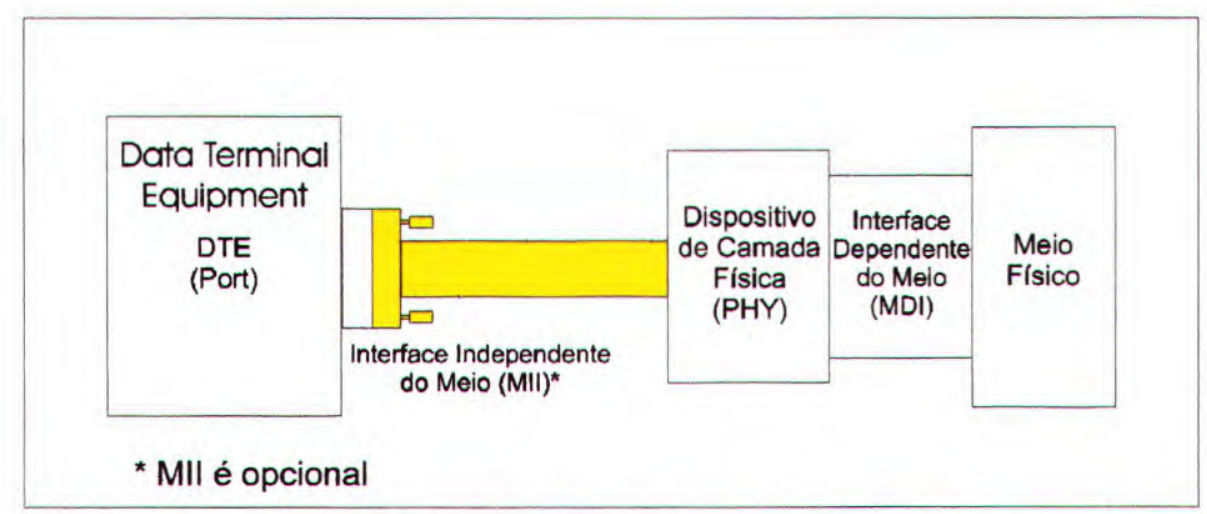

Figura 2.3: Interface Independente do Meio

A Figura 2.3 apresenta os componentes definidos no padrão IEEE para fazer uma ligação a um sistema de $100 \mathrm{Mbits} / \mathrm{s}$. 
Há três meios que foram especificados para transmitir sinais Ethernet a 100Mbit/s: 100BaseT4, 100BaseTX e 100BaseFX. É sempre bom lembrar que "100" indica que a velocidade do meio é de 100Mbit/s, e "Base", significa que o tipo de sinalização é a banda básica, ou seja, apenas sinais Ethernet são transmitidos no meio. Já T4, TX e FX identificam o meio físico utilizado.

- tipo T4 utiliza quatro canais de par trançado tipo telephone grade (UTP - Categoria 3), suportando somente transmissões half-duplex

- TX utiliza dois cabos de par trançado tipo data grade (UTP ou STP Categoria 5), suportando transmissões a half-duplex ou full-duplex

- já o FX utiliza fibra ótica, com transmissão a half-duplex ou full-duplex. Os padrões TX e FX são coletivamente conhecidos como 100Base-X.

Os padrões 100Base-TX e 100Base-FX, usados no Fast Ethernet, foram originalmente desenvolvidos pela ANSI (American National Standards Institute), para o padrão FDDI (Fiber Distributed Data Interface), e são amplamente utilizadas em redes locais FDDI. O padrão T4 foi provido para tornar possivel o uso de fios de par trançado de baixa qualidade para sinais Ethernet a $100 \mathrm{Mbit} / \mathrm{s}$.

\section{Dispositivo da Camada Física}

Este dispositivo realiza as mesmas funções gerais de um transceptor do sistema Ethernet $10 \mathrm{Mbit} / \mathrm{s}$.

Ele pode ser um conjunto de circuitos integrados dentro de uma porta Ethernet de um dispositivo de rede, portanto invisível ao usuário, mas também pode ser uma pequena caixa equipada com um cabo MII (Interface Independente do Meio), como o transceptor outboard e o cabo transceptor usados no Ethernet $10 \mathrm{Mbit} / \mathrm{s}$. 


\section{Interface Independente do Meio}

A Interface Independente do Meio (MII) é um conjunto de dispositivos eletrônicos opcionais que provê uma maneira de ligar as funções de controle de acesso ao meio do dispositivo de rede com o Dispositvo da Camada Física (PHY), o qual envia os sinais para o meio fisico. A MII pode, opcionalmente, suportar tanto operações a 10Mbit/s como a 100 $\mathrm{Mbit} / \mathrm{s}$, permitindo que dispositivos de rede convenientemente equipados possam conectar tanto segmentos 10Base-T como 100Base-T.

O MII é projetado para tornar transparente ao chip Ethernet do dispositivo de rede, as diferenças de sinalização entre os vários tipos de meio fisico. O MII converte o sinal recebido dos vários segmentos de meios pelo transceptor (PHY) em sinais no formato digital que então são providos ao chips Ethernet dos dispositivos. O MII opcional , o conector fêmea de 41 pinos a ele associado e o cabo MII, tornam possível conectar um dispositivo de rede a qualquer um dos diferentes tipos de meio, provendo assim uma maior flexibilidade.

\section{Equipamento de Terminal de Dados (Computador)}

Cada DTE ligado a um canal Ethernet é equipado com uma interface Ethernet. A interface Ethernet provê uma conexão ao meio Ethernet e contém os circuitos eletrônicos e software necessários para realizar as funções de controle de acesso ao meio necessárias para enviar um frame ao canal Ethernet.

É importante notar que as portas Ethernet dos repetidores não usam uma interface Ethernet. Uma porta do repetidor conecta-se ao sistema do meio Fast Ethernet usando os mesmos equipamentos PHY e MDI. No entanto, as portas dos repetidores operam ao nível de bit individual para sinais Ethernet, movendo os sinais diretamente de segmento para segmento.

Por meio do protocolo SNMP, hubs gerenciados tornam possível que um gerenciador de rede monitore remotamente, os níveis de tráfego e condiçø̃es de erro nas portas do hub, ou desligue portas para depurar problemas.

\subsection{3 - GrGABIT ETHERNET}

A tecnologia Gigabit Ethernet surgiu da necessidade criada pelo aumento de largura de banda nas "pontas" das redes (ex.: servidores e estações de trabalho) e também pela redução 
constante dos custos entre as tecnologias compartilhadas e comutadas, juntamente com as demandas das aplicações atuais. Com isso, o "gargalo" passou a ser o backbone e as conexões dos servidores. Assim, o Gigabit Ethernet, por seu apelo de poder oferecer a solução para o congestionamento de backbones, por atender às demandas cada vez maiores das aplicaçôes (multimídia, videoconferência, etc.) e por ser uma Tecnologia familiar e compatível com o padrão Ethernet - o que traz grandes beneficios como economia com treinamento de profissionais e a proteção do investimento já feito - está atraindo, cada vez mais, a atenção da indústria e dos profissionais da área de redes. [Mo98]

Os trabalhos para definição do padrão da tecnologia Gigabit Ethernet, ou IEEE 802.3z, foram iniciados em julho de 1996 e o interesse da indústria pelo padrão levou à criação de um consórcio aberto formado por dezenas de fabricantes, chamado de Gigabit Ethernet Alliance (GEA). O propósito deste consórcio é promover a cooperação da indústria no desenvolvimento do padrão, e tem por objetivos principais suportar as atividades de padronização conduzidas pelo grupo de trabalho IEEE 802.3z, contribuir com conteúdo técnico para facilitar o consenso em especificaç̃es, oferecer um canal de comunicação entre fornecedores e consumidores e fornecer recursos para estabelecer e demonstrar interoperabilidade entre produtos. Em janeiro de 1997, o grupo de trabalho $802.3 \mathrm{z}$ fechou a especificação impedindo a inclusão de novas caracteristicas e apresentou um primeiro draft bem estável. [Mo98]

Baseados nestas especificações, poucos meses depois, alguns fabricantes já foram capazes de produzir produtos Gigabit Ethernet, além de terem sido capazes de montar redes de demonstração com seus equipamentos interconectados em eventos e feiras.

\section{Os Padrões}

Os principais objetivos do grupo de trabalho $802.3 \mathrm{z}$ são, basicamente, desenvolver padroes que:

- Permitam operações half-duplex e full-duplex em velocidades de 1.000Mbps;

- Utilizem o formato do quadro Ethernet 802.3;

- Utilizem o método de acesso CSMA/CD com suporte para um repetidor por domínio de colisão;

- Ofereçam compatibilidade com as tecnologias 10Base-T e 100Base-T. 
O grupo de trabalho também identificou três objetivos específicos com relação às distâncias dos enlaces:

- Enlace de fibra óptica multimodo com comprimento máximo de $500 \mathrm{~m}$;

- Enlace de fibra óptica monomodo com comprimento máximo de $2 \mathrm{Km}$;

- Enlace baseado em cobre (ex.: cabo coaxial) com comprimento máximo de, pelo menos, $25 \mathrm{~m}$.

\section{Full \&Hall-Duplex}

O padrão proposto do Gigabit Ethernet, IEEE 802.3z, fornece uma largura de banda mínima de 1Gbps, tanto em modo full-duplex, como em half-duplex, sendo que, neste último, é necessário o uso de CSMA/CD para a deteç̧ão de colisões. Outro detalhe que não se pode esquecer é que, no modo full-duplex, a largura de banda é de até $2 \mathrm{Gbps}$, pois os equipamentos conectados podem transmitir e receber dados simultaneamente.

Todas as velocidades de Ethernet, 10, 100 e 1.000Mbps utilizam o mesmo formato de encapsulamento, métodos de controle de fluxo e operações full-duplex, não havendo necessidade de traduções entre formatos de encapsulamento, o que reduz a complexidade e aumenta o desempenho da comutação de pacotes. Todas as implementações iniciais do Gigabit Ethernet serão full-duplex, com conexð̃es comutadas e usarão o tamanho mínimo de pacote de 64 bytes. [Gi97]

\section{CSMA/CD Modificado}

Em modo half-duplex, é utilizado um método de acesso CSMA/CD modificado, que mantém um diâmetro de colisões em $200 \mathrm{~m}$ (exigência do próprio algoritmo) mesmo em taxas de velocidade de Gigabit por segundo. Sem isso, pequenos pacotes poderiam ser totalmente transmitidos por uma estação sem que ela "percebesse" que houve uma colisão, violando a regra do CSMA/CD. Assim, a estação não "saberia" que precisa enviar novamente o pacote que se perdeu na colisão e a informação transmitida ficaria incompleta.

A solução encontrada foi alterar o CSMA/CD. O tamanho mínimo do pacote, 64 bytes, não foi modificado. O tempo mínimo da portadora CSMA/CD e o slot-time do Ethernet é que foram estendidos de 64 bytes para 512 bytes. Assim, pacotes menores que 512 bytes recebem a adição de uma extensão de portadora no quadro do Gigabit Ethernet (Figura 2.4). Estas 
modificações, que podem afetar o desempenho na transmissão de pacotes pequenos, foram resolvidas implementando-se um recurso chamado packet bursting, que, em suma, dá a capacidade a servidores, comutadores e outros tipos de equipamentos de entregar "conjuntos" (bursts) de pequenos pacotes para utilizar a largura de banda disponível. [Gi97]

QUADRO ETHERNET ORIGINAL "SLOT TIME" DO ETHERNET ORIGINAL (64 Bytes)

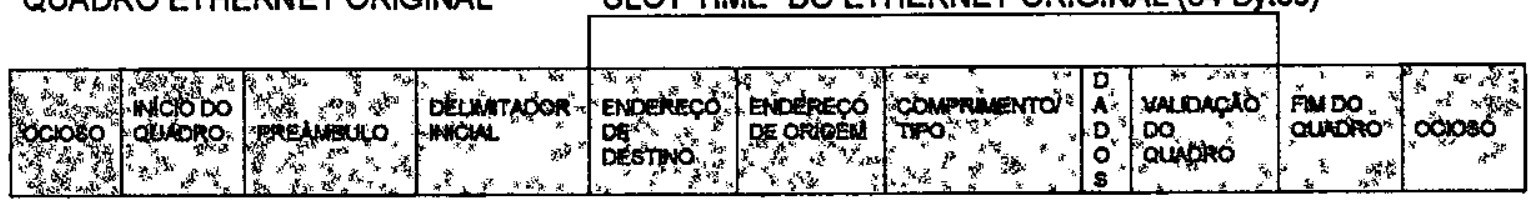

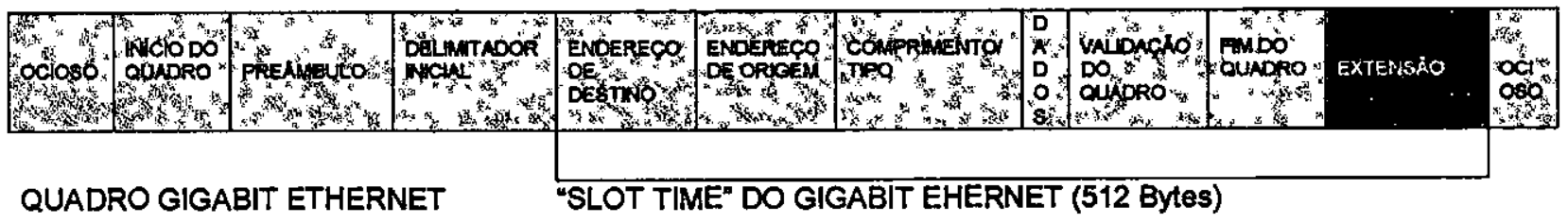

Figura 2.4: $O$ Quadro do Gigabit Ethernet

\section{Vantagens e Desvantagens}

O Gigabit Ethernet tem como principais vantagens a popularidade da tecnologia Ethernet e o seu custo. Basicamente, ele oferece um aumento de 10 vezes em relação ao desempenho da tecnologia mais popular atualmente para conexão entre comutadores e de servidores: o Fast Ethernet. Trata-se de uma tecnologia conhecida, protegendo o investimento feito em recursos humanos e em equipamentos. Não há nenhuma nova camada de protocolo para ser estudada, tendo consequentemente, uma pequena curva de tempo de aprendizagem em relação a atualização dos profissionais. A implementação dos comutadores e hubs Gigabit Ethernet deverá acontecer de forma simples e rápida, após um projeto que analise e defina onde os mesmos devem ser colocados dentro do backbone.

Apesar da alta velocidade, o padrão Gigabit Ethernet não suporta QoS (Qualidade de Serviço), que é um dos pontos mais fortes da tecnologia ATM. Desta forma, ele não pode garantir o cumprimento das exigências de aplicações, como a videoconferência com grande número de participantes, ou mesmo uma transmissão de vídeo em tempo-real de um ponto para muitos pontos. 
Para minimizar este problema, o IEEE trabalha no sentido de desenvolver um padrão que defina um esquema de prioridade (IEEE 802.1p) e possibilite algo "parecido" com o QoS.

É importante lembrar que o Gigabit Ethernet é uma tecnologia MAC e PHY e que, nas atuais implementações, funcionará com outras especificações do IETF e IEEE. Isso quer dizer que o problema da Qualidade de Serviço e Classe de Serviço serão questões a serem resolvidas pêlos protocolos das camadas superiores como o 802.3x (para controle de fluxo), 802.1Q (para redes virtuais - VLANs), 802.1p (para priorização de tráfego) e RSVP para reserva de banda.

Então, apesar do Gigabit Ethernet ser otimizado para alta velocidade de dados, ele poderá ter condições de fornecer filas de prioridade para suportar aplicações como voz e vídeo sobre IP em tempo-real.

\subsection{4 - TECNOLOGIA FDDI}

O padrão ANSI X3T9.5 (FDDI, Fiber Distributed Data Interface) normatiza uma rede com duplo anel em fibra óptica operando a $100 \mathrm{Mbits} / \mathrm{s}$ como mostra a Figura 2.5. O comprimento do anel pode chegar a $100 \mathrm{Km}$, o que dá à rede características de rede metropolitana. Foi adicionado posteriormente ao padrão como meios de transmissão alternativos o par metálico trançado e a fibra óptica monomodo. O padrão define duas classes de estações:

1. classe A: conectadas no duplo anel;

2. classe B: conectadas via $h u b$ (este ligado no duplo anel).

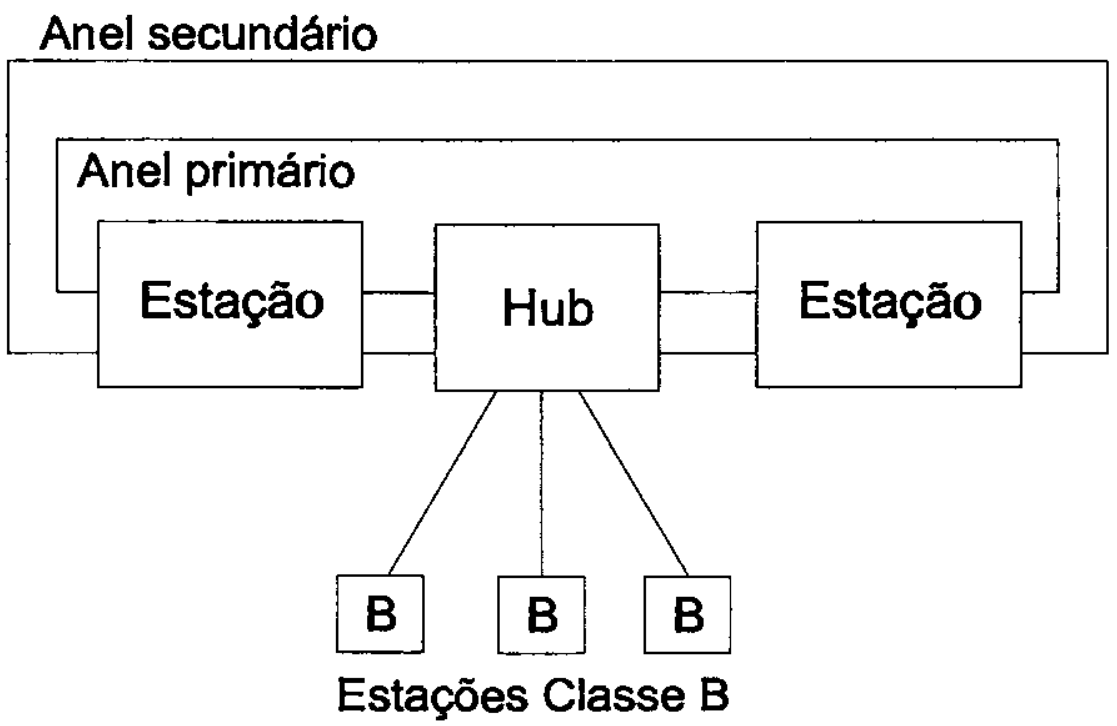

Figura 2.5: Topologia de uma rede FDDI 
O FDDI utiliza apenas um anel (dito primário) para o tráfego de dados, deixando o segundo anel (secundário) para reconfiguração. Os dois anéis se fundem quando uma interrupção é detectada no anel primário.

O padrão FDDI prevê dois tipos de tráfego:

1. síncrono, com garantia de banda e atraso máximo, mas não isócrono;

2. assíncrono, sem qualquer garantia de qualidade de serviço.

No modo assíncrono o FDDI se comporta como uma rede Token Ring de alta taxa de transmissão. $O$ acesso ao meio se dá por passagem de permissão.

O quadro de informação é exposto na Figura 2.6. O padrão admite um campo de dados de tamanho máximo de 4500 bytes. Quadros de permissão (token) possuem os dois primeiros campos idênticos ao quadros de dados, um tipo de quadro que identifica uma permissão e um delimitador de final de quadro.

\begin{tabular}{|l|l|l|l|l|l|l|l|l|}
\hline $\begin{array}{l}\text { PA } \\
>80 \text { bits }\end{array}$ & 1100010001 & $\begin{array}{l}\text { Tipo } \\
10 \text { bits }\end{array}$ & $\begin{array}{l}\text { ED } \\
48 \text { bits }\end{array}$ & $\begin{array}{l}\text { EF } \\
48 \text { bits }\end{array}$ & $\begin{array}{l}\text { Dados } \\
<4500 \text { bytes }\end{array}$ & $\begin{array}{l}\text { CRC } \\
32 \text { bits }\end{array}$ & 10001 & $\begin{array}{l}\text { Status } \\
15 \text { bits }\end{array}$ \\
\hline
\end{tabular}

Figura 2.6: Quadro FDDI

O padrão FDDI define um protocolo de gerenciamento denominado SMT (Station Management) com funçбes que permitem gerenciar a configuração física do anel, gerenciar o estabelecimento de conexões (alocação de banda) e gerenciar a operação de rede. Através de SMT é possível estabelecer parâmetros como o tempo máximo que uma estação pode permanecer sem a posse do token e o tempo máximo para a transmissão de tráfego síncrono. [Ta96]

As estações começam sua operação no modo assíncrono. Quando uma estação desejar utilizar o serviço síncrono, ao capturar a permissão, a mesma transmite quadros da classe de serviço síncrono por um período negociado pelo SMT. Isto dá a cada estação a possibilidade de utilizar um percentual de sua banda máxima para tráfego síncrono e o restante para tráfego assíncrono. O padrão garante um tempo máximo de espera pelo token o que propicia uma banda mínima (de pior caso) para o tráfego síncrono. $O$ padrão ainda prevê oito tipos de prioridade para o tráfego assíncrono. Um percentual do tempo de posse do token é reservado para cada nível de prioridade. [Ca95] 
O tráfego síncrono é um meio termo entre o tráfego isócrono e o tráfego assíncrono para o transporte de áudio e vídeo. O tráfego síncrono torna o FDDI adequado para o transporte de áudio e vídeo pois pode-se compensar o jitter com uma pequena bufferização no destino. Infelizmente, os produtos de transporte atuais como o TCP/IP e TP4 não fazem uso do tráfego sincrono ou níveis de prioridade quando operam sobre redes FDDI. Isto torna o FDDI similar a uma Token Ring mais rápida .

O padrão FDDI II mantém a mesma arquitetura do FDDI mas incorporando o tráfego isócrono. O FDDI I opera exatamente como o FDDI (denominado agora FDDI I) caso não se utilize tráfego isócrono. O FDDI II mantém 16 canais para tráfego isócrono cada um com 6,144 $\mathrm{Mbits} / \mathrm{s}$ (totalizando $98,304 \mathrm{Mbits} / \mathrm{s}$ ). Mesmo que todos os canais isócronos estejam em uso sobra em torno de $1 \mathrm{Mbit} / \mathrm{s}$ para o tráfego síncrono e assíncrono.

Para o tráfego isócrono quadros são gerados por uma estação Mestre de Ciclo a cada 125 $\mu$ s $(8 \mathrm{Khz})$. A rede é iniciada no modo assíncrono e para transmitir tráfego uma estação deve negociar com as demais (via SMT) o direito de se tornar Mestre de Ciclo. Isto se dá troca de quadros de controle utilizado o modo assíncrono.

O quadro para tráfego isócrono é ilustrado na Figura 2.7. O quadro carrega 96 grupos de ciclo cada um contendo 16 bytes. Um grupo destes 16 bytes denomina-se canais de banda larga (WCB). Cada um dos dezesseis canais de tráfego isócrono ocupa um determinado byte. Assim, temos um máximo de $96 \times 8 \times 8000=6,144 \mathrm{Mbits} / \mathrm{s}$ para cada canal.

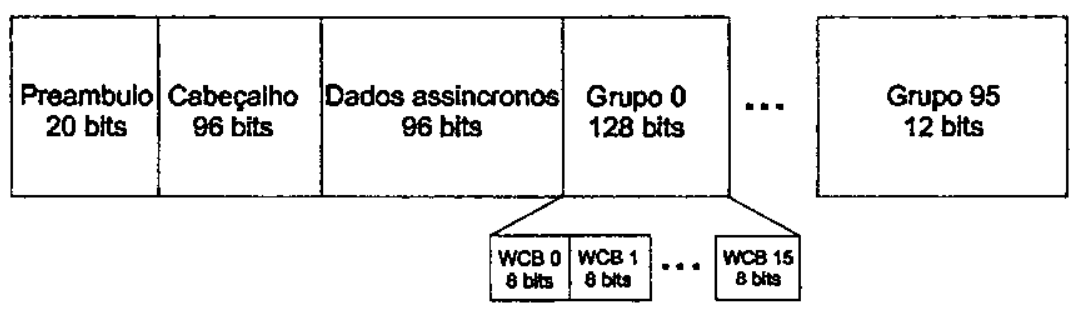

Figura 2.7: Quadro FDDi para tráfego isócrono (um quadro é gerado a cada 125 microsegundos).

Estações designadas como Alocadoras de Ciclo podem requisitar (via SMT) à Mestre de Ciclo a permissão de gerenciar uma WCB (dentre as dezesseis existentes). Obtidas a permissão, a estação propaga às demais que dispõe de 6,144 Mbits/s de tráfego isócrono para "sub-alocar". A "sub-alocação" se dá pela divisão da WCB em bits. A banda mínima consiste de um bit 
alocado, o que totaliza $8 \mathrm{Kbits} / \mathrm{s}$ de banda. Obtido o canal isócrono solicitado a uma Alocadora de Ciclo, a estação passa a escrever nos respectivos bits da WCB gerenciada por esta Alocadora. [Ta96]

\subsection{5 - ATM}

O ATM (Asynchronous Transfer Mode) foi proposto pela Bellcore, uma entidade de pesquisa ligada à AT\&T nos E.U.A. e a várias empresas de telecomunicações na Europa. No julgamento dos peritos da indústria, o ATM é definitivamente o produto indicado para as telecomunicações integradas multimídia e comunicações de dados para as economias globais do fim do século e do início do século XXI. [At96]

A evolução das redes de longa distância (WANs, Wide Area Networks) começa com a comutação de pacotes, passa pelo chaveamento de quadros (Frame Relay) e chega à comutação de células. A rede ATM resulta da junção de dois conceitos: o de comutação de pacotes e o de multiplexação por divisão de tempo (Time Division Multiplexing, TDM). Tanto a comutação de pacotes quanto o chaveamento de quadros transmitem os dados em quadros de tamanho variável, tipicamente contendo centenas ou milhares de bytes de informação. A tecnologia de comutação de células emprega pacotes (denominados agora de células) de tamanho fixo igual a 53 bytes: cinco de cabeçalho e quarenta e oito de dados. A idéia é comutar velozmente essas células durante seu trajeto, identificar conexão pelo número do pacote e carregar, em cada célula, apenas o identificador de conexão e os dados, sendo o tamanho da célula pequeno e fixo, o que facilita a recuperação dos dados no caso de perda por congestionamento ou qualquer outra razão. Essa filosofia é denominada banda sob demanda pelo fato da rede prover exatamente a banda requisitada pelas aplicações. ATM comuta as células na velocidade em que são submetidas para transmissão (toda a comutação é feita por hardware dedicado a esse fim). Este é o ponto central dos sistemas de chaveamento rápido de pacotes, ou "fast packet switching with short fixed lenght packets". [At96]

Os dois extremos de uma conexão em uma rede ATM são associados um com o outro através de um identificador, chamado Identificador de Circuito Virtual (VCI-Virtual Circuit Identifier) em vez de um número de pacote como é feito no STM. O VCI é copiado na porção de cabeçalho do pacote, sendo que no ATM, o pacote não mais possui o rótulo ou designação para o slot como no STM. 


\section{O Pacote, ou Célula, ATM}

Tanembaum [Ta96] apresenta a estrutura de uma célula ATM. Um pacote ou célula ATM possui 53 bytes sendo cinco bytes para o cabeçalho e 48 para a carga. $O$ cabeçalho e a carga estão especificados como mostra a Figura 2.8.

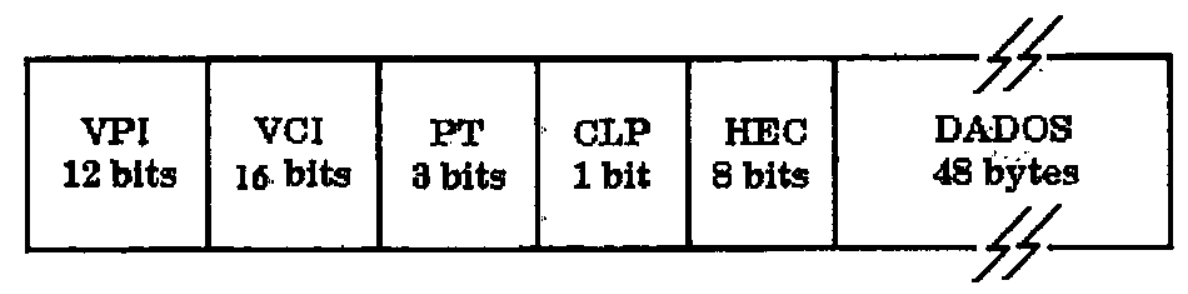

Figura 2.8: Componentes da célula ATM

Os 48 bytes de carga podem opcionalmente conter 4 bytes da camada de adaptação ATM e 44 bytes de dados, ou todos os 48 bytes com dados, dependendo de um bit do campo de controle do cabeçalho. Isto permite fragmentação e remontagem de células em pacotes largos na fonte e destino, respectivamente. O campo VPI é um número inteiro que seleciona um caminho virtual particular. Similarmente, o campo VCI seleciona um circuito virtual, o qual contém o caminho virtual especificado dor VCI. O campo PT especifica o tipo de dado que esta sendo transportado, por exemplo, se a célula contém dados de usuário, informações de manutenção ou de gerenciamento de recursos. O campo CLP especifica se a célula tem alta ou baixa prioridade e o campo HEC contém um checksum do header.

\section{A Camada de Adaptação ATM (AAL)}

O princípio básico da camada de adaptação ATM ( AAL - ATM Adaption Layer) é prover um conjunto de serviços úteis aos programas aplicativos, fazendo com que os mesmos não necessitem executar tarefas a nível de montagem das células na origem e desmontagem da célula no destino [Ta96]. No início da definição do AAL pelo ITU (International Telecommunication Union), levou-se em consideração que diferentes aplicações possuem requisitos diferentes. Por isso, os serviços da camada AAL foram organizados em três categorias diferentes:

1. Serviços real-time versus serviços nonreal-time;

2. Serviços com taxa de bits constante versus serviços com taxa de bits variável; 
3. Serviços orientados a conexão versus serviços não orientados a conexão.

Em princípio, com três categorias e dois tipos de serviços cada, oito diferentes serviços podem ser definidos, como mostra a Figura 2.9.

A $\quad$ B C

\begin{tabular}{|c|c|c|c|c|c|c|c|c|}
\hline $\begin{array}{l}\text { Tempo- } \\
\text { rizaçăo }\end{array}$ & $\begin{array}{c}\text { Tempo } \\
\text { Real }\end{array}$ & Nenhuma & $\begin{array}{c}\text { Tempo } \\
\text { real }\end{array}$ & Nenhuma & $\begin{array}{c}\text { Tempo } \\
\text { real }\end{array}$ & Nenhuma & $\begin{array}{c}\text { Tempo } \\
\text { real }\end{array}$ & Nenhuma \\
\hline $\begin{array}{c}\text { Taxa de } \\
\text { bits }\end{array}$ & \multicolumn{2}{|c|}{ Contante } & \multicolumn{2}{|c|}{ Vartível } & \multicolumn{2}{|c|}{ Constante } & \multicolumn{2}{|c|}{ Varlável } \\
\hline Modo & \multicolumn{4}{|c|}{ Orientado à conexło } & \multicolumn{4}{|c|}{ Sem conexăo } \\
\hline
\end{tabular}

Figura 2.9: Classes originals de serviços suportados pelo AAL (obsoletas)

Porém, o ITU percebeu que apenas quatro destes serviços possuíam alguma utilidade, nomeando-os de classes A, B, C e D. Os outros não são suportados. Se pensarmos em termos de ATM 4.0, a figura anterior fica obsoleta. Ela somente se apresenta aqui como informação de apoio para ajudar a entender porque o protocolo AAL tem sido desenvolvido da maneira como tem sido. Ao invés dessas classes de serviços, a maior distinção agora é feita considerando-se classes de tráfego (ABR, CBR, NRT-VBR, RT-VBR e UBR, citados mais a frente).

Para suportar estas quatro classes de serviços, o ITU definiu 4 protocolos, do AAL1 ao AAL4, respectivamente. Posteriormente descobriu-se que os requisitos técnicos para as classes $\mathrm{C}$ e D eram muito similares e decidiu-se fundir o AAL3 e o AAL4 no que foi chamado de AAL3/4.

O AAL é dividido em duas partes maiores, sendo cada uma delas subdivididas como mostra a Figura 2.10:

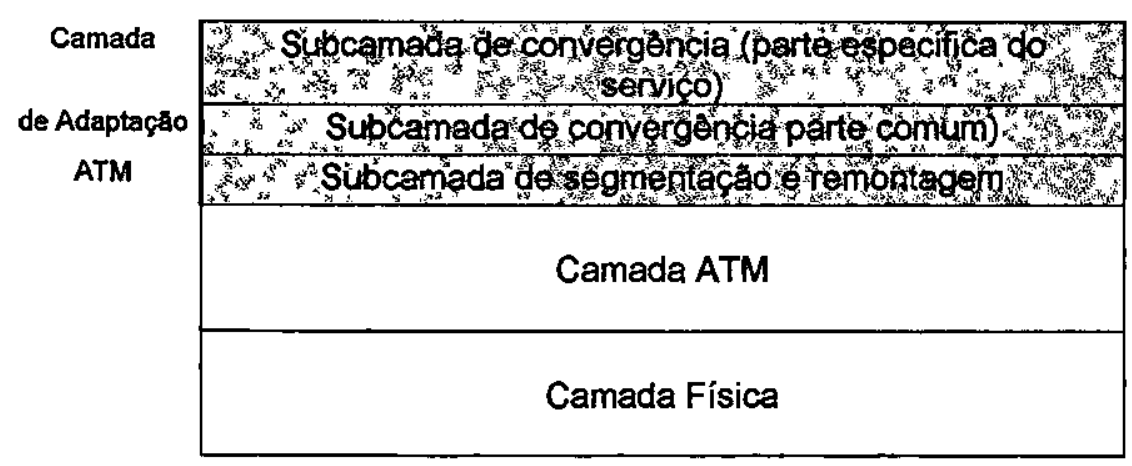

Figura 2.10: $O$ modelo ATM com O AAL \& suas subcamadas 
A parte superior do AAL é chamada de subcamada de convergência. Sua função é prover uma interface para a aplicação. Ela consiste em uma subparte que é comum à todas as aplicações (para um determinado tipo de AAL) e de uma subparte para aplicações especificas. As funções de cada uma dessas subpartes é dependente de protocolo, mas pode incluir quebra de mensagem em frames e deteç̧ão de erros.

Em adição, na origem, a subcamada de convergência é responsável por aceitar streams de bits ou mensagem de tamanho arbitrário vindos da aplicação e por quebrar estes dados em unidades de 44 a 48 bytes para transmissão. $O$ tamanho exato é dependente de protocolo, pois alguns protocolos utilizam parte dos 48 bytes do carga do protocolo ATM para seus próprios cabeçalhos.

No destino, esta subcamada monta novamente as células no formato das mensagens originais, preservando o tamanho original, ou seja, se forem enviadas quatro mensagens de 512 bytes, elas serão remontadas como quatro mensagens de 512 bytes, e não em uma mensagem de 2048 bytes, por exemplo.

A parte inferior do AAL é chamada de SAR (Segmentation and Reassembly). Ela pode adicionar cabeçalhos e trailers (dados adicionados ao final) às unidades de dados recebidas pela subcamada de convergência para formar o campo de carga das células, que são passados para a camada ATM para transmissão. Basicamente, a subcamada SAR trabalha com células, enquanto a subcamada de convergência trabalha com mensagens.

A subcamada SAR está presente em todas as classes de serviços, mas pode executar mais ou menos trabalho, dependendo do protocolo. Por exemplo, pode dar suporte a deteç̧ão de erros e multiplexação para alguns tipos de classes (não todos).

A comunicação entre a aplicação e o AAL se dá em forma de primitivas padrão OSI como request e indication [Ta96]. Já a comunicação entre subcamadas utiliza primitivas diferentes.

\section{5 - Problemas com as Plataformas de Propósto geral PARA APLICAÇÕES MULTIMIDIA}

Os servidores tradicionais foram projetados para transmitir informações tradicionais (texto, registros) que não necessitam de sincronismo. Geralmente essas informações possuem 
tamanho pequeno, a transmissão não é continua e sim por rajadas e a duração das sessões é pequena. Já nas aplicações multimídia, ocorre o contrário necessitam de uma sincronização na transmissão das informações, a transmissão é contínua e as sessões podem ter longas durações. [Ha98]

Num sistema multimídia todos os componentes (Sistema Operacional, Rede de Computadores, Meio de Armazenamento) são gargalos em potencial, já que se um deles não conseguir atender a requisição, todo o sistema estará prejudicado. Serão abordados os principais problemas em um sistema multimídia:

\subsection{1 - Sistemas OPERACIONAIS CONVENCIONAIS}

Os sistemas operacionais convencionais apresentam problemas para o suporte de aplicaç̃es de mídia contínua. Segundo Buford [Bu94] tais problemas são:

- Latência de Interrupção. A grande latência das interrup̧̧⿸̃es é uma das razões pelas quais os sistemas operacionais convencionais não suportam muito bem atividades de tempo real. Aplicações de mídia contínua produzem um número freqüente de interrup̧̧̃̃es no kernel resultando em pesadas trocas de contexto.

Todo kernel não preemptivo provê latência de interrupção muito grande. O processamento dos eventos de tempo real que disparam uma nova thread (ou um novo processo) deve esperar até que o processamento atual do kernel termine, e isto demora vários milissegundos.

Existem três abordagens para reduzir a latência de interrupçð̃es no kernel. A primeira torna o kernel altamente preemptivo modificando sua estrutura interna. A segunda adiciona um conjunto de pontos de preempção no kernel existente. A terceira abordagem é converter o kernel atual em um programa do usuário e executá-lo no topo de um microkernel.

- Gerenciamento de Inversão de Prioridades. Quando um programa de tempo real compartilha os mesmo recursos com um programa não tempo real, ocorrem casos onde o primeiro deve esperar pelo término do segundo. Por exemplo, em aplicaçø̃es que compartilham o mesmo servidor de rede, um pacote de alta prioridade pode ter que esperar até que todos os pacotes de menor prioridade, que já estavam na fila, 
completem sua execução. Essa inversão de prioridade causa um tempo de espera não previsível acarretando problemas como o jitter.

- Gerenciamento de Deadline e Recuperação. Ao contrário de aplicações de tempo real, muitas aplicações de mídia contínua possuem um deadline inerentemente mais suave. Por exemplo, pode-se prosseguir uma videoconferência mesmo que a imagem de vídeo mais recente não possa ser processada a tempo. A perda de um deadline não leva ao caos total, porém a notificação da perda é uma informação importante, pois baseada nessa informação a aplicação pode querer mudar o nível de QoS. Quando a aplicação perde um deadline devido d sobrecarga ou a erros de hardware ou software, o programa do usuário deve estar apto a tomar uma decisão. A decisão geralmente é uma recuperação que, freqüentemente, deve executar com uma prioridade maior que a atividade principal, logo necessita aumentar sua prioridade primeiro.

- Gerenciamento de Qualidade de Serviço e Controle de Admissão. Sistemas operacionais convencionais não possuem um mecanismo para manter um nível de QoS para aplicações de mídia contínua ou esquemas de gerenciamento e prevenção de sobrecarga (através de técnicas de controle de admissão), o que pode acarretar problemas de espera (delay) não predizivel e jitter [Bu94a] [St95a].

\subsection{2 - REDES DE COMPUTADORES}

Os maiores empecilhos na transmissão de dados multimídia sobre uma rede de computadores são : a largura de banda das redes tradicionais que são relativamente baixas para atender uma comunidade de usuários, já que um vídeo comprimido necessita de pelo menos 1.2 Mbits/s de banda passante, e as redes tradicionais operam a uma largura de banda máxima de 10 $\mathrm{Mbits} / \mathrm{s}$ (utilização de $33 \%$ da banda para controle de colisðes); outro problema é o delay não determinístico das redes, que é fundamental no serviço multimídia. Por exemplo, considere um sistema telefônico onde a comunicação sofra um atraso de $60 \mathrm{~ms}$, a mesma fica bastante prejudicada. Experiências práticas com sistema de conferência multimídia e o padrão ITU 
sugerem um delay máximo de $150 \mathrm{~ms}$ para aplicações de vídeo interativos. Um outro problema é manter a sincronização das informações

Uma aplicação multimídia pode possuir fontes de informações diferentes (vídeo, áudio, figuras, etc). Também podem ser transferidas por diferentes rotas e, como foi visto anteriormente, uma aplicação multimídia deve manter um sincronismo entre estes dados, necessitando com isso a utilização de algum mecanismo de sincronização (um desses mecanismos consiste no armazenamento na estação de toda a aplicação - downloading - e a mostra subsequente para o usuário).

Quanto à largura de banda, como se viu anteriormente, já existem novas tecnologias de redes de alta velocidade, que possuem uma largura de banda maior e possuem as características necessárias para a execução de aplicações multimídia como, por exemplo, a rede ATM.

\subsection{3 - Meios de ARMaZenamento}

Os meios de armazenamento tiveram um grande avanço. Com a diminuição do custo do mesmo, foi possível o armazenamento de aplicações multimídia, já que estas ocupam grande volume de armazenamento. O maior empecilho no meio de armazenamento é a sua velocidade de acesso e transferência da informação. Por exemplo, um CD-ROM dupla velocidade possui uma taxa de transferência de $300 \mathrm{Kbytes} / \mathrm{s}$, que é satisfatória para algumas aplicações multimídia, desde que utilizada somente por um único usuário. Já num servidor, o CD-ROM não é recomendado, assim como os discos magnéticos que utilizam o padrão E-IDE, que conseguem uma taxa de transferência de $20 \mathrm{Mbytes} / \mathrm{s}$ (utilizando modo PIO 4). As requisições de acesso ao disco são escalonadas pela CPU; com isso o processamento da CPU é paralisado para atender as requisições de I/O. Já os discos magnéticos que utilizam o padrão SCSI-II conseguem uma taxa de transferência de $40 \mathrm{Mbytes} / \mathrm{s}$, além disso, todo o processo de recuperação ou armazenamento da informação é feito pela própria controladora SCSI, deixando a CPU livre para executar outras tarefas. 


\section{TV E VÍdEO DigITAL}

\section{1 - INTRODUÇÃO}

Para ser usado por um computador, uma imagem deve ser transformada de sua representação natural (captada pelo olho humano) para uma representação eletrônica (analógica) e então de analógica para digital. Sistemas multimídia envolvem fortemente a captura, a transmissão e a apresentação de vídeos digitais, logo, é importante conhecer os padrões de vídeo, bem como suas técnicas e padrões de compressão, uma vez que estes são largamente utilizadas devido ao grande espaço de armazenamento necessário para esses tipos de dados. [Si96]

\section{2 - ANIMAÇÃO DE IMAGENS NO COMPUTADOR}

$\mathrm{A}$ animação de imagens adiciona um impacto visual nos projetos de multimídia. $\mathrm{O}$ aparente movimento de fotogramas estáticos permitindo a criação dos filmes cinematográficos só é possível devido à propriedade de persistência da visão, a qual determina que a imagem de um objeto permanece mapeada na retina por alguns instantes após ela ter sido visualizada.

As técnicas de cell animation que ficaram famosas com Walt Disney usam uma série de desenhos com ligeiras e progressivas diferenças como cada quadro em um desenho animado. Para resolver o problema da continuidade é necessário se expor 24 quadros por segundo. Desta forma, um minuto de animação exige 1440 quadros progressivos.

A produção de desenho animado se inicia com a criação dos keyframes (como são chamados o primẹiro e o último quadro de uma ação). Entre estes dois quadros é então construída toda uma seqüência de quadros que representam os movimentos entre os keyframes. 
O processo de construção desta série de quadros entre os keyframes é conhecido por tweening. $\mathrm{O}$ processo de animação de imagens usando o computador segue essencialmente o mesmo processo que o da construção dos desenhos animados. Para gerar os quadros entre os keyframes, no entanto, existem vários programas que fazem uso de técnicas especiais, como o uso de um gradiente de imagens, que facilitam sobremaneira o processo.

\section{3 - PAdRões de Vídeos Utilizados EM TV}

Um dos problemas enfrentados pelos desenvolvedores para multimídia, particularmente no que diz respeito ao desenvolvimento de projetos vídeo-animação está nos diferentes padrões de vídeos adotados em vários países. São utilizados hoje basicamente três padrões de vídeo, NTSC, SECAM e os diversos sabores de PAL. [Va94]

\subsection{1 - FORMATO NTSC}

O vídeo desenvolvido para ser transmitido ou produzido na América do Norte e no Japão (e em alguns outros países) está baseado no conjunto de especificações do National Television Standards Committee (NTSC) em 1952. O NTSC decretou que um único quadro de vídeo consiste em até 525 linhas de varredura horizontais desenhadas na face interna de um tubo de imagem revestido de fósforo por um raio de elétron de movimento rápido a cada $1 / 30$ de segundo. $\mathrm{O}$ desenho ocorre tão rápido que nossos olhos percebem a imagem como estável. O raio de elétron realmente cria dois passos conforme desenha um quadro de vídeo: primeiro traça todas as linhas ímpares e, depois, todas as linhas pares. Cada um desses passos (eles acontecem a uma taxa de 60 por segundo, ou $60 \mathrm{~Hz}$ ) pinta um campo. O processo de criação de um único quadro de dois campos é chamado entrelaçamento, uma técnica que ajuda a evitar oscilações.

Os fósforos coloridos na tela mostram vermelho, verde ou azul quando eles são energizados pelo raio; com a intensidade do raio de elétron varia conforme ele se move pela tela, algumas cores são mais claras que outras. Os magnetos minuciosamente sintonizados em torno do tubo da imagem miram os elétrons muito precisamente para a tela de fósforo, enquanto a intensidade do raio de elétron varia de acordo com o sinal de vídeo. Todas as atividades eletrônicas funcionaram em conjunto para produzir uma imagem de televisor. 


\subsection{2 - FORMATO PAL}

O sistema de vídeo Phase Alternate Line (PAL) é utilizado no Reino Unido, Europa, Austrália e África do Sul. Este sistema é um método integrado de adicionamento de cores a um sinal preto-e-branco do televisor. O sistema PAL pinta 625 linhas na taxa de 25 quadros por segundo. Como o sistema NTSC, as linhas pares e ímpares são entrelaçadas, cada campo tendo $1 / 50$ de segundo para desenhar $(50 \mathrm{~Hz})$.

\subsection{3 - FORMATO SECAM}

O sistema de vídeo Sequential Color and Memory (SECAM) é utilizado na França, na antiga URSS e em alguns paises. Embora o SECAM seja um sistema de 625 linhas, de $50 \mathrm{~Hz}$, a sua tecnologia básica e o método de transmissão diferem bastante dos sistemas coloridos NTSC e PAL.

\subsection{4 - HTDV}

Existem algumas confusões de termos ao discutir contextos de vídeo no computador e vídeo do televisor. Lembre-se de que video do televisor é baseado em uma tecnologia analógica e possui padronizaçð̃es internacionais para transmissão e apresentação de imagens. O vídeo do computador é baseado na tecnologia digital e outras padronizações mais extensíveis para apresentação de imagens. Na década de 1990, estas duas tecnologias - televisor e vídeo baseado no computador - se uniram, com a introdução do televisor de alta definição (HDTV). [Va94]

A HDTV tem sido desenvolvida por três grupos tecnológicos distintos, que se lançaram à pesquisa com objetivos diferentes. O protótipo japonês da NHK foi o primeiro a ser lançado. A seguir, vieram os europeus, que tinham razões diferentes para obterem a TV de alta definição.

Nos Estados Unidos, o desenvolvimento de um padrão de TV de alta definição está em curso desde 1987, e já existem, no entanto, algumas características técnicas para o padrão americano:

Definida como um sistema que difere dos atuais (como o NTSC, PAL e SECAN) das seguintes maneiras: cinco vezes mais detalhes na informação que constitui a imagem, dez vezes mais definição de cor, resolução horizontal e vertical mais dobrada, aumento substancial da nitidez, e qualidade de som equivalente à do compact-disc, com aumento no número de canais 
de som. Isso aproximará a imagem de HDTV da imagem de cinema, graças principalmente à mudança no aspecto ratio , que é o formato da imagem transmitida e/ou projetada, ou seja, as proporções da imagem na tela. Também conhecido como "scope", é representado por números $(.33,2.85,2.35,1.85: 1$ etc...) obtidos pela divisão da dimensão da largura da imagem pela altura. Uma imagem de 23" de largura e de 17" de altura resulta em um aspecto ratio 1.33:1 (23 dividido por 17, que é a imagem de uma TV 29"). O formato da tela dos aparelhos de TV convencionais é de 1.33 (1.33:1). Na HDTV, será de 1.77. O cinema usual utiliza 1.85; logo, a adaptação de um filme do formato cinema para vídeo ou TV, acarretará uma perda de imagem muito menor: uma porção menor que da imagem deixará de ser transmitida.

Já existe a idéia de associar a TV com os microcomputadores, tornando os televisores do futuro capazes de manipular a informação de imagens. Seria possível, por exemplo, assistir um jogo de futebol no domingo à noite, e mudar o ponto de vista da câmera, escolhendo um novo ângulo, ou mesmo observando a ação a partir de outra câmera.

\section{4. - COMPRESSÃO DE IMAGEM E VÍDEO DIGITAL}

Algoritmos e técnicas de compressão são vitais para a viabilização da multimídia, tanto no que diz respeito à comunicação quanto ao armazenamento da informação. Os objetos da atenção da multimf́dia, tais como voz digitalizada, música, imagens paradas, imagens em movimento, entre outros, são altamente consumidores de espaço de armazenamento e de banda de transmissão. Por exemplo, o sinal de vídeo de televisão sem compressão toma cerca 140 a $270 \mathrm{Mbps}$ (em torno de $8 \mathrm{Mb}$ por quadro) enquanto HDTV sem compressão requer em torno de $1.2 \mathrm{Gbps}$. Assim, a única esperança para se poder manipular arquivos digitalizados de vídeo, em particular os de multimídia, está no uso de esquemas de compressão. Aplicações de multimídia para rede não entrarão no circuito comercial antes de um desenvolvimento mais completo dos esquemas de compressão e descompressão em tempo real e de sua padronização. Até este momento, vídeo e imagem digital ainda estão confinados aos ambientes especializados que podem pagar pelos altos custos dos equipamentos. [Ca95]

$O$ vídeo é uma seqüência de quadros onde cada quadro é uma matriz espacial de pixels. $\mathrm{O}$ objetivo dos algoritmos de codificação de vídeo é extrair as redundâncias presentes na 
informação e reduzir enormemente as taxas de dados. Quando o sinal é digitalizado ele se torna um fluxo de bits e pode, portanto, ser transmitido em qualquer taxa. Entretanto, para aplicações em tempo real, a taxa de transmissão deve acompanhar a taxa de compressão e descompressão do algoritmo sendo implementado. Para outras aplicações a taxa de transmissão pode ser diferente. [Mo95a]

O sinal de vídeo comprimido é altamente sensível aos problemas de erro de transmissão . Tem sido verificado que o vídeo descomprimido é razoavelmente estável a problemas de erros de transmissão; entretanto, quando a redundância é retirada, qualquer erro pode significar uma degradação sensível na reprodução do sinal.

\section{5 - MÉTODOS E PADRÕES DE COMPRESSÃO DE VÍDEO}

Os arquivos de imagens e vídeos necessitam de grande volume de armazenamento. Desta forma é necessário adotar algum método de compressão para que possam ser transmitidos e armazenados. Os principais padrões de compressão são :

\subsection{1 - JPEG E MJPEG}

JPEG é um padrão de codificação para imagens paradas desenvolvido pelo Joint Photographic Experts Group. Embora apresente essa característica, com a utilização de hardware especial é possivel codificar e decodificar uma série de imagens JPEG em tempo real na velocidade requerida por vídeo em movimento [Re95]. Apesar de utilizar o método de codificação JPEG , esta abordagem é chamada de Motion JPEG ou MJPEG. Ainda não foi oficialmente padronizada.

Existem 4 tipos de operação para JPEG: seqüencial, progressivo, lossless e hierárquico [Cr95].

- Seqüencial é o modó mais simples é de fácil implementação, tanto em software como em hardware. Neste modo cada imagem é codificada em uma simples leitura da imagem da esquerda para direita e de cima para baixo. 
- Progressivo: a imagem é codificada em múltiplas leituras. É utilizado para aplicações onde o tempo de transmissão é longo - o usuário vê a construção da imagem em múltiplos passos e a cada passo a qualidade da imagem vai melhorando.

- Lossless: a imagem é codificada de tal forma que sua recuperação é exatamente a imagem original. É bastante utilizada nas aplicações que necessitam de imagens de alta qualidade, como por exemplo, aplicações médicas onde qualquer perda é significativa.

- Hierárquico: Neste tipo a imagem é codificada em múltiplas resoluções; se a versão é de baixa resolução, deve ser decodificada sem interferir na decodificação de versões de alta resolução. Este modo é de grande ajuda quando se utiliza uma rede de comutação de pacotes, em que somente os dados significantes para um determinado QoS (Quality of Service) serão transmitidos, permitindo assim que mais aplicações compartilhem os mesmos recursos de rede. Em casos de transmissão em tempo real em uma rede sobrecarregada, pode-se perder pacotes contendo dados de alta resolução, resultando na perda da qualidade, porém mantendo o sincronismo.

JPEG utiliza uma técnica de compressão espacial intraframe, codificação com transformação de Co-seno Discreta (DCT). Este tipo de técnica é usado também por outros métodos de codificação tal, como o H.261.

Codificação JPEG obtém compressão na ordem de 10:1 até 20:1 [Re95].

\subsection{2 - H.261}

O H.261 é um padrão de compressão de vídeo desenvolvido para redes que trabalham em taxa de transferência entre $64 \mathrm{Kbits} / \mathrm{s}$ a $2 \mathrm{Mbits} / \mathrm{s}$, medida em intervalos de $64 \mathrm{Kbits} / \mathrm{s}$. Esta técnica é também conhecida como "px64" onde " $p$ " varia de 1 até 30 .

H.261 utiliza um método de codificação temporal interframe e codificação espacial intraframe. $O$ algoritmo usado na codificação intraframe é baseado em DCT. No modo de codificação interframe, a compensação em movimento é executada para calcular as diferenças entre os quadros. A diferença por possuir pequena magnitude é então codificada através do método DCT. 
O padrão H.261 suporta dois tipos de formatos, o CIF (Common Intermediate Format) que possui $288 \times 352$ pixels e o QCIF (Quarter CIF) que possui $144 \times 176$ pixels. O QCIF é uma operação mandatária, enquanto que o CIF é uma operação opcional.

A codificação intraframe trabalha basicamente como em JPEG. Blocos de 8x8 são transformados em DCT, quantizados e codificados com entropy/run-length. Na codificação interframe, uma predição para blocos no frame corrente é feita se baseando-se nos frames anteriores. Se a diferença entre o bloco corrente e o bloco preditivo estiver abaixo de um certo valor, nenhum dado é transmitido. De outro modo, a diferença é calculada e transformada com DCT, quantizada e codificada com codificação entropy/run-length.

$\mathrm{Na}$ quantização, quando é determinada a quantidade de informação que será transmitida, quanto mais informação for transmitida melhor a qualidade da imagem. O codificador H.261 ajusta o valor quantizado para conseguir uma taxa de bits constante [Re95].

\subsection{3 - NETWORK VídEO (NV)}

Network Video (nv) foi desenvolvido pela Xerox/ PARC e é uma ferramenta de videoconferência para Internet. Esta é uma das ferramentas de videoconferência comumente utilizada sobre o Mbone Internet [Re95]. O Network Vídeo utiliza a técnica de codificação compressão temporal (interframe) e espacial (intraframe). Essa técnica compara o frame corrente com o frame anterior e marca as áreas que sofreram alterações significativas; então cada área alterada é comprimida, utilizando uma codificação de transformação. Periodicamente, partes não alteradas da imagem são transmitidas com alta resolução, alcançada pela eliminação do passo de quantização. Network video pode alcançar taxas de compressão de $20: 1$ ou mais [Re95].

\subsection{4 - CU-SEEME}

CU-SeeMe foi desenvolvido pela Universidade de Cornell, e é uma ferramenta de videoconferência para Internet. CU-SeeMe trabalha em 16 tonalidades de cinza usando 4 bits por pixel. Também utiliza método de compressão temporal (interframe) e espacial (intraframe). A imagem é dividida em blocos de 8x8 pixels para análise. Novos frames são comparados com os frames anteriores, e se ocorrer alteração significativa de um bloco ele é retransmitido. 
Periodicamente, todos os blocos são retransmitidos para contar as perdas que podem ter ocorrido na rede, que utiliza um método de compressão baseado em um algoritmo lossless desenvolvido na própria Cornell, e que explora a redundância espacial na direção vertical. $O$ algoritmo de codificação CU-SeeMe foi projetado para rodar eficientemente sobre computadores Macintosh, e operar sobre linhas de 84 bit por pixel ou palavras de 32 bit, trabalhando bem em código assembly com 680x0. A taxa de transmissão típica do CU-SeeMe é de $80 \mathrm{Kbits} / \mathrm{s}$. Este número é ajustado automaticamente através da analise do número de pacotes perdidos [Re95].

\subsection{5 - INDEO}

Esta técnica de compressão de vídeo foi projetada pela Intel e envolve tecnologia DVI (Digital Video Interactive). Indeo inicia-se com entradas YUV (Sistema de luminância e crominância usado pelo sistema PAL de televisão), sendo que U e V são subamostrados a uma razão de 4:1, tanto horizontal como verticalmente. Indeo suporta movimento estimativo, usando os frames anteriores para predizer os valores do frame corrente e os dados serão serão transmitidos se a diferença for significante. A codificação de transformação é feita usando uma transformação Slant Fast $8 \times 8$ na qual todas as operações são trocadas ou adicionadas (não múltiplos). Quantização e codificação run-length/entropy são usados como nos algoritmos anteriores. Indeo especifica que fluxo de bit codificado terá no máximo $60 \%$ dos dados de entradas; por isso, a compressão garante que na pior das hipóteses 1.7:1 [Re95].

\subsection{6 - MPEG}

Diz-se que o MPEG é um padrão genérico uma vez que o meio de armazenamento digital deve suportar várias aplicações. Isto porque vários segmentos da indústria estavam presentes junto ao comitê da ISO que definiu o padrão genérico, neste contexto quer dizer que o padrão é independente de uma aplicação em particular, mas não quer dizer que ignore os requerimentos das aplicações. Um padrão genérico possui características que o tornam universal. Muitas aplicações foram propostas baseadas em que uma qualidade de vídeo aceitável pode ser obtida para uma banda de aproximadamente 1.5 Mbits/s. [Ma94] 
O grupo ISO trabalhou na especificação de padrão de compressão de imagem em movimento em três fases, tendo cada uma um tipo particular de uso. Essas fases não são obrigatoriamente consecutivas e algumas sobreposições podem ocorrer entre elas.

Cada fase recebeu um nome : MPEG-1, MPEG-2, MPEG-3 e MPEG-4. Na prática, o desenvolvimento da MPEG-3 foi abandonada. [F195]

MPEG-1 é utilizado para armazenamento de qualidade VCR de seqüência de áudio e vídeo sobre CD-ROM. Funciona a uma taxa de $1.2 \mathrm{Mbits} / \mathrm{s}$. MPEG-2 tem como objetivo a televisão com qualidade de estúdio e qualidade de $\mathrm{CD}$ com múltiplos canais de áudio, a uma taxa de 4 a 6 Mbits/s. Pode ser estendido para HDTV. MPEG-4 é uma nova iniciativa que tem como objetivo a qualidade de videoconferências, a uma taxa de transmissão muito baixa.

\section{Propósito do MPEG-1}

MPEG-1 foi desenvolvido para o armazenamento de áudio e sinais de animações coloridas sobre CD-ROM. Na prática, se o canal de áudio requisitar de 200 a $250 \mathrm{Kbits} / \mathrm{s}$ para qualidade de $\mathrm{CD}$, a taxa do canal de vídeo não poderá ser superior a 1.15 ou $1.2 \mathrm{Mbits} / \mathrm{s}$.

O taxa de compressão de vídeo é da ordem de 26:1.

\section{Propósito do MPEG-2}

MPEG-2 teve como intenção inicial a gravação e transmissão de animações com qualidade de estúdio a uma taxa de transmissão da ordem de 4 a $6 \mathrm{Mbits} / \mathrm{s}$. Foi projetado para resolução recomendada pelo ITU-R 601, que é 720 x 480 pixels para o sinal de luminância e 360 x 480 para o espaço de cor.

O MPEG-2 pode operar tanto no modo progressivo como no modo entrelaçado. $\mathrm{Na}$ prática, MPEG-2 pode operar em taxa mais alta, conseguindo com isso qualidade de imagem HDTV.

\section{MPEG-3 foi abandonada}

Inicialmente chamada de MPEG-3, tinha como objetivo a compressão e descompressão de HDTV. Contudo, com os resultados rápidos e positivos do desenvolvimento do MPEG-2, o MPEG-3 foi cancelado e o grupo do MPEG-2 ficou responsável para suportar HDTV.

Propósito do MPEG-4 
O objetivo do MPEG-4 é reduzir drasticamente a taxa de transmissão. A taxa de transmissão considerada muito baixa é de 4.8 a $64 \mathrm{Kbits} / \mathrm{s}$. A dimensão do frame $\left(\mathrm{n}^{\circ} \mathrm{de} \mathrm{n}\right.$ linhas/ $\mathrm{n}^{\circ}$ de colunas) é a recomendada pelo padrão ITU H.261. A taxa de frames é de $10 \mathrm{fps}$.

MPEG-4 é um padrão extremamente poderoso para qualidade de videoconferências a uma taxa de transmissão extremamente baixa. As aplicações podem ser por videoconferências e videofone.

\section{7 - VIDEO-ON-DEMAND (VOD)}

Serviços de vídeo interativos são similares ao serviço de difusão de TV, mas apresentam uma alteração fundamental no paradigma da interface de TV. Eles foram projetados para suportar muitos canais simultâneos sobre um mesmo banco de dados. No sistema de TV tradicional, cada estação executa sua programação simultaneamente, e o usuário seleciona um canal especifico. Em contraste, um sistema interativo faz com que toda a programação seja apresentada ao usuário sem nenhuma restrição. $O$ usuário pode executar qualquer parte da programação a qualquer hora [Li94].

\subsection{1 - TIPOS DE SERVIÇOS INTERATIVOS}

Pode-se classificar os serviços de vídeo interativos em muitas categorias, dependendo do nível de interatividade que fornecem:

- Serviços Broadcast (No-VOD), similar aos canais de televisão, em que o usuário é um participante passivo e não possui nenhum controle sobre a sessão.

- Serviço Pay-Per-View (PPV) em que o usuário paga por uma programação especifica, similar ao serviço existente CATV (Cable TV).

- Serviço Quasi video-on-demand (Q-VOD), em que os usuários são agrupados pelo interesse comum que possuem. Os usuários possuem um controle rudimentar, ativado por chaveamento para os diferentes grupos. 
- Serviços Near Video-On-Demand (N-VOD), em que funções de avançar e voltar são simuladas por transições em um intervalo de tempo discreto (da ordem de 5 minutos). Isto é feito utilizando vários canais que possuem a mesma programação, porém em tempos diferentes.

- Servico True Video-On-Demand (T-VOD), em que o usuário possui total controle sobre a apresentação. O usuário tem todas as funções de VCR, incluindo avançar, voltar, congelar e posicionar diretamente. T-VOD aloca para cada usuário um canal exclusivo; com isso, o número de usuários do serviço fica limitado pelo número de canais disponiveis.

T-VOD necessita de um sinal bidirecional entre o usuário e o controle central. Serviços T-VOD são essenciais para aplicações de jogos interativos, onde todas as ações dos jogadores são vistas pelos outros jogadores.

Os serviços interativos podem ser usados nas mais diversas aplicações, como se mostra na tabela 3.1, abaixo.

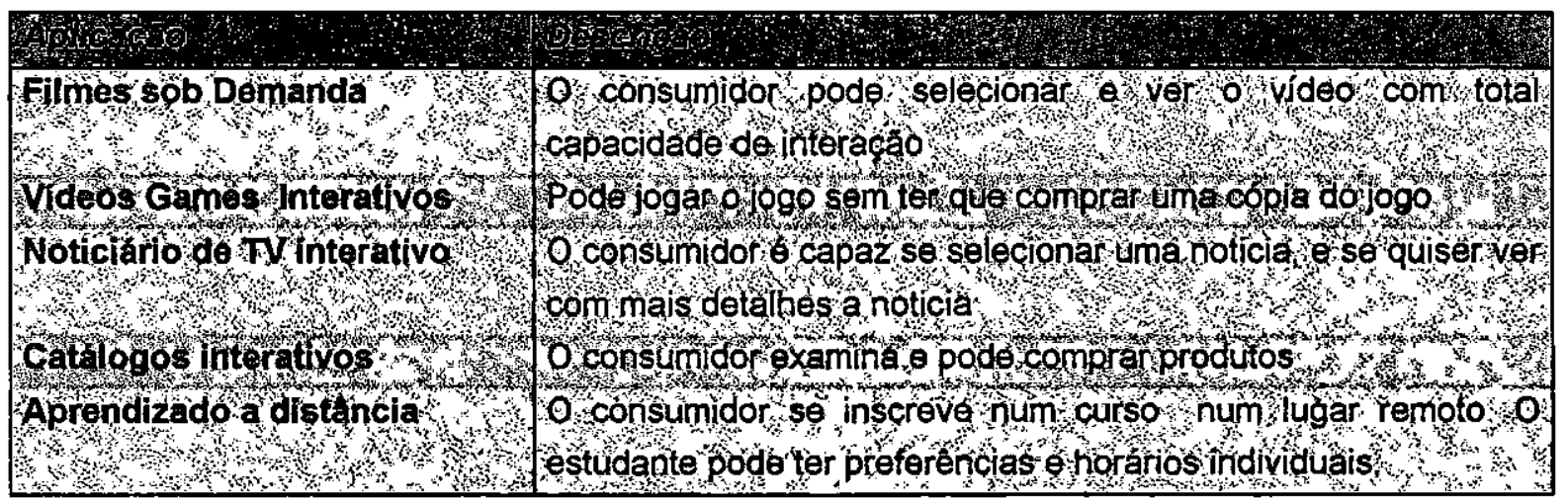

Tabela 3.1: Tipos de servlços interativos [FI95]

\subsection{2 - COMPONENTES DE UM SISTEMA VIDEO-ON-DEMAND}

Um sistema VOD pode ser acessado simultaneamente por centenas de usuários com diferentes preferências. O sistema tem que ser capaz de garantir a qualidade de serviço 
satisfatória ao consumidor. Um cenário típico de um VOD consiste em um banco de dados local e conectado com a casa dos usuários por uma rede de comunicação. Na casa do usuário, há uma interface de rede e um monitor (STB - Set Top Box). A interação do usuário com o sistema pode ser feita através de um controle remoto ou um teclado de computador (Figura 3.1)

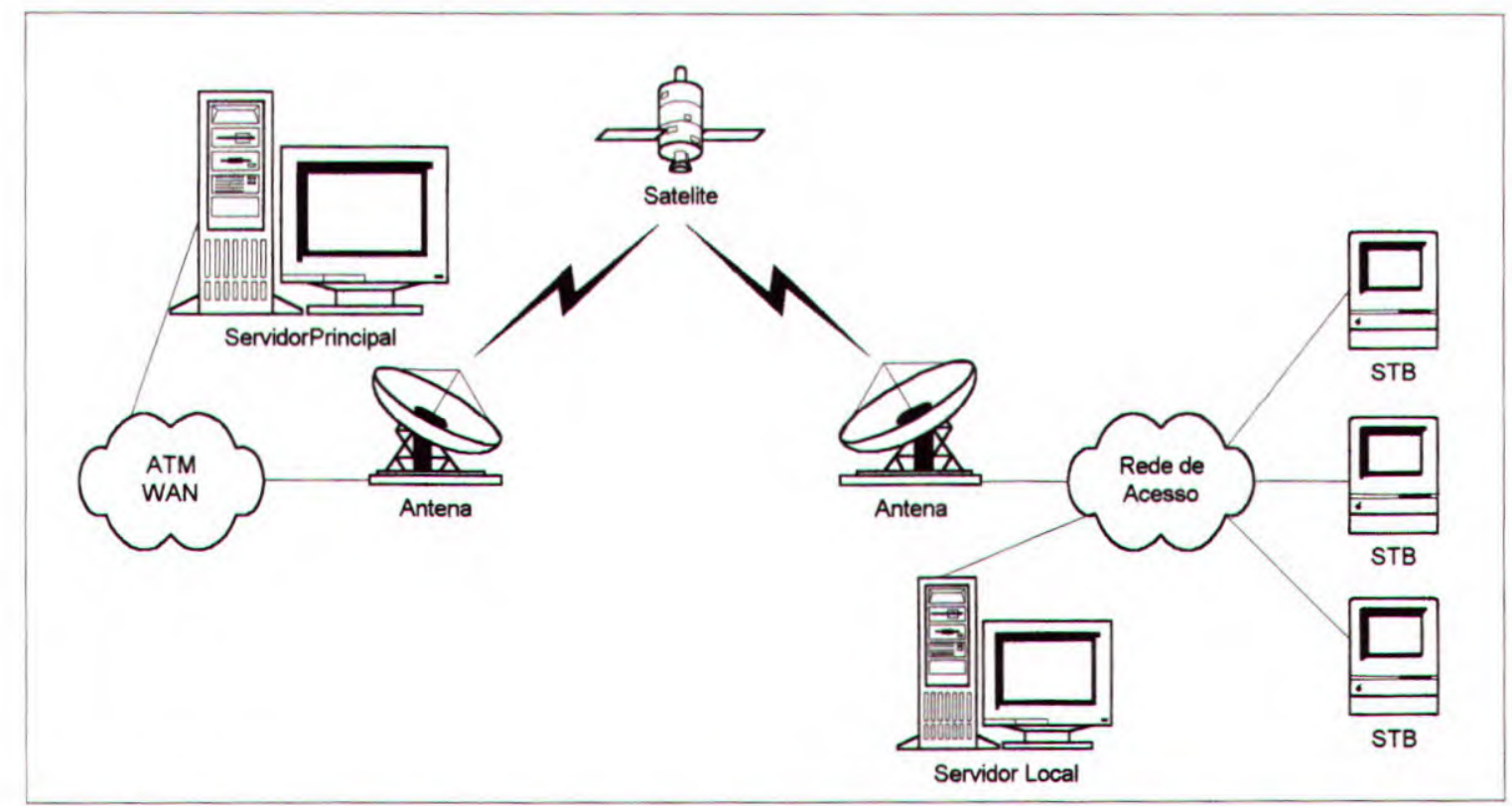

Figura 3.1: Componentes de um Sistema Video-on-Demand

Esse sistema consiste na informação/arquivo de programação no servidor que está conectado a uma rede de alta velocidade entre as regiões, e que estão conectadas com as casas dos usuários. Informações são copiadas do servidor principal e armazenadas nos servidores regionais, ficando a disposição dos usuários. [Fe94][Oh94]

Sessões VOD possuem tempo de duração longo, se comparadas às tradicionais, e requerem uma continua transferência de dados. Os dados transmitidos (vídeo, áudio) necessitam de grande banda passante para serem transmitidos para as casas dos consumidores. Por esse motivo, utilizam métodos de compressão, com a finalidade de diminuir o volume de bits a serem transmitidos. 


\section{TeCNOLOGIAS de SUPORTE EMPREgadAS NESTE PROJETO}

Para a especificação e implementação do ambiente multimídia distribuído com diversas tecnologias de rede e das aplicações de transferência e apresentação de vídeos, foi necessário o estudo de várias tecnologias, tais como:

\section{1 - HTML E APPLETS}

O padrão HTML (Hypertext Markup Language)[Be94] tomou-se amplamente utilizado como formato para hiperdocumentos disponibilizados na WWW (World Wide Web). Esse formato, conhecido pelos browsers existentes (Netscape, Internet Explorer, etc), é formalmente definido por um DTD (Document Type Definition), que define as regras para a especificação de uma classe de documentos SGML (Standard Generalized Markup Language). Desse modo o padrão determina a maneira como um conjunto de elementos deve ser estruturado para compor um documento, além de definir entre seus elementos, elos hipertexto e inclusão de outras mídias, referenciadas a Applets.[Le94a][Tr97]

Uma applet Java é um programa Java transferido dinamicamente através de uma rede de computadores e apresentado através de browser que possuam a Java Virtual Machine. A diferença entre um applet e um arquivo de som ou vídeo, por exemplo, é que uma applet não corresponde a uma animação ou a um arquivo de formato de mídia, mas sim a um código de programa. [Mo97]

A tag <applet> é usada para inicializar uma applet em um documento HTML. Sua sintaxe é mostrada na Figura 4.1. 


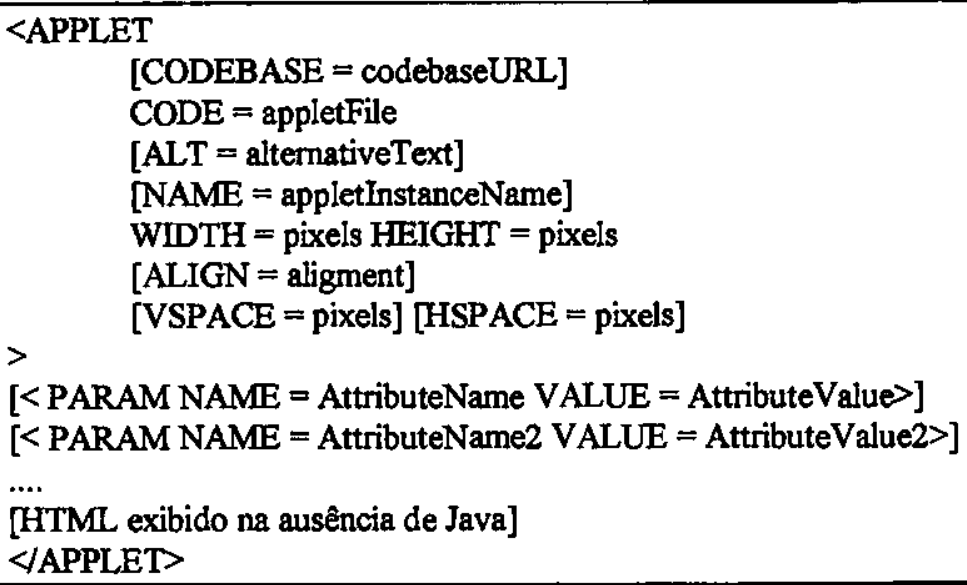

Figura 4.1: Sintaxe de um applet

A tag <appler> possui, como atributos obrigatórios, o nome do arquivo compilado que contém a applet (CODE), e o comprimento e a altura iniciais da janela em que a applet será exibida. Outro atributo importante é o codebase, que especifica uma URL onde o arquivo executável da applet é procurado. É possível passar parâmetros para uma applet através do elemento PARAM.

\section{2 - JAVA}

Java é, ao mesmo, tempo um ambiente e uma linguagem de programação, desenvolvida pela Sun Microsystems Inc., e comercializada a partir de 1995. Seu desenvolvimento teve início em 1991, quando um grupo criado pela Sun Microsystem, com o objetivo de projetar e implementar um ambiente de desenvolvimento de software multiplataforma, para ser utilizado na programação de aparelhos eletrônicos portáteis (Ex: televisões interativas) [Ja97].

A tecnologia Java consiste de uma linguagem Java, um ambiente de execução e um conjunto de ferramentas. É uma linguagem de programação orientada à objeto e derivada do $\mathrm{C}++$, isto é; apesar de bastante similar, não se trata de um segmento da linha de linguagem C. A equipe responsável pelo estudo do Java, promoveram uma revisão das linguagens de programação (Objective-C, Smalltalk, Eiffel, Modula-3, e etc) e eliminaram vários itens desnecessários. Desse esforço, esta nova linguagem - Java - foi gerada, permitindo o rápido 
desenvolvimento de aplicativos. O resultado mais prático foi a economia de tempo e mão-deobra.[La97]

Uma das principais características que tornou o Java tão popular foi a sua arquitetura neutral, permitindo ao programador desenvolver um aplicativo que podesse rodar em qualquer plataforma : UNIX, Windows, Windows NT, OS/2 ou Macintosh, dentre outras. É apenas necessário que o computador em que estiver sendo executado o programa escrito em Java contenha a Plataforma Java que fará a interface entre a aplicação Java e o computador(hardware). A plataforma java é mostrada na figura 4.2.[Kr96]

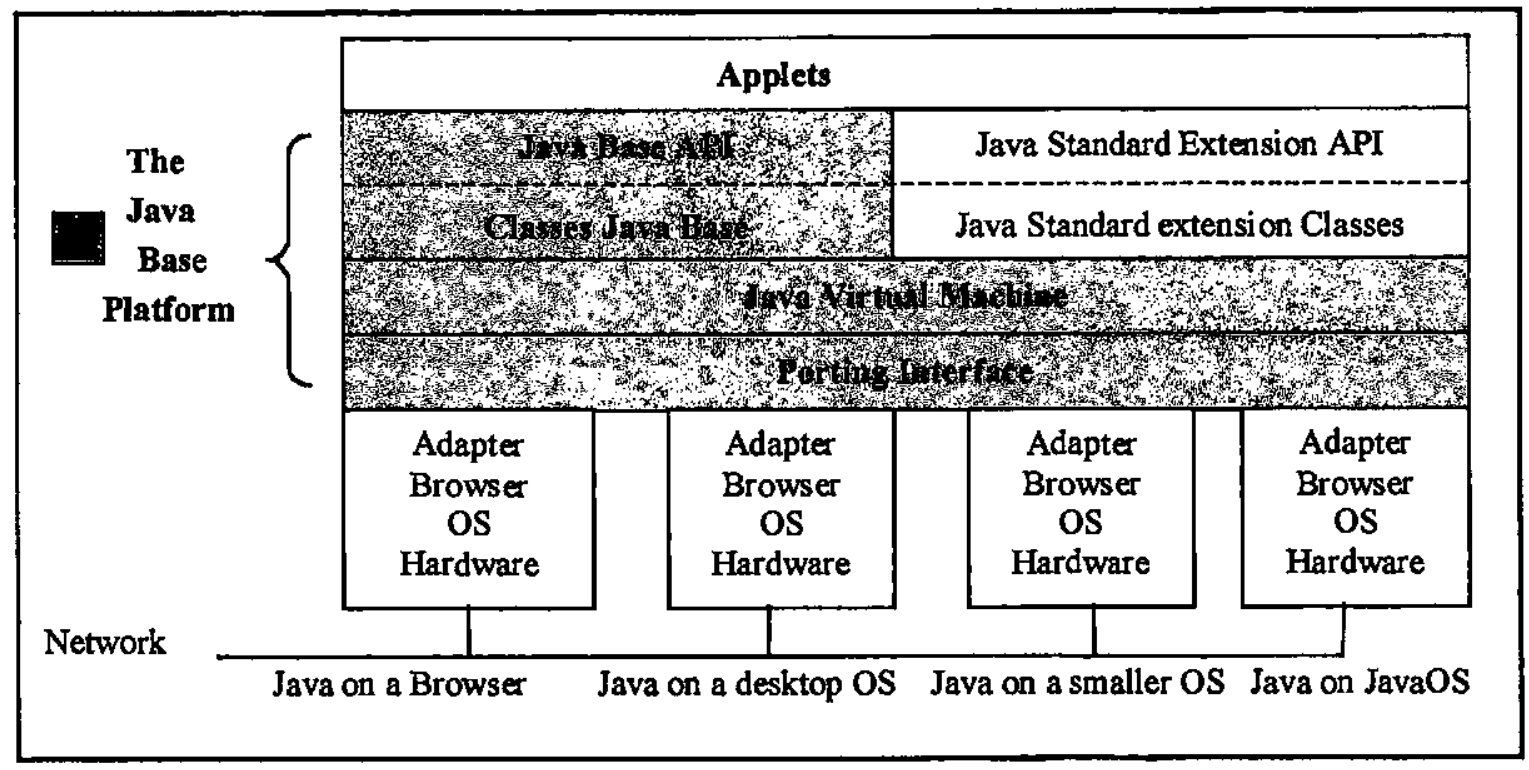

Figura 4.2 - Plataforma Java

\subsection{1 - Plataforma Java}

A Plataforma Java possui duas partes principais: a Java Virtual Machine e a Java Api, como é mostrada na Figura 4.3.

Java Virtual Machine - A Java Virtual Machine é um "software" computador que pode ser implementado em software ou hardware. É uma máquina abstrata, desenvolvida para ser implementada sob o topo de processadores existentes. A porting interface e adapters permitem que seja fácil a portabilidade para novos sistemas operacionais sem a necessidade de sua rescrita. 
Java $A P I$ - A Java $A P I$ forma uma interface padrão para applets e aplicativos, independente do sistema operacional. A API Java é a estrutura essencial para o desenvolvimento de aplicações, pois ela especifica um conjunto de interfaces essenciais em um número crescente de áreas chaves, que os desenvolvedores poderão utilizar para construir suas aplicações Java.

$\mathrm{Na}$ figura 4.2, a Base da Plataforma Java é mostrada em cinza, incluindo o bloco dos adaptadores. A Java API inclui as classes Java Base API, Java Standard Extension API, que são as implementações das API. A Java Virtual Machine é o núcleo da plataforma. A Porting Interface possuí uma parte independente da plataforma e uma parte dependente da plataforma, mostrada como Adapters. O Sistema Operacional e JavaOS provêem a janela, arquivamento e funções de rede. Por fim, diferentes máquinas podem ser conectadas por uma rede.

Java permite que os desenvolvedores criem dois tipos diferentes de programas, a saber :

- Applets : são programas que exigem um browser para ser executados. Quando a página é acessada por um usuário, tanto sobre a internet ou intranet corporativas, $o$ applet é automaticamente transferido do servidor e executado sobre o computador do cliente. Por serem transferidos, eles tendem a ser desenvolvidos de forma pequena ou modular, evitando, assim, longos tempos de transferência.

- Applications : são programas que não necessitam de um browser para serem executados - eles podem ser embutidos em mecanismos de transferências, que seja: quando uma aplicação é chamada, ela é executada. Deste modo, esses aplicativos são iguais a programas de outras linguagens: podem efetuar tarefas tradicionais, como um editor de texto, planilha eletrônica ou aplicativos gráficos. Como um applet, estes aplicativos necessitam da Plataforma Java para poderem ser executados, contudo a plataforma ou pode estar disponível num programa separado, ou ser embutida direta e independentemente do sistema operacional, ou ainda, ser embutida dentro do próprio aplicativo.

\section{3 - JAVA MEDIA FRAMEWORK}

O Java Media Framework (JMF) provê uma API (Application Programming Interface) para execução e captura de mídias, além da videoconferência. A JMF API foi desenvolvida para 
suportar diversos tipos de mídia, incluindo MPEG-1, MPEG-2, QuickTime, AVI, WAV, AU, e MIDI. Usando Java Media player, um programador pode sincronizar e apresentar mídia baseada em tempo de diversas fontes.

Existem players sobre computadores pessoais que estão fortemente dependentes do código nativo, para tarefas de intenso processamento computacional, como é o caso de descompressão e renderização. Alguns Java Media Players necessitam de código nativo para suportar recursos específicos do hardware ou do sistema operacional. Como Java aceita tanto Java bytecode quanto métodos nativos, desenvolvedores e usuários podem escolher formas diferentes de implementação do player usando não só Java, como também objetos nativos.[Jm97]

O Java Media Player APIs suporta três níveis de uso:

- Nível Cliente - um programador pode criar e controlar um Java Media Player para qualquer tipo de mídia padrão para ser usado em algumas chamadas de métodos simples.

- Nível avançado - um programador pode modificar um player existente e adicionar novas funcionalidades. Para permitir a troca de partes de um player individual, JMF provê uma forma para adicionar funcionalidades para um player sem a necessiadede construir outro novo.

- Nivel projeto - um programador pode adicionar novos players para suportar formatos novos de mídia. Novos players são criados por extensões da JMF, podendo ser utilizados lado a lado com os players já existentes.

\subsection{1 - ORIGeM DA MÍDIA}

Um Java Media Player encapsula a mídia original; ele é construído para uma mídia original particular, identificada por uma URL (Universal Resource Locator) e não pode ser reutilizada por outras streams media.

Java Media Players pode obter os dados de mídia de uma grande variedades de origens, como arquivos locais e arquivos da rede. 
Existe duas formas de ser feita a transmissão dos dados para o cliente, a saber:

- Downloading - o cliente recebe todo o pacote(arquivo) de uma fonte de dados confiável, como um arquivo local ou um arquivo da rede. Somente após o recebimento total é que o arquivo é executado. $O$ protocolo utilizado para isto é o HTTP (Hypertext Transfer Protocol) ou FILE.

- Streaming - o dado de uma fonte media streaming não é garantida. Os tipos de dados streaming incluem a broadcast media, multicast media, e video-on-demand (VOD). Para dados broadcast, um dos protocolos utilizados é o RTP (Real-time Transport Protocol), desenvolvido pela Internet Engineering Task Force (IETF). O protocolo Media Bases desenvolvido pela SGI é o protocolo utilizado pelo VOD.

\subsection{2 - CRIAÇÃO DE UM APPLET PARA EXECUTAR UM ARQUIVO DE MÍDIA}

Um programa-exemplo PlayerApplet demonstra como criar uma java Media player e apresentar um vídeo MPEG de um Java applet.

O tag Applet é usado para invocar PlayerApplet dentro de um arquivo HTML, sendo especificado na tag Applet os campos WIDTH e HEIGHT do HTML tag Applet determinam a dimensão da apresentação dentro da janela do browser. O tag PARAM identifica o arquivo de mídia para ser executado. O PlayerApplet pode ser invocado, como se mostra a Figura 4.3 , abaixo:

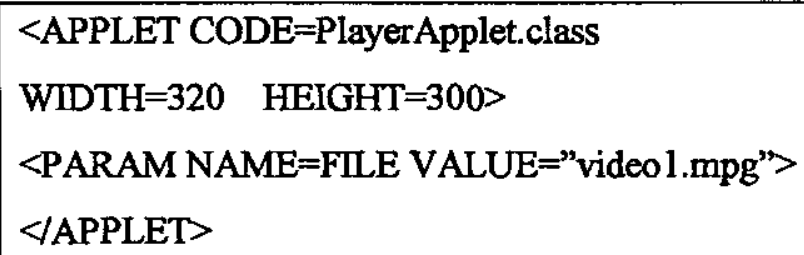

Figura 4.3 - Criação de um Applet JMF

Quando o usuário abre a página que contém PlayerApplet, o applet carrega automaticamente $o$ arquivo de vídeo e executa $o$ vídeo em um espaço específico de apresentação, que contém os componentes visuais do player e os controles padrões. 


\subsection{RAID (REDUNCE ARRAY OF INEXPENSIVE DISK)}

Outro aspecto importante quando se fala em Video sob Demanda é a forma de armazenamento e acesso aos vídeos. O RAID consiste na criação de uma pilha de discos, onde vários discos são agrupados fazendo com o que o sistema operacional os reconheça como se fossem um único. Com isso, quando um arquivo é copiado para esse disco (lógico) cada parte do arquivo fica armazenado em um dos discos (físico) que compõe o disco lógico, como é mostrado na Figura 4.4. A vantagem desse procedimento é o aumento do número de requisições que o computador pode atender concorrentemente, já que, na verdade, o acesso está ocorrendo em vários discos e não em um único.[Lo93][Le94b]

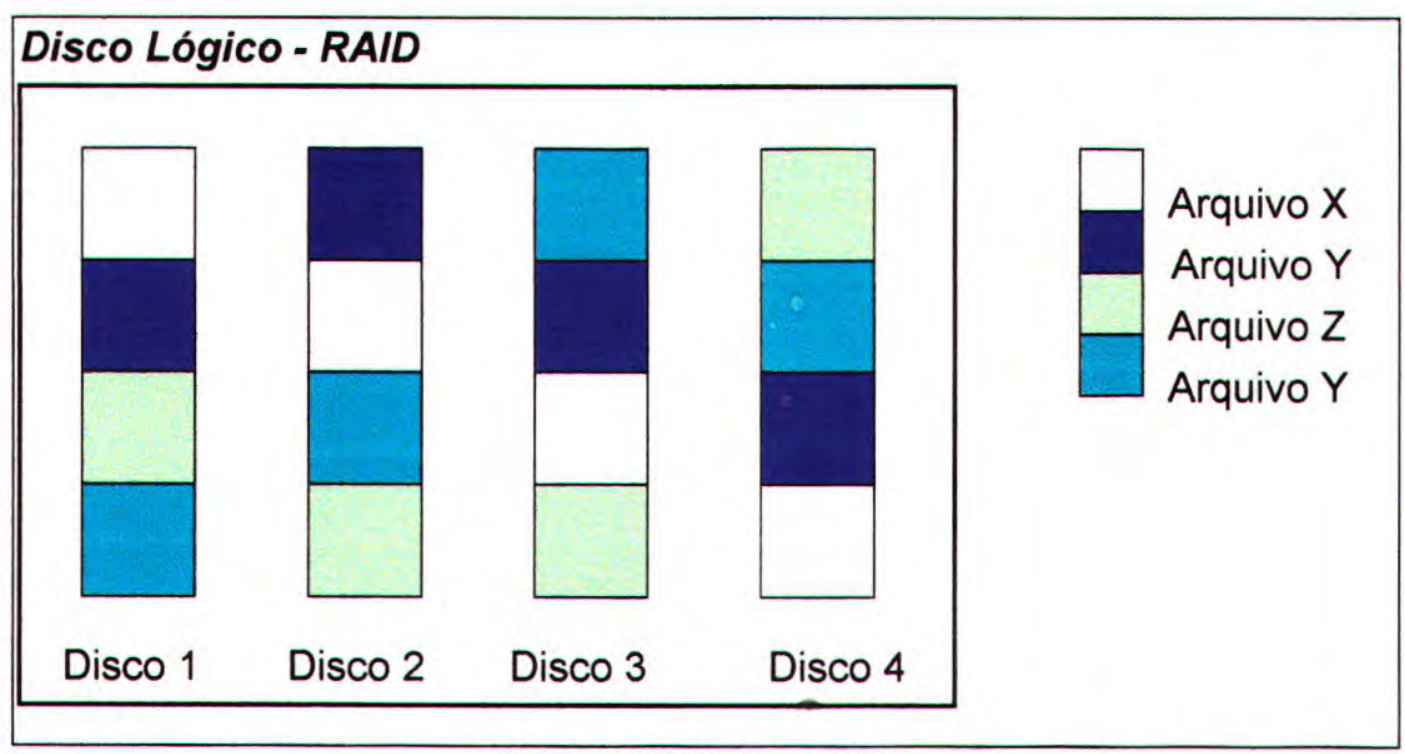

Figura 4.4: Sistema RAID

\subsection{1 - OS DIFERENTES NÍVEIS DE RAID}

RAID-0. O nível 0 não é redundante: os dados são divididos entre os discos, resultando em uma alta taxa de transmissão de dados. Como não há informações redundantes no armazenamento, o desempenho é muito bom, mesmo existindo a desvantagem de, se algum disco falhar, haver perda de dados.

RAID-1. Esse nível provê a redundância de dados pela gravação de todos os dados para dois ou mais discos. O desempenho do nível 1 tende a ser lento para as gravações e mais rápido 
para ler se comparado com um único disco, porém possui a vantagem de, se um dos discos falhar, nenhum dado é perdido.

RAID-3. Nesse nível, os blocos dos dados são em nível de byte entre muitos discos, possui um mecanismo de segurança contra falhas que consiste na gravação de informações adicionais (paridade), que possibilita a recuperação das informações. Nesse nivel a paridade é armazenada sobre um único disco. Ele é similar ao nível 4 . O nível 3 requer suporte de hardware para seu uso eficiente.

RAID-4. Nesse nível os blocos são a nível de bloco entre muito discos, a paridade é armazenada sobre um único disco. $O$ desempenho do nível 4 é muito bom para leitura (o mesmo do nivel 0). Para a escrita, contudo, necessita que os dados de paridade a cada vez. Esse método é lento para gravações randômicas, no entanto, para gravaç̃̃es de arquivos grandes ou sequências, é bastante rápido. Isso ocorre porque somente um disco armazena dados redundantes. $O$ custo por megabyte do nível 4 pode ser extremamente baixo.

RAID-5 É similar ao nível 4, mas distribui os dados de paridade entre os discos. Eles podem ser rápidos para a gravação de pequenas quantidades de dados sobre sistemas multiprocessados, desde que o disco de paridade não se torne o gargalo. $O$ desempenho para leitura, contudo, tende a ser mais lento para leitura que o nível 4 . $O$ custo por megabyte é o mesmo pelo nível-4.

\section{5 - ForMAS de APRESENTAÇÃo de VÍDEO}

Existem duas formas principais para a apresentação de vídeo em redes de computadores: o downloading e o streaming vídeo.

$\mathrm{O}$ processo de downloading, bastante comum na Web, consiste em conectar um computador remoto e transferir um arquivo deste para ser apresentado em seu computador. A transferência ocorre através de protocolos de transmissão de dados pela rede (como FTP e HTTP), utilizando um browser. Nesse processo, $o$ arquivo é primeiramente todo transferido para 
depois ser utilizado. Esse meio de transferência é geralmente lento, por isso os vídeos disponíveis na Web via downloading raramente possuem alta resolução (para reduzir o tamanho do arquivo). Uma vez que o arquivo tenha sido transferido, o vídeo pode ser apresentado em um Browser através de plug-in ou em um player.

No processo de streaming vídeo, assim que os primeiros dados chegam ao seu destino eles são apresentados, enquanto a fonte continua a transmitir. Não existe uma fase intermediária de armazenamento entre a transmissão e a apresentação.

Existem diversos fatores a serem considerados na transmissão streaming vídeo. $O$ vídeo, como todo dado de mídia continua (mídias que variam com o tempo), é gerado a uma certa taxa e deve ser apresentado nessa mesma taxa, de forma que o video apresente características de tráfego contínuo, exigindo uma taxa contínua de transmissão. Cada quadro tem um tempo limite para sua apresentação (deadline), se esse tempo for ultrapassado, ocorrerão tremores na imagem (jitter) [Bu94]. Explicando de forma mais detalhada, imagine um video com 10 minutos de duração sendo transmitido de uma máquina à outra através da rede. O quadro número 15 (hipotético) deve ser apresentado no tempo 1'00", o quadro $16 \mathrm{em} \mathrm{1'03",} \mathrm{e} \mathrm{assim} \mathrm{por} \mathrm{diante.} \mathrm{Se}$ o quadro 16 sofre um atraso na sua transmissão, ele poderá chegar no tempo 1'06", que é deadline para a apresentação do quadro 17. Então, ou o quadro 16 será descartado ou será apresentado, causando tremores ou congelando a imagem por alguns instantes.

Se o propósito é a transmissão do vídeo em uma pequena rede local, os problemas pode desaparecer, dependendo da tecnologia de rede utilizada.

Streaming Vídeo é o modo de transmissão adotado para a apresentação de programas ao vivo pela Web e para a realização de videoconferências. Apesar de todos os problemas discutidos, existem tecnologias já bem desenvolvidas para suportar vídeo em tempo real através da Internet. VDO e Vxtreme são duas dessas tecnologias. Ambas utilizam arquivos AVI sem compressão, convertem e comprimem o mesmo para seus próprios formatos. O VDO utiliza o formato VDO e o Vxtreme utiliza o formato VXI. As taxas de compressão chegam a 500:1 com Vxtreme. A qualidade de apresentação é impressionante, em se tratando de transmissão de vídeo pela Internet. Dependendo das condições de tráfego da rede, o desempenho é igual ao de uma apresentação local. O Vxtreme possui ferramentas para a captura, codificação e editoração de vídeo, podendo inclusive construir páginas HTML que interagem com o vídeo. O VDO não possui ferramenta para interação com HTML e nem ferramenta própria para editoração de 
vídeos, mas é compatível com várias delas, como o Adobe por exemplo. Para visualizar um vídeo VDO ou Vxtreme em um computador, basta instalar o respectivo plug-in (player) no Browser.

Os vídeos apresentados pelos clientes estão armazenados em máquinas remotas que executam um programa servidor. O servidor recebe pedidos de transmissão de vídeo dos clientes e, envia o vídeo através da rede. 


\section{AMBIENTES DE TESTE E RESUlTAdOS}

\section{1- INTRODUÇãO}

O laboratório Intermídia, do ICMC da USP em São Carlos, esta desenvolvendo um sistema de auxílio à editoração e apresentação de material didático com recursos multimídia, conhecido como Interland. Novos tipos de mídia (áudio e vídeo) podem ser manipulados e utilizados em aplicações de auxilio ao professor. A utilização dos recursos deste sistema em sala de aula pode funcionar como um elemento motivador do aluno.

Esse ambiente, baseado em tecnologia WWW, prevê a distribuição de vídeos sob demanda a um conjunto de clientes em rede. A escolha correta da tecnologia de rede e da arquitetura das aplicações a ser utilizada é fundamental para evitar sobrecarga no sistema devido ao grande volume dos dados transmitidos. Esses dados devem ser armazenados em servidores de vídeos capazes de atender sob demanda, uma comunidade de clientes, de forma que o sistema não seja prejudicado. [Ha98]

Esse trabalho procura avaliar como podem ser balanceados o desempenho do servidor com o desempenho das tecnologias de rede disponíveis no mercado (Ethernet, SwitchedEthernet, Fast Ethernet e FDDI) e a distribuição e apresentação de vídeos utilizando técnicas de downloading e streaming, de modo que o usuário possa ter uma idéia de como especificar seu ambiente à partir de um determinado perfil de aplicação.

\section{2 - CONFIGURAÇÃO dO AMBIENTE}

Para a realização das avaliações, alguns dos componentes descrito no ambiente multimidia distribuído da Figura 5.1 foram utilizados: 


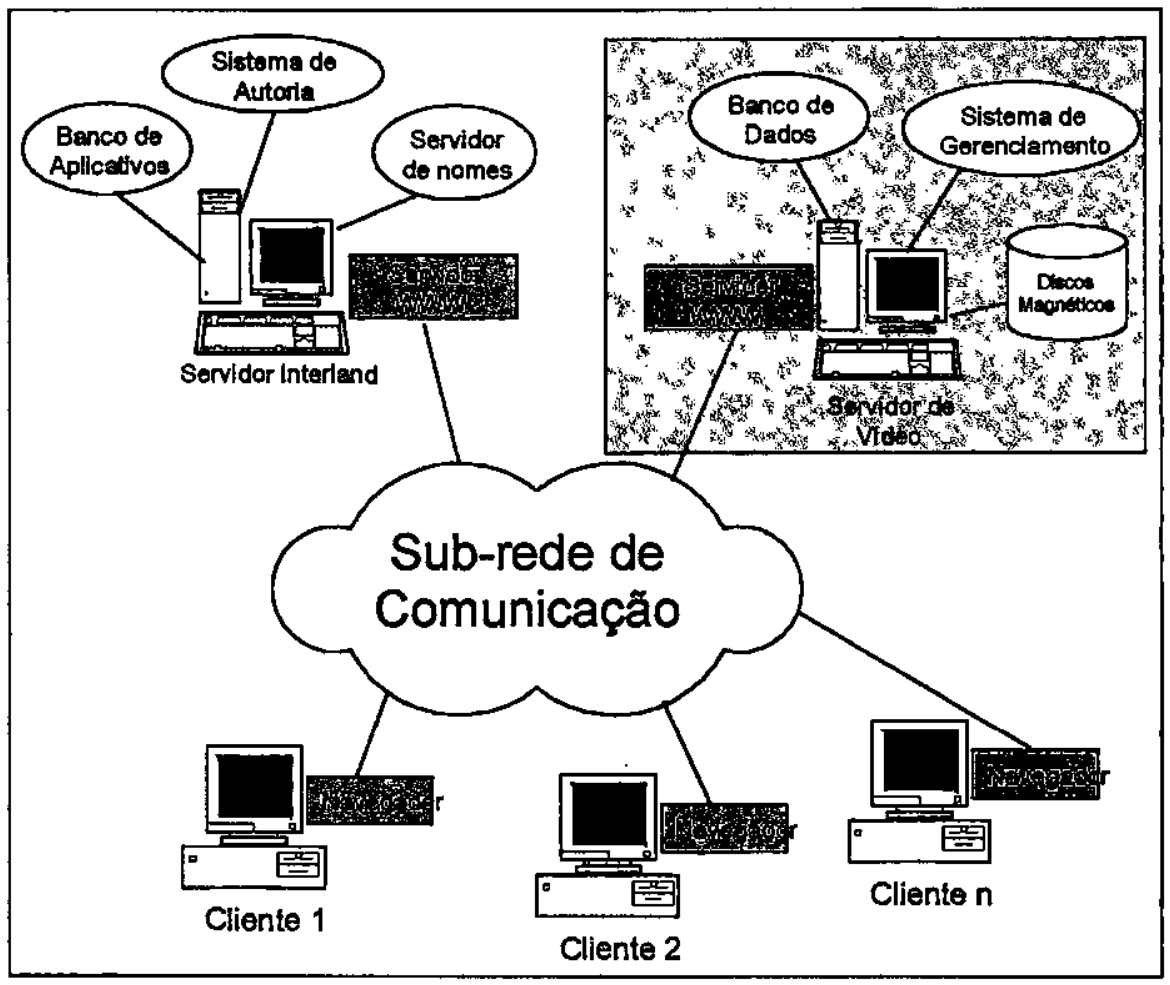

Figura 5.1: O Amblente Multimidia Distribuido

\subsection{1 - O SERVIDOR DE VÍDEO}

O servidor de vídeo deve atender, sob demanda, clientes organizados em um ambiente WWW. Como vídeos são objetos volumosos e dependem de modos especiais de apresentação eles requerem formas de armazenamento e distribuição diferentes das convencionais.

A utilização de servidores de dados multimídia baseados em sistemas VOD (Video-OnDemand) [Flu95] é uma alternativa para se alcançar este objetivo. Esses servidores realizam o armazenamento de vídeos em algum tipo de dispositivo fisico (disco, fita, $\mathrm{CD}$, etc) e os disponibilizam com eficiência a vários clientes simultaneamente.

Hachisuca [Ha98] implementou um servidor de vídeo com as características abaixo e que foi utilizado para a realização dos testes do projeto:

- Microcomputador Pentium/200 MMX;

- 96MB de memória RAM;

- 1 disco SCSI seagate de 20/5;

- 1 disco SCSI quantum fireball de 2 GB;

- 2 discos SCSI quantum fireball de 4GB; 
- placa controladora SCSI Adaptec 3985 com 3 canais independentes;

- Sistema Operacional Linux com RAID.

Num dos discos SCSI de 2GB foi instalado o sistema operacional, assim como todos os softwares que compõem o servidor. Os arquivos de video encontram-se nos outros três discos SCSI que compõem o disco lógico do sistema RAD (configurado pelo software do Linux, como nível 0), Figura 5.2.

Foi escolhida a controladora SCSI Adaptec 3985 por possuir uma característica especial em relação ds controladoras tradicionais: três canais de dados independentes - como se fossem três controladoras SCSI - sendo que cada canal trabalha a uma taxa de transmissão de $10 \mathrm{MB} / \mathrm{s}$, resultando numa taxa total de $30 \mathrm{MB} / \mathrm{s}$. Dessa forma, cada disco que compõe o RAID foi colocado em um canal diferente, fornecendo uma taxa agregada que pode chegar a $30 \mathrm{MB} / \mathrm{s}$ melhorando o serviço em acessos simultâneos.

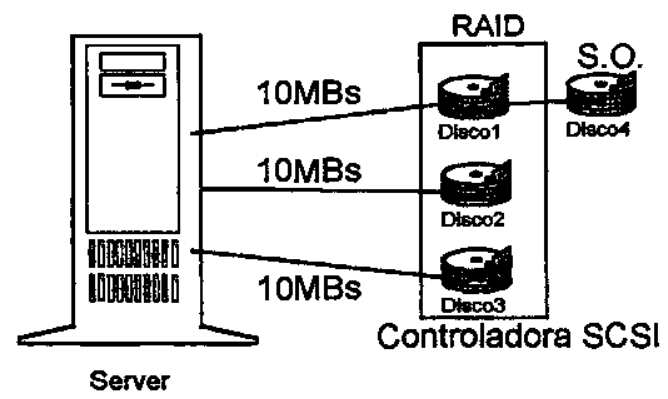

Figura 5.2: Sistema de Disco do Servidor de Video

\subsection{2 - As EstaÇÕES}

A quantidade de clientes acessando um servidor de vídeo influencia o desempenho do sistema. Dessa forma, foi configurado um conjunto de 10 estą̧̃os com as seguintes características cada:

- Microcomputador Pentium $166 \mathrm{Mhz}$;

- $32 \mathrm{MB}$ de memória RAM;

- Disco rígido IDE quantum de $1.7 \mathrm{~GB}$;

- Placa de rede Fast-Ethernet 3Com PCI 10/100Mbps;

- Sistema Operacional Windows 95. 


\subsection{3 - CONFIGURAÇóES DE REDE IMPLEMENTADAS}

As seguintes configurações de rede foram implementadas para a realização das avaliaçőes:

\section{Servidor e Estações em um Único Segmento Ethernet}

Nesta configuração (Figura 5.3), a largura de banda total da rede é de $10 \mathrm{Mbit} / \mathrm{s}(1.25$ MBytes/s). Dessa forma, como o servidor e as estações estão em um mesmo segmento, a banda será compartilhada por todos e, dependendo da quantidade de estações e da demanda de rede imposta pela aplicação, esta configuração pode se tornar inviável para a distribuição de vídeo, já que cada estação estaria conseguindo no máximo $1 \mathrm{Mbit} / \mathrm{s}$ da banda passante quando todas as 10 estações estiverem transmitindo.

Os equipamentos de rede utilizados nessa configuração foram:

- Hub Ethernet- Digital DECrepeater 900TM, com 32 portas Ethernet $10 \mathrm{Mbits} / \mathrm{s}$;

- Placa de Rede 3 Com Ethernet $10 \mathrm{Mbits} / \mathrm{s}$ no servidor.

- Placa de rede Fast-Ethernet 3Com PCI 10/100Mbps nas estações;

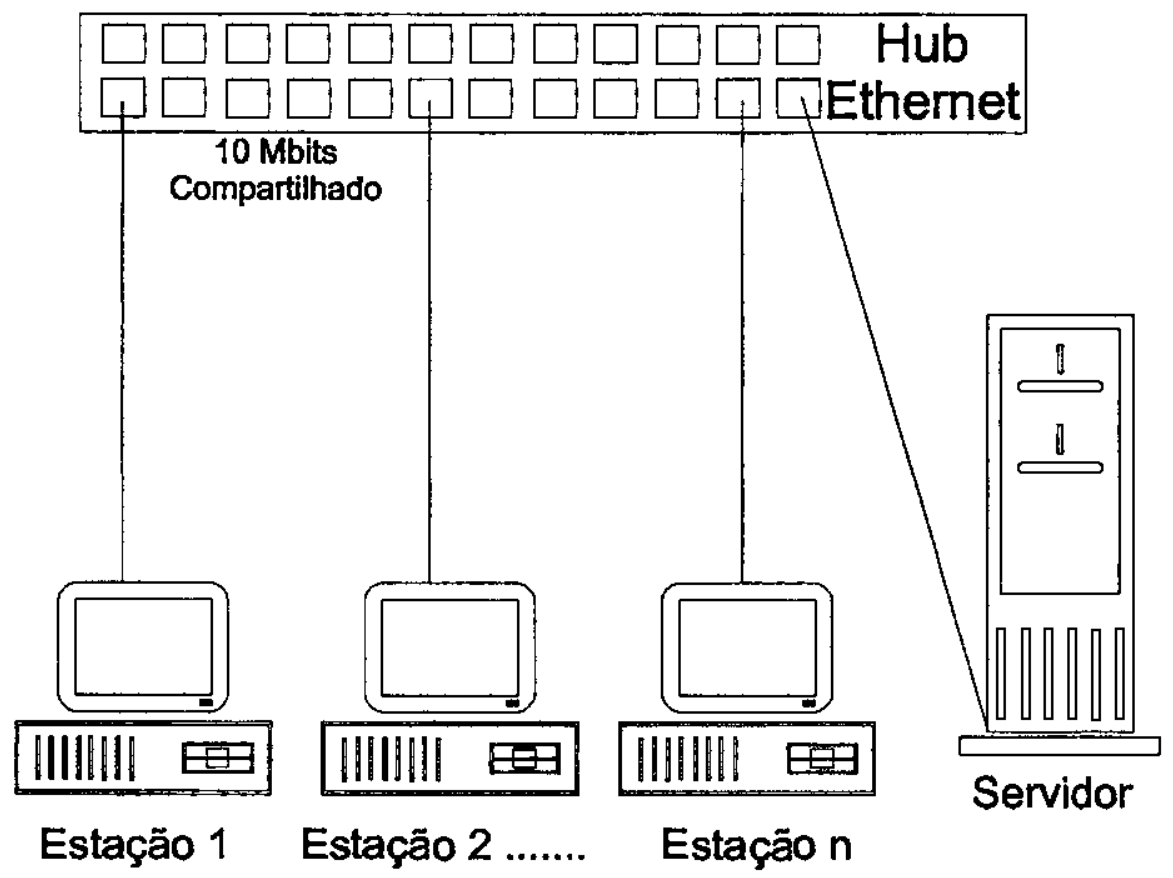

Figura 5.3: Servidor e Estaçరeses em um Único Segmento 


\section{Servidor e Estações em um Único Segmento Fast Ethernet}

Nesta configuração (Figura 5.4), a largura de banda total da rede é de $100 \mathrm{Mbits} / \mathrm{s}$ (12.50 MBytes/s). Apesar de possuir uma banda considerável, não é possível reservar uma parte da mesma para uma estação ou servidor, pois o segmento Fast Ethernet é compartilhado por todos que estiverem conectados nele. Mas, claramente, esta é uma configuração melhor que a anterior.

Os equipamentos de rede utilizados nessa configuração foram:

- Hub Fast Ethernet - Dlink DFE-812TX+ , com 12 portas $100 \mathrm{Mbits} / \mathrm{s}$;

- Placa de Rede 3Com Fast Ethernet 10/100 Mbits/s no servidor;

- Placa de rede Fast-Ethernet 3Com PCI 10/100Mbps nas estações;

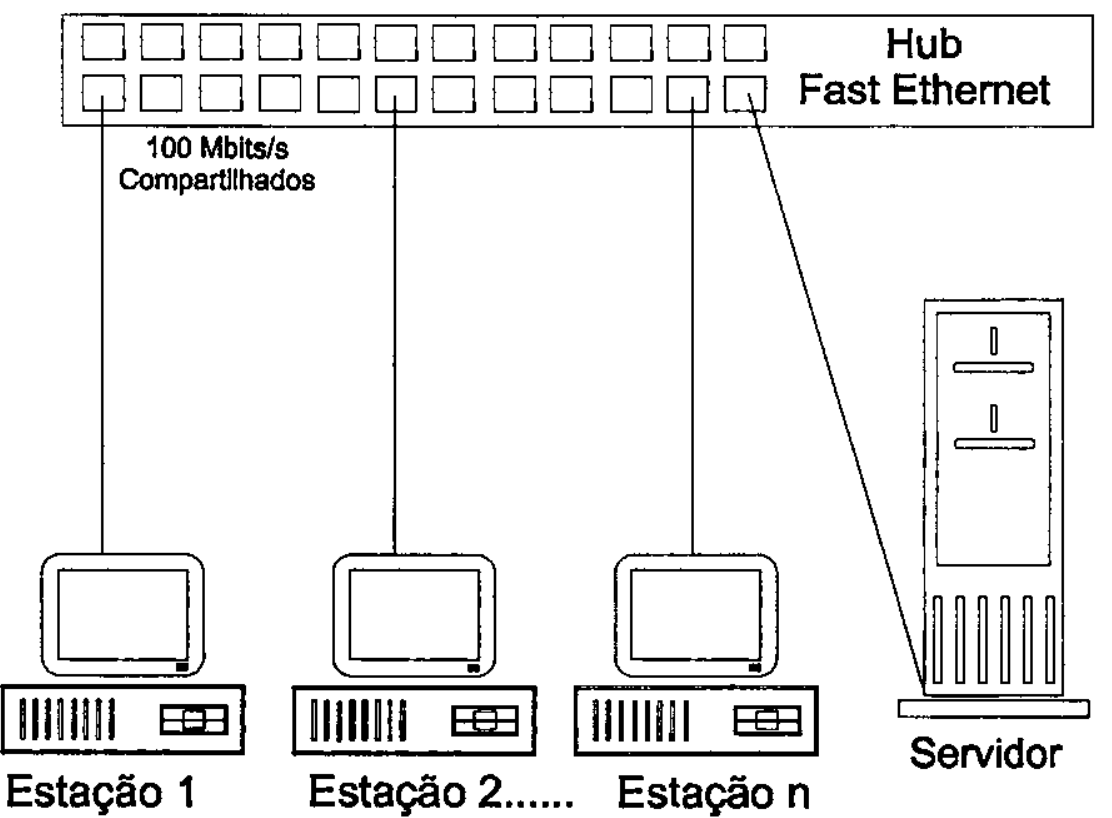

Figura 5.4: Servidor e Estaçס̋es em um Único Segmento Fast Ethernet

\section{Servidor em Porta FDDI e Estaçōes em Portas de uma Switch Ethernet}

Quando se utiliza Switch Ethernet (Figura 5.5), a largura de banda da rede é de $10 \mathrm{Mbit} / \mathrm{s}$ para cada porta da Switch. Dessa forma, cada estação conectada individualmente a uma porta, pode transmitir até $10 \mathrm{Mbits} / \mathrm{s}$, tornando-se indispensável a conexão do servidor a um segmento de rede mais rápido, nesse caso, ao anel FDDI (largura de banda de $100 \mathrm{Mb} / \mathrm{s}$ ), pois se conectássemos o servidor a uma porta de mesma largura à das estações, estaríamos limitando o acesso ao servidor, pois seriam $n$ estações a $10 \mathrm{Mb} / \mathrm{s}$ cada, acessando o servidor também a 10 $\mathrm{Mb} / \mathrm{s}$.

Os equipamentos de rede utilizados nessa configuração foram: 
- Switch Ethernet - Digital DECswitch 900EF, com 1 porta FDDI 100Mbits/s e 6 portas Ethernet $10 \mathrm{Mbits} / \mathrm{s}$ cada;

- Placa de Rede FDDI digital DEFPA-AA no servidor.

- Placa de rede Fast-Ethernet 3Com PCI 10/100Mbps nas estações;

Os testes realizados com essa configuração ficaram limitados à um conjunto de até 6 estações, devido ao limite do equipamento de rede disponível.

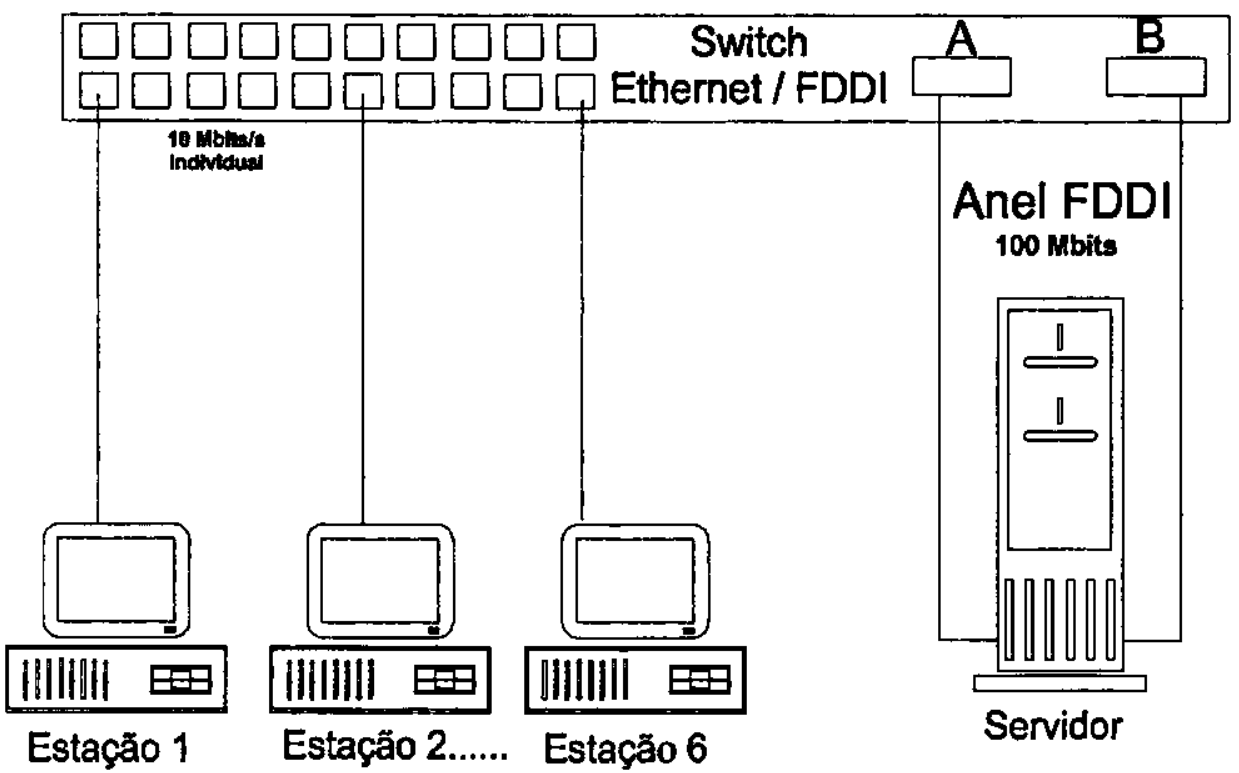

Figura 5.4: Servidor em Porta FDDI e Estaçðes em Portas Ethernet em uma Switch

\section{3 - APLICAÇÕES DESENVOLVIDAS}

Para a realização das avaliações propostas no projeto, houve a necessidade de implementação de duas ferramentas, que estão descritas abaixo:

Ferramenta 1: Avaliação de desempenho do sistema utilizando transferência simultânea de um ou mais arquivos quaisquer

Por meio dessa ferramenta torna-se possível identificar onde o desempenho fica limitado (rede, servidor ou estações) quando se realiza transferências de arquivos em um ambiente de rede. Dessa forma, arquivos do servidor de vídeo são transferidos ao mesmo tempo para um número $x$ de estaçð̃es. Nas estações, um programa que aguarda requisições por uma conexão socket (porta 4321) é executado (esp_transmite). O serviço desse programa será requisitado quando um outro programa (transmite) for executado do servidor ou de qualquer estação 
estabelecendo uma conexão com o servidor de vídeo para a transmissão do arquivo especificado para cada estação, Figura 5.6. Ao término da operação é identificado o tempo da transferência, a quantidade de bytes total transferida. $O$ cálculo da quantidade de bytes por segundo transferidos por estação e o total de bytes transferidos na rede são então computados. Os arquivos transmitidos não são apresentados nas estações. A ferramenta foi desenvolvida em Jova, sendo executada a partir de prompt do sistema operacional das estações (Windows 95).

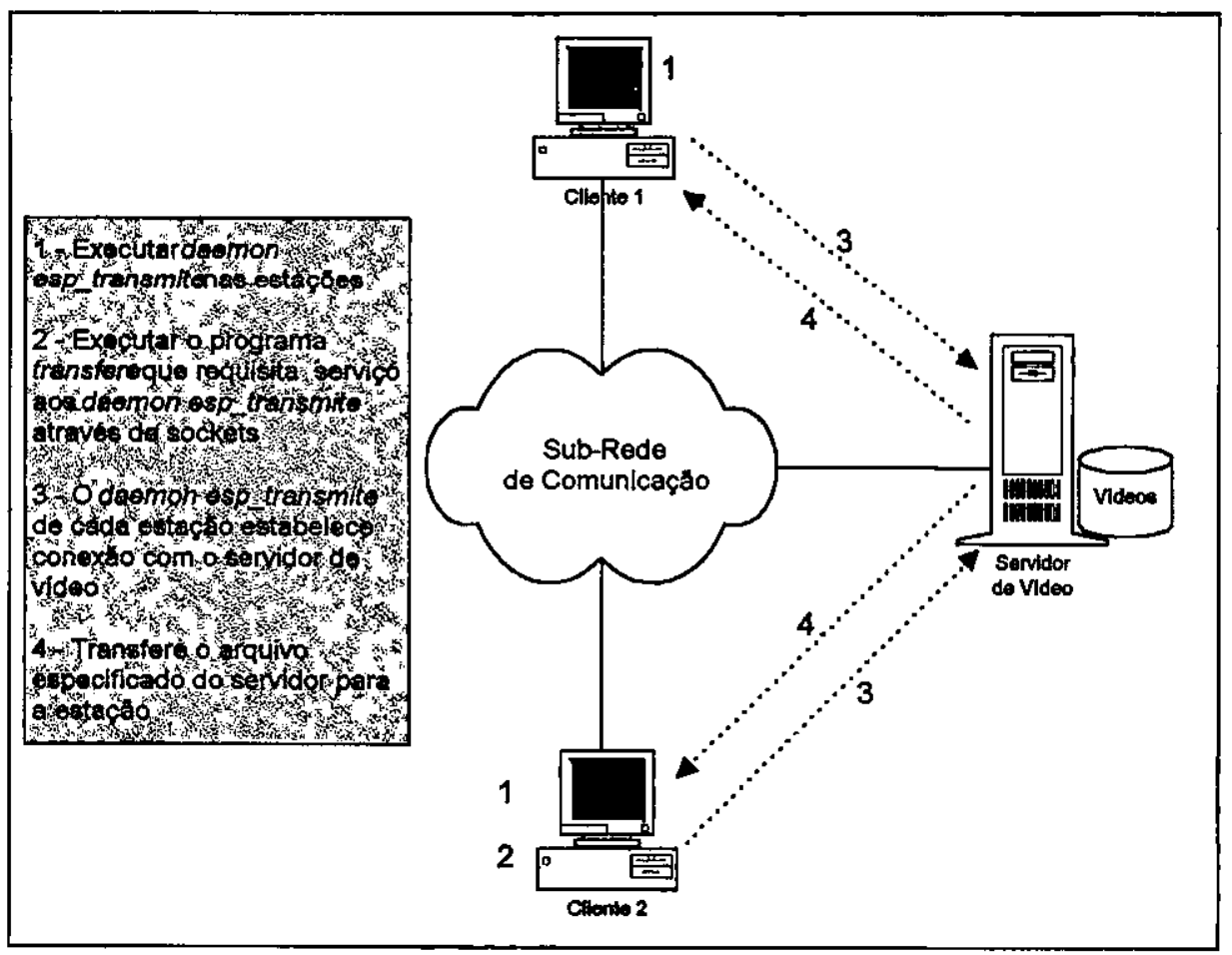

Figura 5.6: Funcionamento da Ferramenta de Avaliaçăo de Desempenho da Rede

Ferramenta 2: Avaliação de desempenho do sistema utilizando transferência e apresentação simultânea de arquivos de vídeo

Por meio dessa ferramenta torna-se possível avaliar a distribuição de vídeos (AVI e MPEG) em um ambiente multimídia distribuído. A ferramenta foi implementada como um applet Java inserido em uma página HTML (Figura 5.7) a qual pode ser visualizada (juntamente com o applet) através de qualquer browser (Netscape, Internet Explorer, etc). Ela se encontra no próprio servidor de vídeo e pode ser acessada pelo endereço http://servidor_video/ DistrVideo.html.

Os componentes da ferramenta são: 
- O programa DistrVideo.java, que é um applet iniciado ao carregar a página e que aguarda uma requisição através de uma conexão socket (porta 4321). Ao receber a requisição o mesmo inicia o programa MostraVideo;

- O programa DispVideo.java, que deve ser executado em linha de comando no servidor (javac DispVideo), o qual é responsável em enviar uma requisição ao DispVideo (que esta sendo executado em uma ou mais estações) para iniciar a transmissão do vídeo;

- O programa MostraVideo.java, é iniciado pelo DispVideo, sendo responsável pela utilização da classe JMF, que faz a transmissão e apresentação do vídeo nas estações, e de efetuar os cálculos necessários para a avaliação.

A classe JMF, descrita na seção 4.3, possui todos os controles necessários para apresentação de vídeos (iniciar, parar, voltar ao início e ir para o fim) e também consegue identificar o tipo de vídeo a transmitir. O tipo de transferência utilizado pelo JMF é variável. Assim, para os vídeos AVI, é necessário efetuar a transferência total do arquivo ao destino antes de apresentá-los (downloading). Para os vídeos MPEG, assim que os primeiros dados chegam ao seu destino são buferizados e então apresentados, enquanto a fonte continua a transmitir e buferizar (streaming).

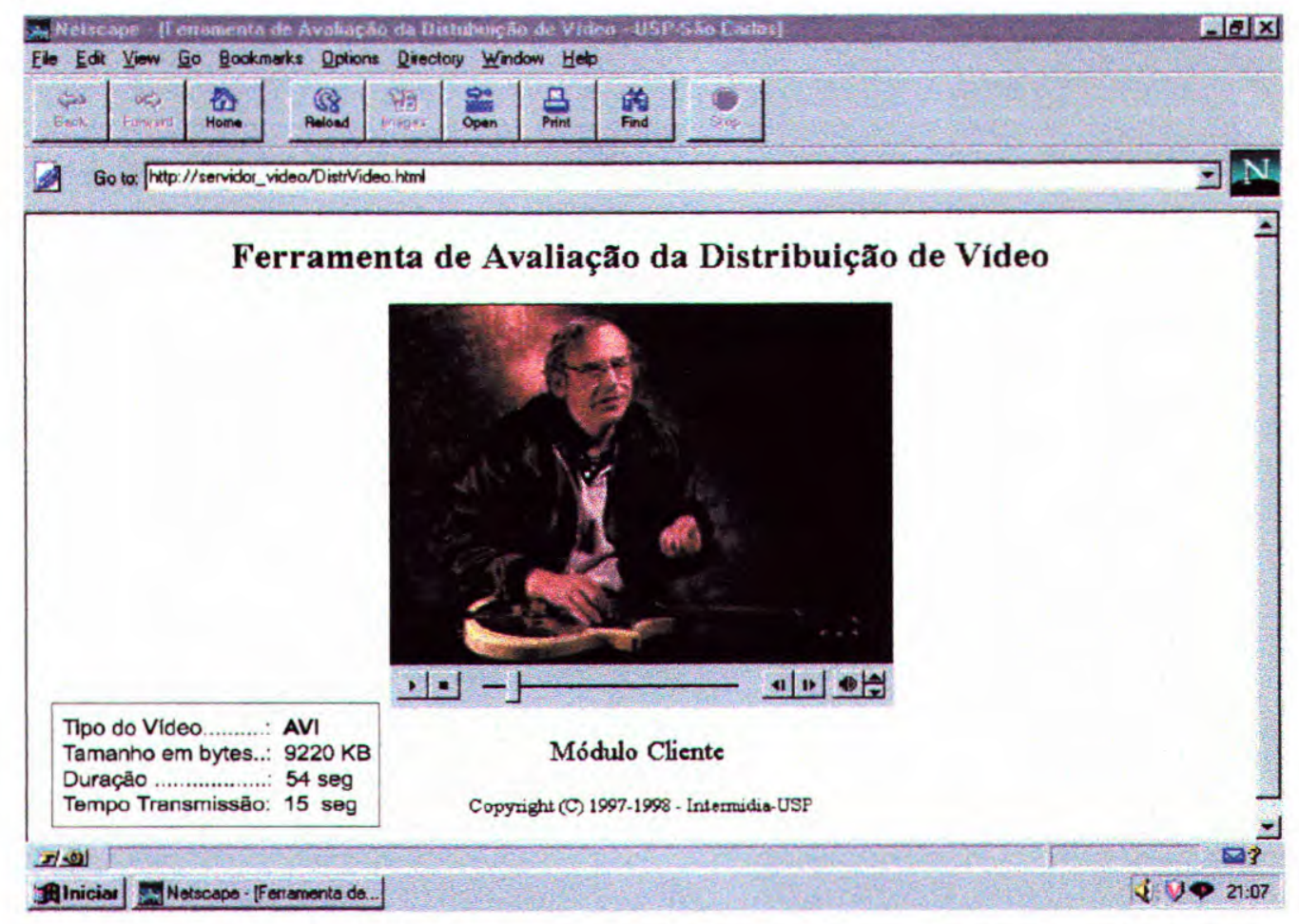

Figura 5.7: Tela Principal da Ferramenta de Avaliação da Distribuição de Vídeo 
Ao término da apresentação, a ferramenta identifica para os vídeos AVI o tempo gasto para transferir o arquivo de vídeo do servidor para as estações antes de apresentá-lo. Para os vídeos MPEG identifica o tempo gasto para transferir e apresentar o arquivo de vídeo nas estações. Esses tempos podem variar de acordo com o número de estações que estarão transmitindo os vídeos.

\section{4 - Casos de Testes}

Para a realização das avaliações foram utilizadas as ferramentas descritas na seção 5.3, sendo que através das mesmas vários testes foram realizados variando-se as configurações de rede, citadas na seção 5.2.3:

\section{A) Testes realizados com a Ferramenta 1:}

Teste 1) Transferência de um mesmo arquivo (81MB) do servidor para os discos das estações (os arquivos são gravados nos discos das estações): dependendo da tecnologia de rede utilizada o desempenho fica limitado pelos discos das estações;

Teste 2) Transferência de um mesmo arquivo (81MB) do servidor para a memória física das estações (os arquivos não são gravados nos discos das estações): eliminase o problema com os limites dos discos das estaç̃̃es, passando a ser a rede o limite em quase todas as configurações;

Teste 3) Transferência de arquivos diferentes (81MB) do servidor para os discos das estações (os arquivos são gravados nos discos das estações): Para avaliar o impacto nos serviços do servidor numa situação em que pouca memória cache é utilizada.

O tempo de acesso ao disco para leitura dos arquivos influencia na transferência e apresentação dos vídeos. Dessa forma, torna-se indispensável a utilização de uma grande quantidade de memória em servidores de vídeo, pois é possivel armazenar nessa memória (mais precisamente no cache gerenciado pelo sistema operacional) os últimos dados consultados. Com isso, se dois ou mais usuários acessarem o mesmo arquivo, somente um acesso ao disco será feito. Apesar de termos utilizado $96 \mathrm{MB}$ de Ram, acreditamos que seria aconselhável aumentar bastante este número (512 MB, por exemplo). 
Nos testes acima, utilizou-se arquivos de 81MB para que o uso da memória cache só fosse possível quando estivesse transferindo o mesmo arquivo. Através da transferência de arquivos diferentes foi possível detectar o gargalo do sistema de arquivo do servidor de vídeo.

\section{B) Teste realizados com a Ferramenta 2:}

Teste 4) Transferência de um vídeo AVI (30 Seg - 9 MB) do servidor e apresentação nas estações (Downloading): para os vídeos AVI é necessário efetuar a transferência total do arquivo antes de apresentá-lo. O teste avalia o tempo para transferir $\mathrm{o}$ arquivo em várias configurações diferentes;

Teste 5) Transferência de um vídeo MPEG (54 Seg - 9 MB) do servidor e apresentação nas estações (Streaming): para os vídeos MPEG, assim que os primeiros dados chegam ao seu destino, eles são apresentados. $\mathrm{O}$ teste avalia $\mathrm{o}$ tempo total para transferir e apresentar o vídeo.

Todos os testes especificados acima foram realizados variando o número $(1,2,3,4,6,8 \mathrm{e}$ 10) de estações e a sub-rede de comunicação (Ethernet, Switched-Ethernet com FDDI e Fast Ethernet) para que através dos dados obtidos fosse possível detectar os possíveis pontos limitantes no desempenho do sistema.

\section{5 - AVAliaÇÃo dOS ReSultados OBTIDOS}

Os testes foram realizados seguindo os casos descritos na seção 5.4, e através dos mesmos foi possível apresentar avaliações comparativas da distribuição de vídeo. Os resultados dos testes e suas respectivas avaliações são descritas abaixo: 
Teste 1: Transferência de um mesmo arquivo (81MB) do servidor para os discos das estações

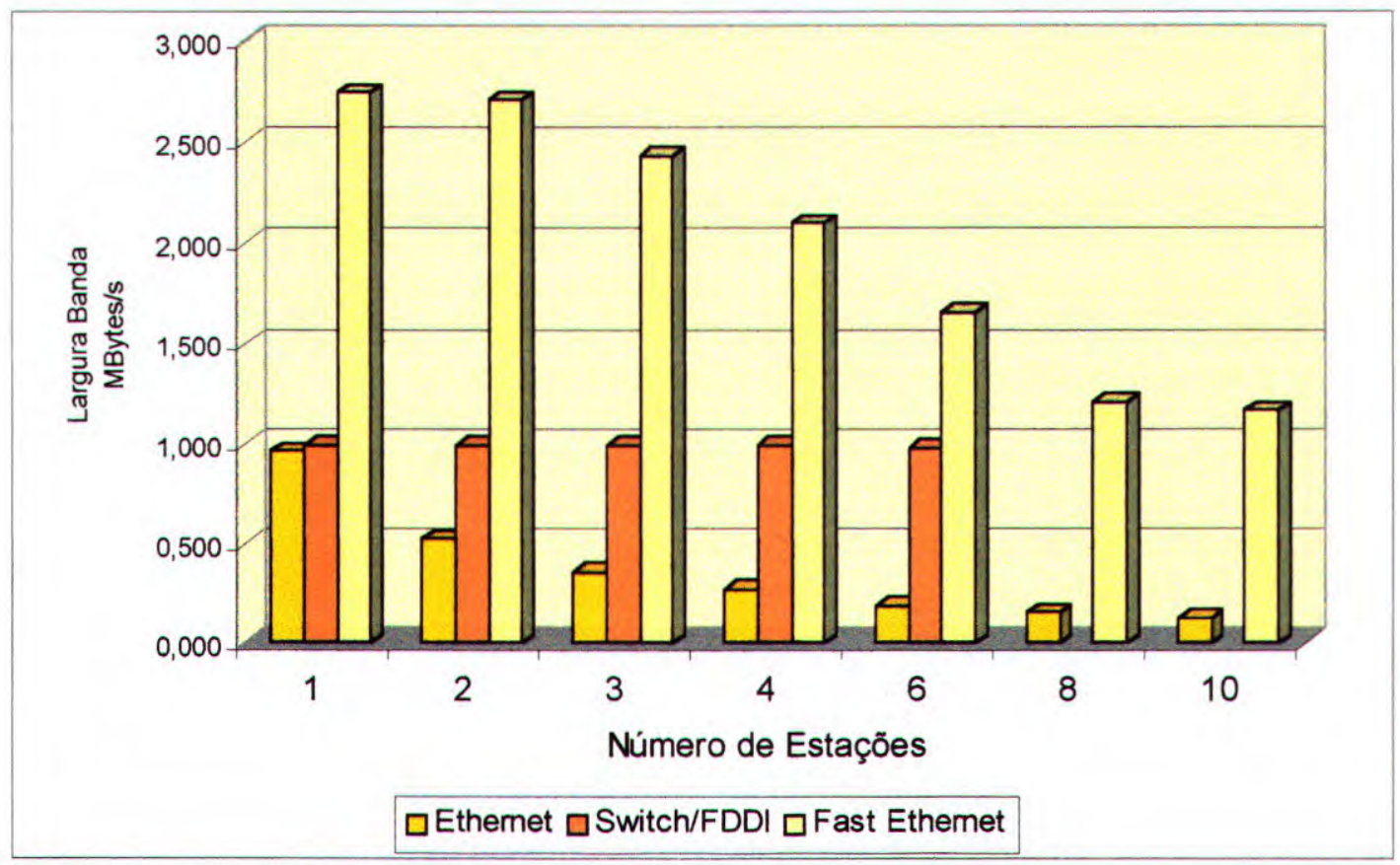

Gráfico 5.1: Transferência de um arquivo (81MB) do servidor para os discos das estaçø̃es

\begin{tabular}{|c|c|c|c|c|c|c|c|c|c|}
\hline \multicolumn{2}{|c|}{ Número de Estações } & 1 & 2 & 3 & 4 & 6 & 8 & 10 & \multirow{3}{*}{$x$} \\
\hline \multirow{2}{*}{$\begin{array}{c}\text { Ethernet } \\
10 \text { Mbps } \\
\text { Compartilhado }\end{array}$} & $\begin{array}{c}\text { Total por } \\
\text { estação }\end{array}$ & 0,960 & 0,525 & 0,361 & 0,274 & 0,186 & 0,157 & 0,127 & \\
\hline & $\begin{array}{c}\text { Total } \\
\text { Combinado }\end{array}$ & 0,960 & 1,049 & 1,084 & 1,097 & 1,119 & 1,252 & 1,268 & \\
\hline \multirow{2}{*}{$\begin{array}{c}\text { Switch } \\
\text { 10 Mbps } \\
\text { Individual } \\
+ \text { FDDI } \\
\end{array}$} & $\begin{array}{c}\text { Total por } \\
\text { estação }\end{array}$ & 0,990 & 0,990 & 0,990 & 0,990 & 0,980 & & & \multirow[t]{2}{*}{ Y } \\
\hline & $\begin{array}{c}\text { Total } \\
\text { Combinado }\end{array}$ & 0,990 & 1,980 & 2,970 & 3,960 & 5,880 & & & \\
\hline \multirow{2}{*}{$\begin{array}{c}\text { Fast } \\
\text { Ethernet } \\
\text { Compartilhado }\end{array}$} & $\begin{array}{l}\text { Total por } \\
\text { estação }\end{array}$ & 2,743 & 2,710 & 2,434 & 2,101 & 1,656 & 1,212 & 1,167 & \multirow[t]{2}{*}{ Z } \\
\hline & $\begin{array}{c}\text { Total } \\
\text { Combinado }\end{array}$ & 2,743 & 5,420 & 7,302 & 8,405 & 9,933 & 9,696 & 11,667 & \\
\hline
\end{tabular}

Tabela 5.1: Resultados do Teste 1 (Valores em Mbytes/s)

Analisando o Gráfico 5.1 observamos que:

- Com redes Ethernet (10 Mbps), na medida que o número de estações aumenta, diminui a fatia de banda disponivel para cada estação (linhas $X$ da tabela 5.1), sendo um fator limitante na transmissão de arquivos. 
- Quando se utiliza Ethernet Switched, cada estação transmite a $10 \mathrm{Mb} / \mathrm{s}$, e neste caso, estando o servidor conectado ao Anel FDDI (100MB/s), foi possível a utilização de toda a largura de banda disponível $(10 \mathrm{Mb} / \mathrm{s})$ por cada uma das estações (linhas Y da tabela 5.1).

- Com a rede Fast Ethernet, utilizando poucas estações (até 2 estações) a transmissão se limita ao disco das estações (colunas 1 e 2 das linhas $Z$ da tabela 5.1). A partir de 2 (duas) estações, provavelmente o fator limitante na transmissão seja o tempo de acesso aos discos do servidor e das estações, sendo necessário a realização de testes adicionais futuros para a determinação exata do problema.

Teste 2: Transferência de um mesmo arquivo (81MB) do servidor para memória física das estações

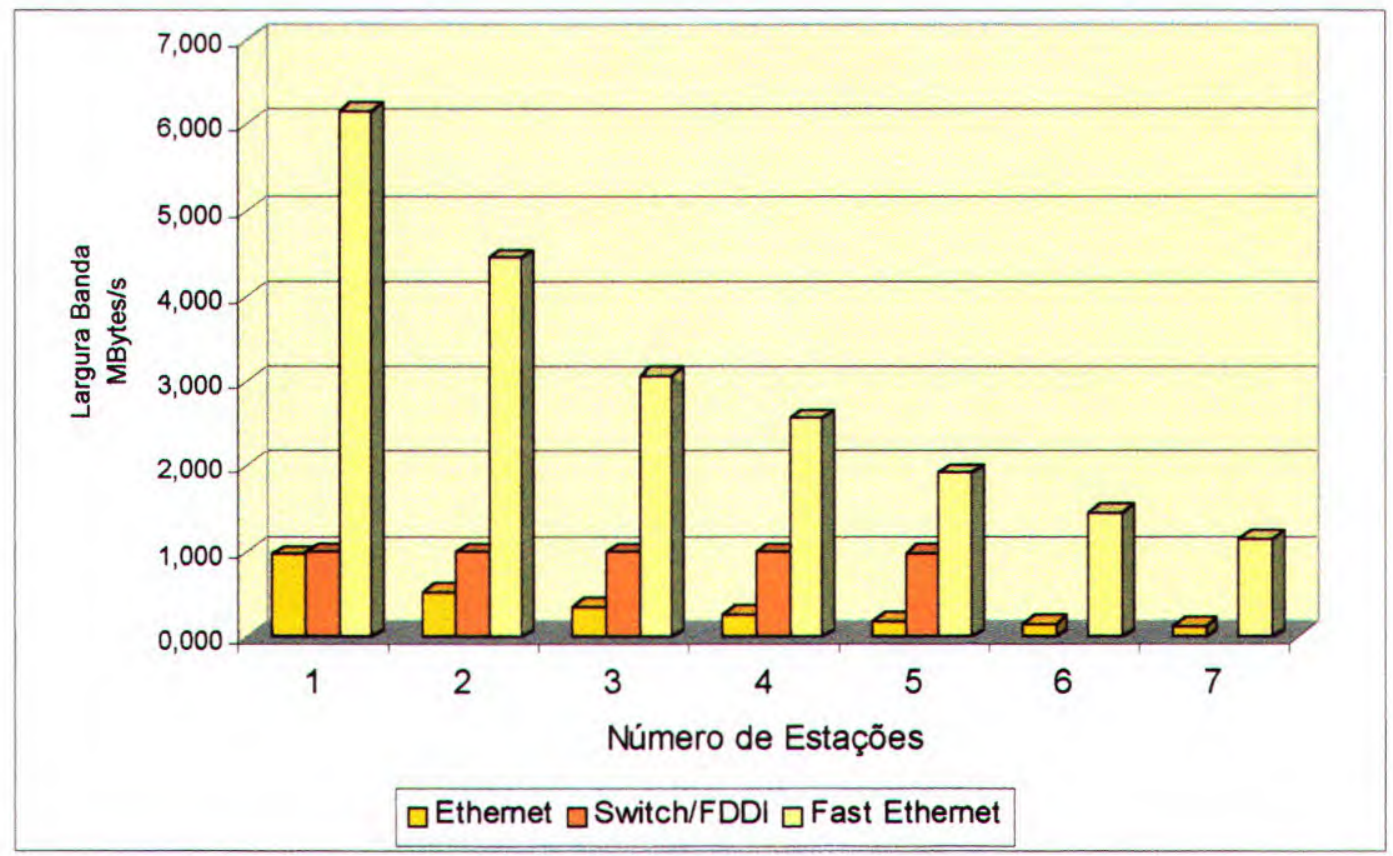

Gráfico 5.2: Transferência de um arquivo (81MB) do servidor para a memória física das estações 


\begin{tabular}{|c|c|c|c|c|c|c|c|c|c|}
\hline \multicolumn{2}{|c|}{ Número de Estaçós } & 1 & 2 & 3 & 4 & 6 & 8 & 10 & \\
\hline \multirow{2}{*}{$\begin{array}{c}\text { Ethernet } \\
10 \mathrm{Mbps} \\
\text { Compartilhado }\end{array}$} & $\begin{array}{c}\text { Total por } \\
\text { estação }\end{array}$ & 0,960 & 0,525 & 0,361 & 0,274 & 0,186 & 0,157 & 0,127 & \multirow[t]{2}{*}{$x$} \\
\hline & $\begin{array}{c}\text { Total } \\
\text { Combinado }\end{array}$ & 0,960 & 1,049 & 1,084 & 1,097 & 1,119 & 1,252 & 1,268 & \\
\hline \multirow{2}{*}{$\begin{array}{c}\text { Switch } \\
10 \mathrm{Mbps} \\
\text { Individual } \\
+ \text { FDDI } \\
\end{array}$} & $\begin{array}{c}\text { Total por } \\
\text { estação }\end{array}$ & 0,990 & 0,990 & 0,990 & 0,990 & 0,980 & & & \multirow[t]{2}{*}{$Y$} \\
\hline & $\begin{array}{c}\text { Total } \\
\text { Combinado }\end{array}$ & 0,990 & 1,980 & 2,970 & 3,960 & 5,880 & & & \\
\hline \multirow{2}{*}{$\begin{array}{c}\text { Fast } \\
\text { Ethernet } \\
\text { Compartilhado }\end{array}$} & $\begin{array}{c}\text { Total por } \\
\text { estação }\end{array}$ & 6,170 & 4,454 & 3,081 & 2,578 & 1,923 & 1,460 & 1,150 & \multirow[t]{2}{*}{ Z } \\
\hline & $\begin{array}{c}\text { Total } \\
\text { Combinado }\end{array}$ & 6,170 & 8,907 & 9,244 & 10,312 & 11,537 & 11,679 & 11,504 & \\
\hline
\end{tabular}

Tabela 5.2: Resultados do Teste 2 (Valores em Mbytes/s)

O Gráfico 5.2 demonstra que o limite no disco das estações pode ser eliminado através da transferência dos arquivos para a memória das estações, surgindo então novos fatores limitantes, descritos abaixo:

- Note-se que no caso de apenas 1 (uma) estação a taxa total alcançada foi de 6.17 Mbytes/s. Esta taxa esta provavelmente sendo limitada pelo servidor. $O$ aumento do número de clientes faz com que a performance geral aumente, provavelmente devido ao cache feito pelo servidor.

- Note que, para 10 estações a taxa de transferência total é próxima à taxa do teste anterior.

- Os valores para as redes Ethernet e Switched Ethernet (linhas X e Y da tabela 5.2) não sofreram alteração em relação ao teste anterior, pois o limite na transmissão continua sendo a rede. 
Teste 3: Transferência de arquivos diferentes (81MB) do servidor para os discos das estações

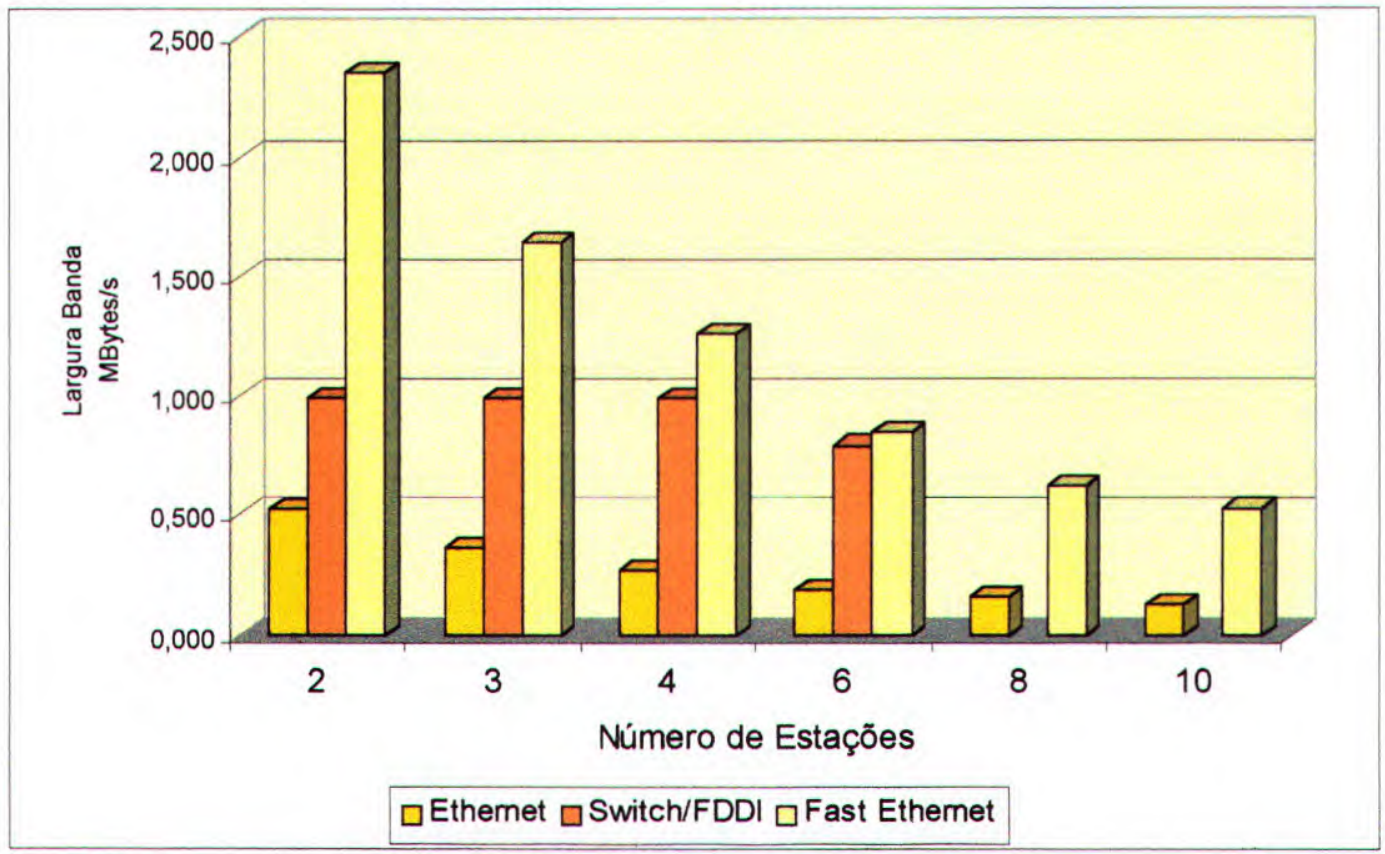

Gráfico 5.3: Transferência de arquivos diferentes (81MB) do servidor para os discos das estações

\begin{tabular}{|c|c|c|c|c|c|c|c|c|}
\hline \multicolumn{2}{|c|}{ Número de Estações } & 2 & 3 & 4 & 6 & 8 & 10 & \multirow{3}{*}{$x$} \\
\hline \multirow{2}{*}{$\begin{array}{c}\text { Ethernet } \\
10 \text { Mbps } \\
\text { Compartilhado }\end{array}$} & $\begin{array}{c}\text { Total por } \\
\text { estação }\end{array}$ & 0,525 & 0,361 & 0,274 & 0,186 & 0,157 & 0,127 & \\
\hline & $\begin{array}{c}\text { Total } \\
\text { Combinado }\end{array}$ & 1,049 & 1,084 & 1,097 & 1,119 & 1,252 & 1,268 & \\
\hline \multirow{2}{*}{$\begin{array}{c}\text { Switch } \\
10 \text { Mbps } \\
\text { Individual } \\
+ \text { FDDI }\end{array}$} & $\begin{array}{l}\text { Total por } \\
\text { estação }\end{array}$ & 0,990 & 0,990 & 0,990 & 0,790 & & & \multirow[t]{2}{*}{ Y } \\
\hline & $\begin{array}{c}\text { Total } \\
\text { Combinado }\end{array}$ & 1,980 & 2,970 & 3,960 & 4,740 & & & \\
\hline \multirow{2}{*}{$\begin{array}{c}\text { Fast } \\
\text { Ethernet } \\
\text { Compartilhado }\end{array}$} & $\begin{array}{c}\text { Total por } \\
\text { estação }\end{array}$ & 2,350 & 1,640 & 1,260 & 0,847 & 0,627 & 0,529 & \multirow[t]{2}{*}{ Z } \\
\hline & $\begin{array}{c}\text { Total } \\
\text { Combinado } \\
\end{array}$ & 4,700 & 4,921 & 5,042 & 5,080 & 5,016 & 5,287 & \\
\hline
\end{tabular}

Tabela 5.3: Resultados do Teste 3 (Valores em Mbytes/s)

Analisando o Gráfico 5.3 observar-se que: 
- Quando se utiliza Ethernet Switched com até 4 estações, o limite na transmissão é a rede, e a partir desse ponto o limite passa a ser o sistema de arquivo do servidor (linhas Y da tabela 5.3).

- Para a rede Fast Ethernet, o limite passou a ser o sistema de arquivo do servidor (linhas Z da tabela 5.3).

- Para a rede Ethernet o limite continua sendo a rede (linhas X da tabela 5.3).

Teste 4: Transferência de vídeo AVI (30 Seg - 9 MB) do servidor e apresentação nas estações (Downloading):

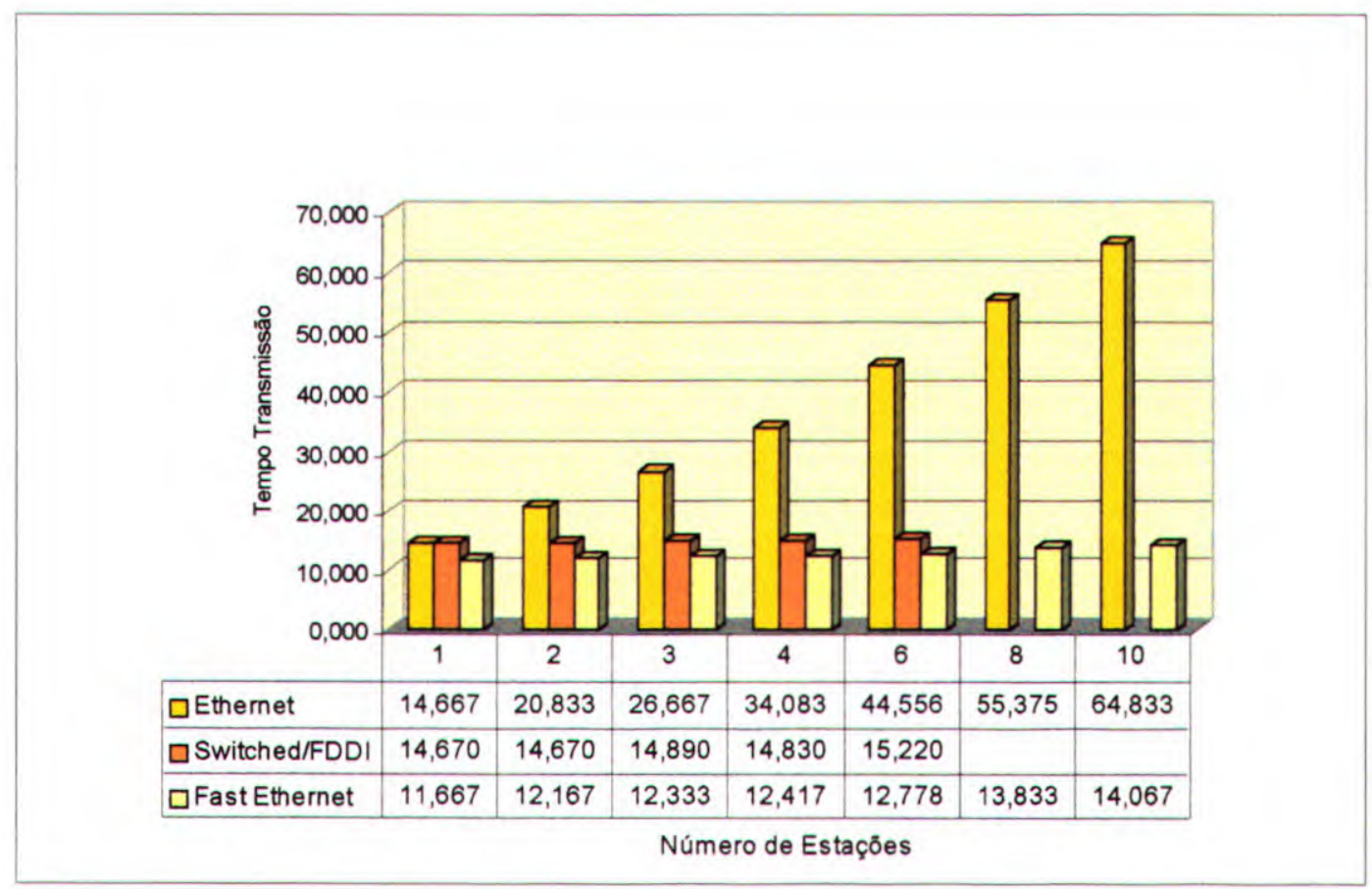

\section{Gráfico 5.4: Teste 4 - transferência de um vídeo AVI do servidor e apresentação nas estações}

Um dos grandes problemas na distribuição de vídeo é a utilização de padrões em que os arquivos necessitam ser transferidos totalmente antes de serem apresentados. Através do Gráfico 5.4 , pode-se observar que: 
- A utilização de grandes arquivos para um número grande de estações torna-se inviável, devido ao tempo que deve ser aguardado para a transferência do arquivo. No teste realizado com rede Ethernet, notamos que o tempo necessário para distribuir o arquivo de vídeo para cada uma das 10 (dez) estações foi o dobro do tempo do vídeo a ser apresentado.

- A distribuição de vídeos AVI torna-se viável para as redes com Switched Ethernet e Fast Ethernet quando os arquivos a serem distribuídos forem pequenos (inferior ou igual a $10 \mathrm{MB}$ ).

- Na transferência dos arquivos de vídeos o JMF não utiliza toda a banda da rede para equilibrar o provimento para várias máquinas (por exemplo: 10 estações transferindo o mesmo arquivo de $9 \mathrm{MB}$ a uma taxa de $1.16 \mathrm{Mbytes} / \mathrm{s}$ levaria em média 9 segundos, enquanto que no teste acima levou 14 segundos).

5) Transferência de um vídeo MPEG (54 Seg - 9 MB) do servidor e apresentação nas estações (Streaming):

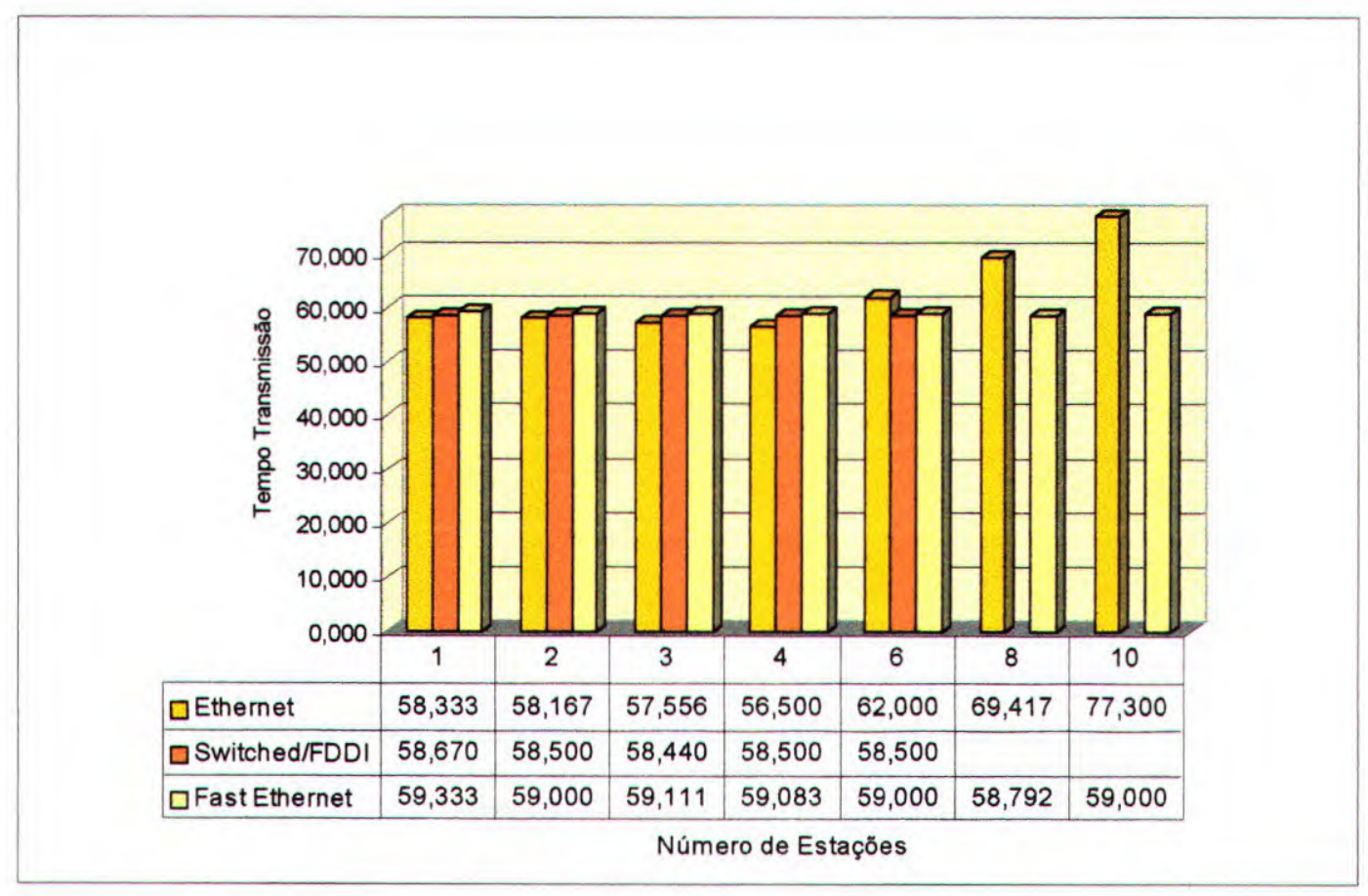

Gráfico 5.5: Teste 5 - transferência de um vídeo MPEG do servidor e apresentação nas estações 
A utilização de vídeos Streaming é a forma mais viável atualmente para a distribuição de vídeo em ambientes distribuldos onde não se tem garantia da qualidade de serviço (QoS). Analisando o Gráfico 5.5 observa-se que:

- Para todas as tecnologias de rede utilizadas o tempo total para transferência e apresentação do vídeo foi superior a no máximo $10 \%$ do tempo de apresentação normal do vídeo.

- Para as redes Ethernet com mais de 5 (cinco) estações, não foi possível buferizar o vídeo antes de apresentá-lo, de forma que em algumas estações a transmissão foi bloqueada até a chegada de informaçð̃es no buffer. 


\section{CONCLUSÕES}

\section{1- INTRODUÇÃo}

A medida que se verifica o aumento do número de computadores na sociedade e a interconexão dos mesmos através de uma rede de computadores, surge uma nova classe de aplicações. Uma das aplicaçð̃es - a utilização de áudio e vídeo - começa a aparecer com um certo destaque. Adicionalmente, torna-se cada vez mais complexa a criação de um ambiente computacional capaz de atender a essas necessidades de maneira eficiente, pois a manipulação de objetos multimídia envolve fatores como o armazenamento, a editoração, transmissão e a apresentação eficiente desse material.

A questão da disponibilização de dados multimídia em ambientes WWW é um ponto fundamental, uma vez que a transmissão deve ser gerenciada de forma eficiente para evitar sobrecarga do sistema devido ao grande volume de dados e ao eventual número elevado de usuários acessando o sistema.

\section{2- BENEFÍCIOS DO TRABALHO}

Os testes realizados mostram que é perfeitamente possível a implementação de sistema de distribuição de vídeo via tecnologias padrão de rede utilizadas correntemente. Para contornar os problemas oriundos da precariedade dos protocolos TCP/IP e Ethernet para a transmissão de mídia contínua, nota-se o aparecimento de várias tecnologias que possibilitam o uso de um sistema de armazenamento remoto de vídeo e sua apresentação local com razoável qualidade sem a utilização de sincronismo durante o processo, através de técnicas de streaming de vídeo (p.ex. VXtreme, RealVideo, CU-Seeme e o padrão JMF). A utilização das técnicas de downloading de vídeo, torna-se inviável para a distribuição de grandes arquivos ou em 
ambientes onde a quantidade de usuários é grande, devido ao tempo de transmissão do arquivo as estações.

Apesar destes sistemas poderem ser utilizados na "grande rede", este trabalho centrou esforços numa avaliação em redes locais, pois prevê-se uma demanda maior para serviços como este em redes locais (empresas e escolas). Vários esquemas diferentes de rede podem ser utilizados para a distribuição. Os testes nesta área mostram o ganho que se pode ter quando se utiliza switches que possuem portas de alto desempenho (no caso foi utilizado FDDI) para conexão do servidor. Por exemplo, supondo-se que uma aplicação necessitasse de 600 KBytes por segundo (padrão MPC3) e que esta fosse utilizada simultaneamente por 20 máquinas, a quantidade agregada de dados transmitidos seria de 12 MBytes por segundo (96 Mbits por segundo). Uma configuração possível de rede testada seria a conexão das 20 estações numa Switch Ethernet com porta FDDI para o servidor.

Situações de demanda de maior de largura de banda precisam de diferentes arquiteturas de rede, pois no caso descrito a conexão FDDI (12,5 MBytes/s) está próxima do limite de sua capacidade. Uma troca de FDDI por ATM a $155 \mathrm{Mbps}$ ou 622Mbps poderia prover uma capacidade adicional ao sistema.

\section{3- SUGESTÕES PARA TRABALHOS FUTUROS}

As seguintes sugestões podem gerar trabalhos futuros dando continuidade ao projeto em questão, ou ainda motivando desenvolvimento de outros projetos:

- Realizar as avaliações nos ambiente já configurados, mas utilizando protocolos que possuem os padrões de QoS (IPV6);

- Outro trabalho de grande importância seria o estudo e avaliação de ambientes de redes de alta velocidade (por exemplo: ATM, Gigabit Ethernet, etc), tendo como objetivo descobrir os novos gargalos inerentes ao servidor.

- Avaliar os beneficios na utilização de multicast;

- Refazer o perfil dos testes, desta vez colocando um número maior clientes demandando taxas menores de dados $(100 \mathrm{~Kb} / \mathrm{s})$, de modo a se ter uma idéia mais precisa da carga sobre o servidor. 


\section{GLOSSÁRIO}

API Application Programming Interface Especifica como um programador deve descrever um aplicativo para acessar o comportamento e estados de classes e objetos.

Applet Um programa escrito em Java para ser executado sobre um navegador Web compatível Java, como Hotjava, Netscape ou Internet Explorer.

ATM Modo de Transferência Assíncrono. Padrão da ITU destinada para altas taxas de bits para redes WAN com estrutura broadband ISDN, desenvolvido e baseado no princípio de multiplexação por divisão de tempo assíncrono. A tecnologia também é destinada para redes locais. Baseado no transporte de pequenas unidades de dados de tamanho fixo (53 bytes) que recebe o nome de célula.

B-ISDN Rede digital de serviços integrados de banda larga. Termo genérico estudado e padronizado pela ITU e ISO para uma tecnologia de alta largura de banda, suportando todos os tipos de serviços digitais em um caminho integrado.

Bandwidth Largura de Banda. Em transmissão, o número de frequências que um sistema pode transmitir sem excessiva redução. Em redes de dados, usado para referir a capacidade de uma rede expressado em bits por segundo.

Broadcasting Em telecomunicações, broadcasting é a propagação de um fluxo de informação de uma fonte para todos os destinos. Exemplo: canal de TV.

Browser - Um browser é um aplicativo para a apresentação de hiperdocumentos. A maioria dos 
browsers disponiveis trabalha com hiperdocumentos HTML, e são utilizados na navegação pela Internet para a visualização das informações (textos, gráficos, imagens, sons, animações e vídeos) disponíveis.

Bytecode Código independente de máquina gerado por um compilador Java e executado por um interpretador Java.

CCITT Comitê que faz parte da ITU que produz padrões para telefone e sistema de comunicação de dados. Foi renomeado para ITU-TS.

CELP Code Excited Linear Prediction. Um esquema de compressão baseado em quantização de vetor para voz.

CIF Common Intermediate Format. Troca de Formatos para imagens de vídeo em movimento.

Comutação de Pacotes Técnica de multiplexação por divisão de tempo usado em comunicação de dados onde o fluxo de bits são divididos em pequenas unidades de dados mandados um a um com um intervalo de tempo, e são também chamados de pacotes, frames, ou células.

Compilação Um programa é traduzido do código original para um código que possa ser executado por um compilador. Um compilador java traduz o fonte para bytecode Java.

Crominância Termo usado para se referir as diferenças de cor. Em analogia a TV broadcast, sinais de crominância são construídos pela combinação linear de sinais de diferentes cores.

DAC Digital para Analógico. Refere-se ao processo de transformação do sinal digital para um fenômeno físico que o humano pode sentir (ver, ouvir).

Descompressão Em computador, refere-se ao processo pelo qual as informações comprimidas são expandidas pela adição de informaçães redundantes eliminadas no estágio de compressão. 
Download - Processo de transferência de dados via WWW. Os dados são completamente transferidos para depois serem utilizados.

Downloading - Termo usado para designar o tipo de transferência de dados que determinados sistemas utilizam. "O sistema $\mathrm{x}$ trabalha com downloading de imagens .gif.". Termo usado também para fazer referência à tecnologia oposta ao streaming

fps - frames per second (quadros por segundo), taxa de transmissão de frames em redes de computadores.

Frame - Um frame corresponde a um quadro de vídeo. Pode-se imaginar um frame como uma foto. Uma sequência de fotos exibidas consecutivamente a uma velocidade entre 10 e 30 frames por segundos dando a ilusão de movimento é o vídeo.

HDTV High-Definition Television. Refere-se a tecnologia de TV com qualidade superior a TV broadcast convencional. 1920 pixels/linha, 1080 linhas/frame a alta taxa de $60 \mathrm{fps}$.

HTML HyperTExt Markup Language É um formato de arquivo, baseado sobre SGML, para documentos hypertextos sobre a Internet. Ele é muito simples e fácil para a associação de imagens, sons, streams de vídeo, formulários e textos simples formatados.

HTTP Hypertext Transfer Protocol O protocolo Internet, baseado em TCP/IP, utilizado para buscar objetos hypertextos de computadores remotos.

IP (Internet Protocol). O protocolo de "nível transporte" comum na rede de computadores Internet; fornece os endereços que os roteadores necessitam para transferir pacotes através de redes para seus destinos. Permite que "pacotes" de dados sejam enviados de uma rede para outra, presumindo que $o$ nível seguinte cuide de despachar essas informações. A porção do TCP/IP que move os pacotes de dados através das diversas redes que compõem a Internet para seus destinos corretos; o IP sozinho, no 
entanto, não garante que os dados alcançarão seus destinos, cabendo à parte TCP esta tarefa. Os endereços IP possuem 32 bits.

ITU - International Telecomunications Union é uma organização internacional na qual setores privados e governamentais coordenam redes e serviços globais TELECOM. Suas atividades incluem coordenação, regulamentação e padronizações de telecomunicações e a organização de eventos regionais e mundiais da TELECOM.

Jitter Em comunicação de dados, é a variação sobre o tempo de atraso do tráfego da rede.

LPC Linear Predictive Coding. Um esquema de compressão baseado na quantização de vetor para voz.

Mídia discreta Em sistemas multimidia refere-se a mídias que não mudam com o tempo, como texto, gráficos e imagens.

Mídia contínua Em sistemas multimídia refere-se a mídias que mudam com o tempo, como áudio, vídeo e animações.

Multimídia É a utilização simultânea de vários tipos de mídia (texto, sons, imagens, gráficos, vídeos e animações).

Pacotes Em uma transmissão por rede, os dados são desmembrados em pequenas porções chamadas de "pacotes". O tamanho dos "pacotes" pode variar de 40 até 32.000 bytes, dependendo da rede. Normalmente menos de 1.500 bytes.

Plug-in É um software que pode ser instalado de forma a agir de dentro de um Browser, como se fizesse parte do mesmo.

QoS - Quality of Service. Em redes de computadores e sistemas operacionais, é um conceito que as aplicações usam para especificar suas necessidades para o sistema, antes da transmissão ou 
processamento inicial.

RAID - Redundant Array of Inexpensive Disks. Técnica utilizada em armazenamento de dados onde um arquivo é dividido em partes e cada parte é armazenada em um disco diferente, paralelamente, obtendo uma velocidade maior na gravação e na recuperação dos dados.

SGML Standardized Generalized Markup Language. Um padrão ISSO/ANSI/ECMA que especifica um meio para anotações de documentos extto com informaç̃̃es sobre tipos de seções de um documento.

Stream Em computação refere-se a um fluxo de dados.

Streaming Termo usado para designar o tipo de transferência de dados que determinados sistemas utilizam. Neste processo os dados vão sendo apresentados à medida que vão chegando, em contraste ao processo de downloading que espera todos os dados chegarem para realizar a apresentação. Muito utilizado em transferência de áudio e vídeo.

TCP Transmission Control Protocol. A parte do conjunto de protocolos TCP/IP que controla o transporte de dados. Assegura que os dados transmitidos por redes que o utilizam alcancem seu destino, detectando e reenviando pacotes perdidos, adulterados ou duplicados, além de oferecer a correção de erros não disponivel no IP.

TCP/IP Transmission Control Protocol/Internet Protocol. Protocolo de controle de transmissão - na verdade uma pilha (stack) de protocolos para comunicação, dos quais o TCP e o IP são os mais importantes. Em uma arquitetura de comunicação em camadas, com protocolos distintos cuidando de tarefas distintas, pode-se dizer, simplificando, que ao TCP cabe dividir mensagens em pacotes em uma ponta da comunicação e recompô-las da outra, garantindo a entrega segura das mensagens, enquanto ao IP cabe descobrir o caminho adequado entre $o$ remetente $e$ destinatário e enviar os pacotes. 
Tráfego Isócrono Suporta transferência de bytes com um tempo entre chegadas constantes.

UDP User Datagram Protocol. Um dos protocolos de transporte sem conexão, que antecederam o TCP/IP, usado em aplicações como 0 gerenciamento de redes (SNMP) e de serviços de fornecimento de nomes de domínio na Internet. 


\section{REFERÊNCIAS BIBLIOGRÁFICAS}

[At96] THE ATM FORUM. - ATM Tutorial, 1996.

[At95a] ATKINSON, R. - IP Authentication Header", RFC 1826, Naval Research Laboratory, Agosto 1995.

[At95b] ATKINSON, R. - Security Architecture for the Internet Protocol", RFC 1825, Naval Research Laboratory, Agosto 1995.

[Bo94] BorKo, F. - Multimedia Systems : An Overview, IEEE Multimedia, p. 4759,Spring 1994.

[Bu94] BUFORD, J.; RUTLEDGE, L.; KeSKIN, C. - HyOctane: a HyTime Engine for na MMIS. Multimedia Systems, vol. 1, n. 4, pp. 173-185, 1994.

[Bu94a] BUFORD, J. F. K. - Multimedia Systems, Addison-Wesley, 1994.

[Ca95] CARDozo, E. et allu - Sistemas Multimídia, Universidade Estadual de Campinas - Faculdade de Engenharia Elétrica, 1995.

[Fe94] FEDERIGH, C; RowE, L. A - A Distributed Hierarchical Storae for a Videoon-Demand System, Symp. On Elec. Imaging Sci. \& Tech., San Jose, Fevereiro, 1994.

[F195] FLUCKIGER, F.- Understanding Networked Multimedia applications and technology., Prentice Hall, 1995.

[Ge95] GEMMELL, D. J.; VIN, H. M.; KANDLUR, D.D.; RANGAN, P. V.; ROWE, L. A. Multimedia Storage Servers : A Tutorial, IEEE Computer, pag.40-48, Maio, 1995.

[Gu94] GUARNERI, R.; LANTING, C. J. M. - Frame Relaying as a Common Acess to N$I S D N$ and B-ISDN data Services, IEEE Communications Magazine, p.39-43, Junho, 1994.

[Hi96b] HINDEN, R. E DEERING, S.- IP Version 6 Addressing Architecture, Network 
Working Group RFC1884. 1996.

[Ja97] JaCKSON, J. R.; MACClellaN, A. L. - Java by Example, Iprentice Hall Title, 1997.

[JM97] JAVA MEDIA FRAMEWORK - INTEL, [Online].

Available: http://developer, intel,com/ial/jmedia/Documentation, htm

[Ka95] KARN, P.; METZGER, P.; SIMPSON, W. - The ESP DES-CBC Transform, RFC 1829, Qualcomm, Piermont e Daydreamer, Agosto/1995.

[Kr96] Krammer, D. - The Java Platform: A White Paper, maio 1996, [Online] Available: ftp://ftp.javasoft.com/docs/papers/javaplatform.ps

[La97] LALAN, S.; JAMSA, K. - Java: Biblioteca do Programador, Makron Books, 1997.

[Le94a] BERNERS-LEE, T. ET AL. - The World-Wide Web, Communications of the ACM, Vol. 37, pp.76-82, 1994.

[Le94b] LeE, E. K.; Chen, P. M.; HaRTMan, J. H.; DRaPEAU, A. L. C.; MilleR, E. L.; KARTZ, R. H.; GIBSON, G. A.; PATTERSON, D. A. - RAID-II: A Scalable Storage Architecture for High-Bandwidth Nwtwork File Service, $21^{\text {st }}$ International Symposium on Compute Architecture, Chigaco, Illinois, Abril, 1994.

[Li95] LINDSTROM, R. L. - Guia Business para Apresentações em Multimidia, Makron Books, 1995

[Li95] LIEIRA, J.; MOREIRA, E.D.S. - Utilização de Som e Imagem em Sistemas de Gerenciamento de Redes de Computadores, submetido para o SEMISH, Canela, RS, 1995.

[L093] LOUGHER, P.; SHEPHERD, D. - The Design of a Storage Server for Continuous Media, The Computer Journal, pag. 32-41, Vol. 36, No. 1, 1993.

[Ma94] MatTison, P. - Pratical Digital Video with Programming Examples in C, Wiley Professional Computing, 1994.

[Me96] MENDES, G. A. - A Nova Geração de IP Toma Forma, Business Communication Review Brasil, $N^{\circ}$ 2, Maio/1996.

[Me95] METZGER, P.; SIMPSON, W. - IP Authentication using Keyed MD5, RFC 1828, Piermont e Daydreamer, Agosto/199

[Mo95a] MOREIRA, E.D.S; REAMI, ELDERCLEY REGIS; PISSIOLI, MAURICIO - Live Video for Distributed Multimedia/Hypermedia Applications: Directly 
Connecting Video Sources to TCP/IP Networks, aceito para apresentação e publicação nos proceedings do 18th Annual International Conference MIPRO' 95 on Multimedia/Hypermedia Systems, Croacia, maio, 1995.

[Mo95b] MOREIRA, E.D.S. et allu - Design Issues for the Process of Developing a Hypermedia-based Distributed Tutoring System (HyDTS), submetido para o SBIA, Florianópolis, SC, out/ 95.

[Mo97] Morandini, M.; Castro, M. A. S.; Pimentel, M. G. C. - Princípios de Interação Usuário-Computador Aplicados ao Projeto de um Quiosque Hipermídia: uma Experiência, Submetido ao WoHM97 (III Workshop em Sistemas Hipermídia e Multimídia), São Carlos, 1997.

[Oh94] OHR, S. - Digital video spearheads TV and videoconferencing applications, Computer Desing, pag. 59-70, dezembro, 1994.

[O197] OliveIRA, D.F.N; - Estendendo o Protocolo IPv6 para suportar tráfego de Sistemas de Realidade Virtual; Mini-dissertação de Mestrado, ICMSC-USP, 1997;

[Ot95] OtsuKa, J. LeE - Fast Ethernet, Universidade Federal do Rio Grande do Sul, 1995.

http://penta.ufrgs.br/rc952/trab2/fe.html

[Re95] RETTINGER, L. A. (1995) - Desktop VideoConferencing: Technology and Use for Remote Seminar Delivery [On-Line]. Available:

http://www2.ncsu.edu/eos/service/ece/project/succeed_info/larettin/thesis/tit.html [17 de novebro de 1996].

[Si97] SIlva, A. J. S. - O que Vai Mudar na Sua Vida com o IPV6, RNP News Generation, Vol. 1, No 2, Junho/1997.

[Si96] SiscoutTo, R. A. - Sistema de VideoConferência em Redes de Computadores. Mini-dissertação de Mestrado, ICMSC-USP, 1996.

[St95] SteINMETZ, R. - Analyzing the Multimedia Operating System, IEEE Multimedia, pp. 68-84, Spring, 1995.

[Ta96] Tanembaum, A. - Computer Network, 3rd edition, Prentice-Hall, 1996.

[Tr97] TrINDADE, C. C. - Minimal Hyperlinking HyTime Documents: Especificação e Apresentação de Estruturas Clássicas de Hipertexto, Dissertação de Mestrado apresentada ao ICMSC-USP em fevereiro de 1997.

[Va94] Vaughan, Tay - Multimídia na Prática, Makron Books, 1994 


\section{APÊNDICE A}

\section{AVALIAÇÃO DE DESEMPENHO DE UM AMBIENTE COMPUTACIONAL PARA PROVIMENTO DE VÍDEO}

Artigo submetido e aceito no: "IV International Congress of Internation Engeineering" Buenos Aires/Argentina - 1998 


\title{
AVALIAÇÃO DE DESEMPENHO DE UM AMBIENTE COMPUTACIONAL PARA PROVIMENTO de Vídeo
}

\author{
Antonio Marcos M. Hachisuca, Ronaldo C. M. Correia, Edson dos Santos Moreira \\ Departamento de Ciências de Computação e Estatística - ICMSC - USP - São Carlos \\ ICMSC-USP, Seção de Pós-Graduação, Av. Dr. Carlos Botelho, 1465. Cx. Postal 668 São Carlos - SP \\ E-mail:\{shiro, ronaldo, edson\}@icmsc.sc.usp.br
}

\section{RESUMO}

Este artigo discute as principais necessidades e problemas de um ambiente para provimento de vídeo via Intemet. Testes foram realizados para a avaliação comparativa de várias altemativas tecnológicas para os vários componentes do sistema. As avaliações incluem sistema operacional (NT e Linux), o sistema de armazenamento (SCSI e RAID) e a rede (ethernet e uma switch ethernet com uma porta FDDI para o servidor)..

\section{ABSTRACT}

This paper discusses the main requirements and the problems concerned to the development an enviroment for video delivery over the internet. The tests were carried out to comparatively evaluate several hardware and software tecnological alternatives for the different components of the system. The evaluations include the operating systems (NT an Linux), storage system (SCSI alone and RAID) and network (single-bus ethernet and switched ethernet with a FDDI port for the server).

\section{Introdução}

À medida que se verifica o aumento do número de computadores na sociedade e a interconexão dos mesmos através de uma rede de computadores, surge também uma nova classe de aplicações dos mesmos. Dentro desta classe, aplicações que utilizam áudio e vídeo, começaram a aparecer com destaque. Toma-se cada vez mais complexas a criação de um ambiente computacional capaz de atender estas necessidades de maneira eficiente, pois a confecção de material multimídia (notadamente com fins educacionais) envolvem fatores como o armazenamento, a editoração e a apresentação eficiente desse material. [Mo97] [F195]

A questão do armazenamento de dados multimídia em ambientes WWW é ponto chave, uma vez que o fomecimento do material desejado deve ser gerenciado de forma eficiente para evitar sobrecarga do sistema devido ao grande volume dos dados e ao eventual grande número de usuários acessando o sistema. [Fe94] [Le94]

Apresentamos neste artigo a avaliação de um sistema servidor para aplicações multimídia sobre o ambiente WWW (Figura 1). O servidor tem que ser capaz de atender, sob demanda, a uma comunidade de clientes disposta em um ambiente WWW. Para o cliente, a utilização do servidor é totalmente transparente, ele precisa somente direcionar o browser para o endereço do vídeo (Figura 2). O servidor fica responsável pela procura deste vídeo na base de dados e disponibilização do mesmo. [Lo93] 


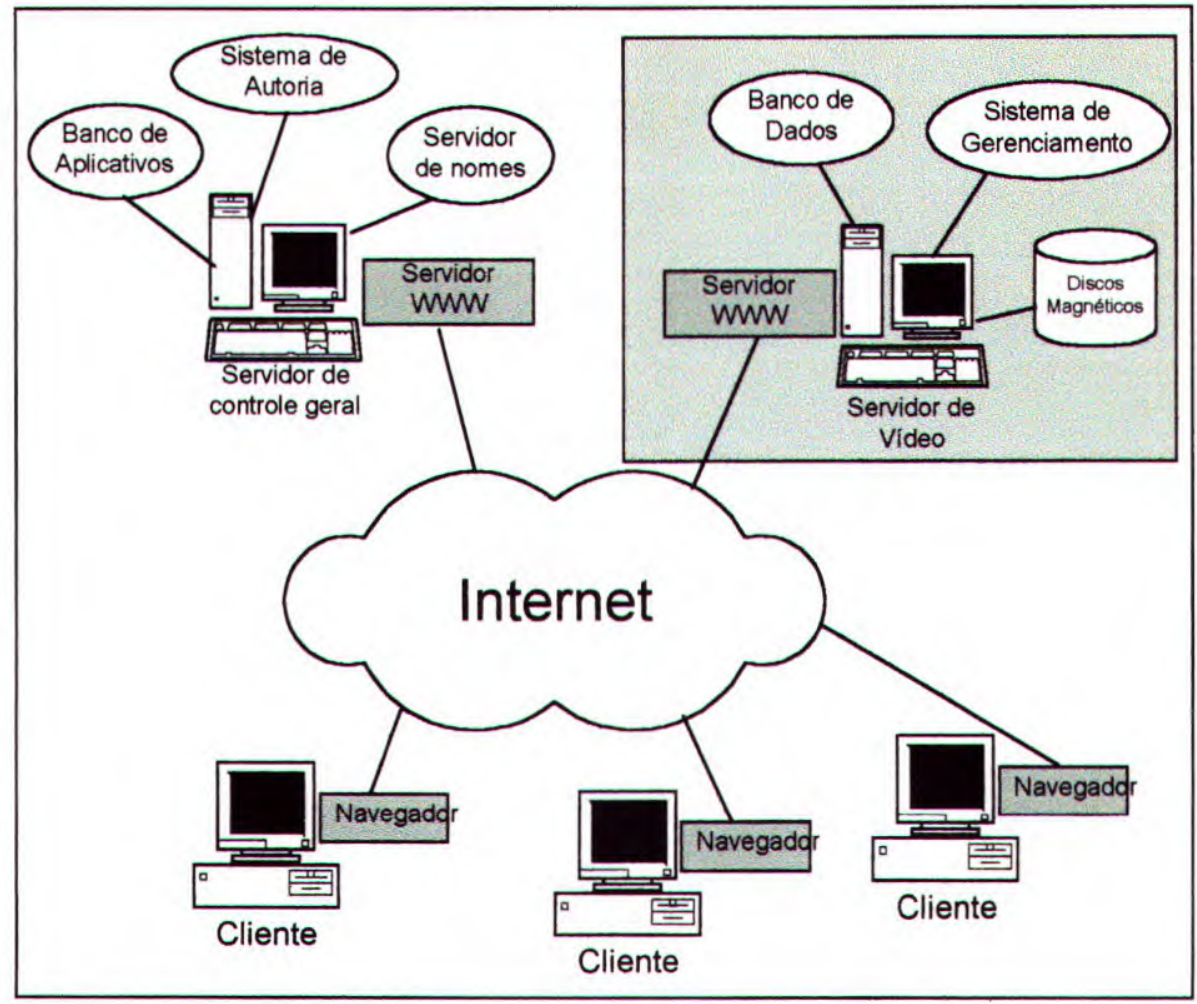

Figura 1 - O ambiente WWW

Estudo e avaliação dos diversos componentes envolvidos na cadeia de elementos e dutos (rede, cpu, meios de armazenamento, etc) que se encontram no caminho entre o armazenamento (no servidor de vídeo) e a apresentação (no cliente) foram realizados. Após o estudo, definiu-se a especificação do sistema, com a escolha da plataforma, sistema operacional, tipo de CPU, quantidade de memória RAM, o tipo e quantidade de discos rígidos, o tipo de placa de rede, etc.

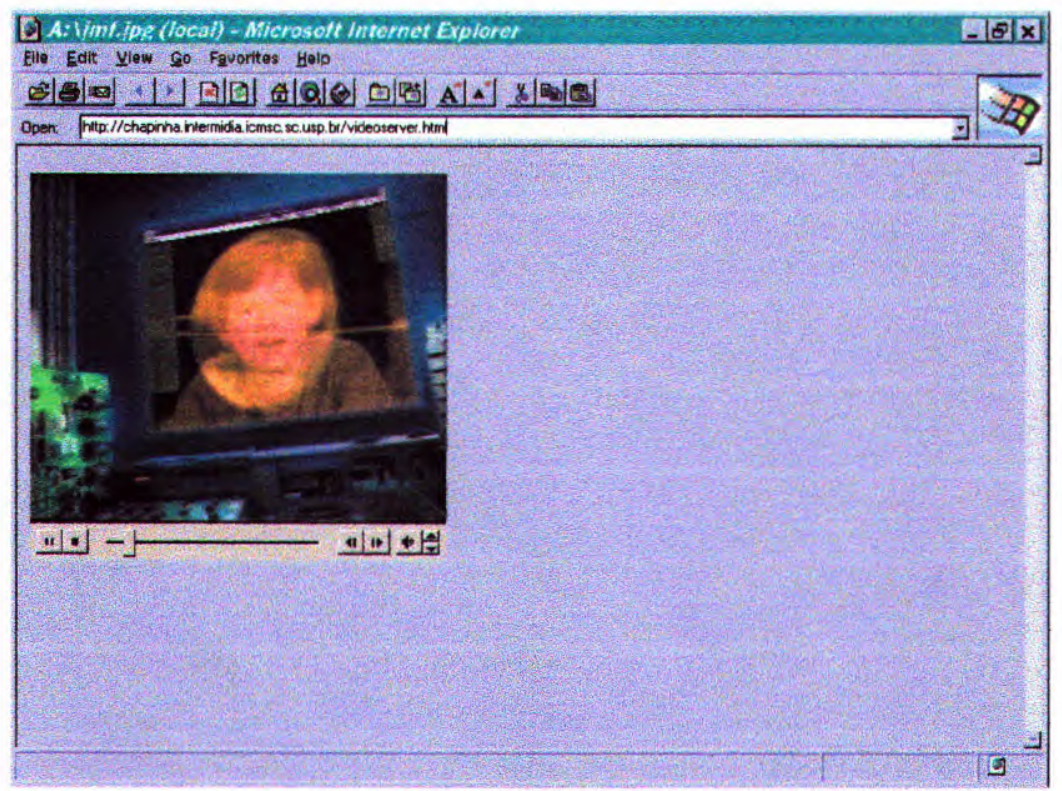

Figura 2-O ambiente do cliente 


\section{Especificação do Ambiente}

Para a realização das avaliações, foi montado um ambiente (figura 3) com as seguintes características:

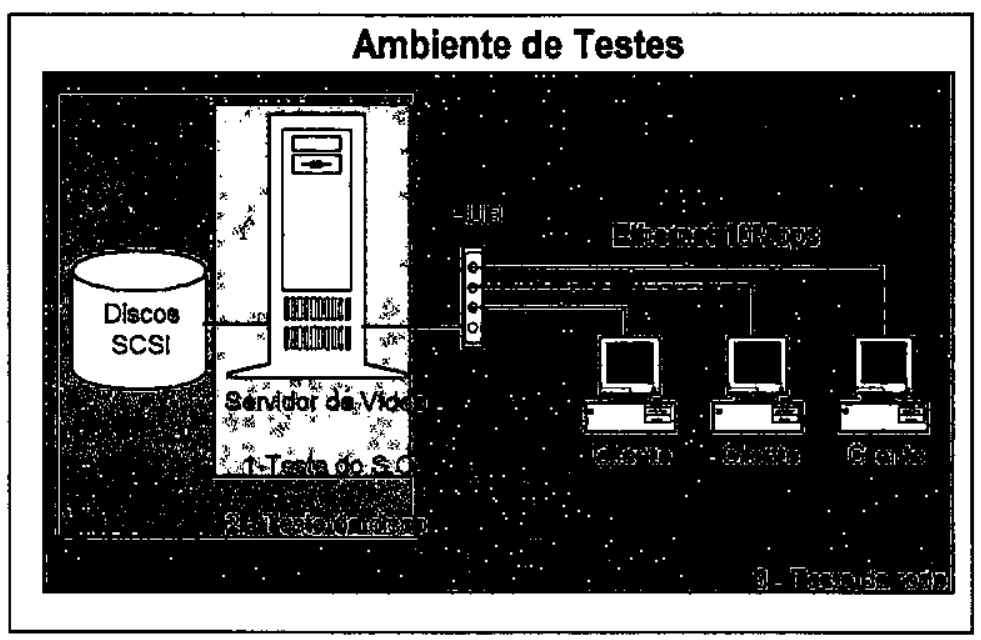

Figura 3 - Ambiente de testes

\subsection{0 hardware do servidor :}

- Processador Pentium/200 MMX

- $96 \mathrm{MB}$ de memória RAM

- 1 disco rígido Seagate 2 GB - SCSI

- 1 disco rígido Quantum 2 GB - SCSI

- 2 discos rígidos Quantum 4 GB - SCSI

- Placa controladora SCSI - Adaptec 3985

- Placa controladora SCSI - Adaptec 1740 *

- Placa controladora SCSI - Adaptec 2940AU *

- Placa de rede ethemet 3 com ISA

$2.2 \mathrm{O}$ hardware que compõem as estações, são :

- Processador Pentium/166 Mhz

- $32 \mathrm{MB}$ de memória RAM

- 1 disco rígido $1.7 \mathrm{MB}-\mathrm{IDE}$

- Placa de Rede Fast-Ethemet 3Com PCI 10/100 Mbps 


\subsection{Equipamentos de conectividade :}

- Switch digital DECswitch 900EF, possui uma porta FDDI, uma porta AUI e 4 portas RJ45 Ethernet 10Mbps

- Hub digital DECrepeater 900TM, possui 24 portas RJ45 Ethemet 10Mbps

- Placa FDDI digital DEFPA-AA, possui uma porta FDDI.

Não nos preocupamos com a placa de vídeo ou o monitor, o servidor não necessita de uma resolução gráfica boa, todo acesso ao servidor será feito no próprio microcomputador do cliente.

Definimos uma grande quantidade de memória principal(RAM) com o intuito de diminuir o acesso ao disco, já que o sistema operacional Linux, armazena na memória principal (cache) os últimos dados acessados. Com isso se dois ou mais usuários acessarem o mesmo arquivo, somente um acesso ao disco será feito.

Foi adotado o uso de discos SCSI, pela vantagens que ele oferece em relação a discos IDE, principalmente quando utilizados em servidores de arquivos. No primeiro disco SCSI (2GB) foi instalado o Sistema Operacional, assim como todos os softwares que compõe o servidor (servidor de httpd, gerenciador $\mathrm{mSQL}$, linguagem java, etc). Os arquivos de vídeo encontram-se nos outros 3 discos SCSI, que estão configurado para se tornar único disco lógico, através da tecnologia RAID, que consiste na criação de uma pilha de discos, onde vários discos são agrupados fazendo com o que o sistema operacional os reconheça como se fossem um único disco. Com isso quando um arquivo é copiado para este disco (lógico) cada parte do arquivo fica armazenado num dos discos (fisico) que compõe este disco lógico. A vantagem disto é o aumento do número de requisições que o computador pode atender concorrentemente, já que, na verdade, o acesso está ocorrendo em vários discos e não num único. Desta forma quando um arquivo é copiado para esse disco lógico cada bloco do arquivo é armazenado, paralelamente, em um disco fisico. A vantagem é uma redução no tempo de armazenamento e leitura dos arquivos armazenados. [Lo93]

Foi escolhida a controladora SCSI Adaptec 3985 por esta possuir uma característica especial em relação as controladoras tradicionais, pois esta possui 3 canais de dados independentes (como se fosse três controladoras SCSI), sendo que cada canal trabalha numa taxa de transmissão de $10 \mathrm{MBs}$, resultando com isso numa taxa total de 30 MBs. Desta forma cada disco que compõe o Raid foi colocado num canal diferente, com o objetivo de permitir acessos das informações de vídeo a uma taxa de 30MBs, além de melhorar o acesso concorrentes das informações. [Lo93].

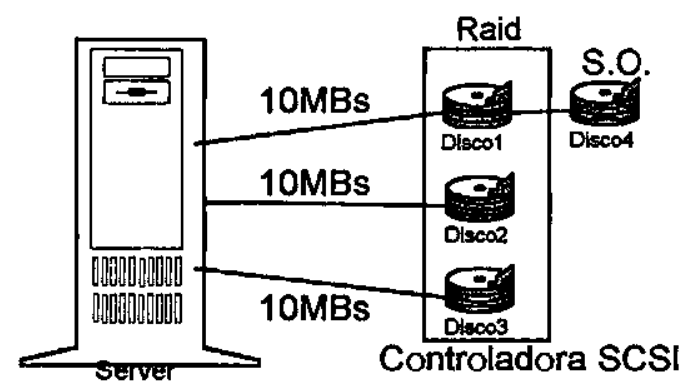

Figura 4 - Sistema de disco do servidor de vídeo 
Foi utilizado várias placas de rede: Ethernet NE2000, Ethernet 3com, Fast-Ethernet 3Com, FDDI digital, o qual foram utilizadas para medir o desempenho do servidor

\section{Metodologia Adotada}

A análise de desempenho de cada componente do sistema, foi feita utilizando o programa FTP, pois ele fornece o tempo total e taxa de transmissão na transferência de arquivo e está disponível em duas plataformas (Windows NT e Linux), além de funcionar de forma muito parecida daquela quando é requisitado pelo cliente um arquivo no ambiente WWW. Foram utilizados dois arquivos padrões, um de $7 \mathrm{MB}$ e outro de $81 \mathrm{MB}$, com o objetivo de verificar o sistema de cache e o desempenho na busca de informação de cada plataforma.

Os testes foram divididos em várias etapas, com o objetivo de medit em cada etapa um componente isolado do sistema, estas etapas foram:

- Sistema Operacional : visa medir o desempenho do sistema operacional no atendimento de requisições de disco e requisições da rede, foram feitos testes utilizando dois tipos de rede, a Ethemet $10 \mathrm{Mb}$ s no servidor e clientes, e FDDI 100Mbps no servidor e Ethernet $10 \mathrm{Mbps}$ nos clientes conectados através de uma Switch Ethernet.

- Acesso ao Disco : visa medir o desempenho do disco no atendimento de uma requisição feita por uma população de clientes, foram sub-divididos em várias partes:

- utilizando uma rede Ethemet no servidor e clientes, com sistema de arquivo tradicional.

- utilizando uma rede Ethernet no servidor e clientes, com sistema de arquivo com tecnologia Raid-0.

- Utilizando uma rede FDDI (100Mbps) no servidor e clientes conectados através de uma switch ethemet (10Mbps), com sistema de arquivo tradicional.

- Utilizando uma rede FDDI (100Mbps) no servidor e clientes conectados através de uma switch ethernet (10Mbps), com sistema de arquivo com tecnologia raid-0.

Nas tabelas que se seguem os números dos testes significam:

- 1 - 1 único acesso ao disco;

- 2 - 2 acessos concorrentes ao disco, utilizando o mesmo arquivo;

- 3 - 3 acessos concorentes ao disco, utilizando o mesmo arquivo;

- 4 - 2 acessos concorrentes ao disco, utilizando arquivos diferentes;

- 5 - 3 acessos concorrentes ao disco, utilizando arquivos diferentes;

\section{Testes Realizados}

Os testes realizados foram: 


\subsection{Testes com Sistemas Operacionais Diferentes - Linux e Windows NT}

O objetivo desse teste é comparar o desempenho do servidor de vídeo (com e sem a tecnologia RAID) em dois sistemas operacionais diferentes, Linux (versão Slakware 3.3 kernel 2.0.30) e Windows/NT 4.0. Os dois SOs foram instalados no servidor de vídeo. Foram realizadas transferências de arquivos seguindo a metodologia descrita acima.

\section{Desempenho do Sistema Operacional Local}

Os testes realizados compararam o desempenho do servidor, em plataforma Linux, quando esta utiliza e quando não utiliza RAID. Também comparam o desempenho do servidor em plataformas diferentes (Windows/NT e Linux) sem utilizar RAID. Nesse teste não foi possível comparar o desempenho do servidor entre os dois sistemas operacionais utilizando a tecnologia RAID, já que o Windows/NT não possui suporte para a placa Adaptec 3985 (controladora de RAID). Para os testes sem a tecnologia RAID empregou-se um (único) disco rígido SCSI quantum de $4.0 \mathrm{~GB}$ e uma placa controladora SCSI Adaptec 2940AU. A tabela 1 mostra os resultados obtidos com os testes, que expressam a taxa de transferência dos arquivos em KiloBytes por segundo.

Tabela 1 - Desempenho do servidor com SOs diferentes.

\begin{tabular}{|c|c|c|c|}
\hline Teste & WindowsNT (kbytes/ seg) & Linux (kbytes/ seg) & Linux c/ RAID (kbytes/ seg) \\
\hline $\mathbf{1}$ & 1372 & 2780 & 3530 \\
\hline $\mathbf{2}$ & 745 & 1917 & 2687 \\
\hline $\mathbf{3}$ & 522 & 1482 & 2138 \\
\hline $\mathbf{4}$ & 571 & 898 & 1483 \\
\hline $\mathbf{5}$ & 416 & 660 & 948 \\
\hline
\end{tabular}

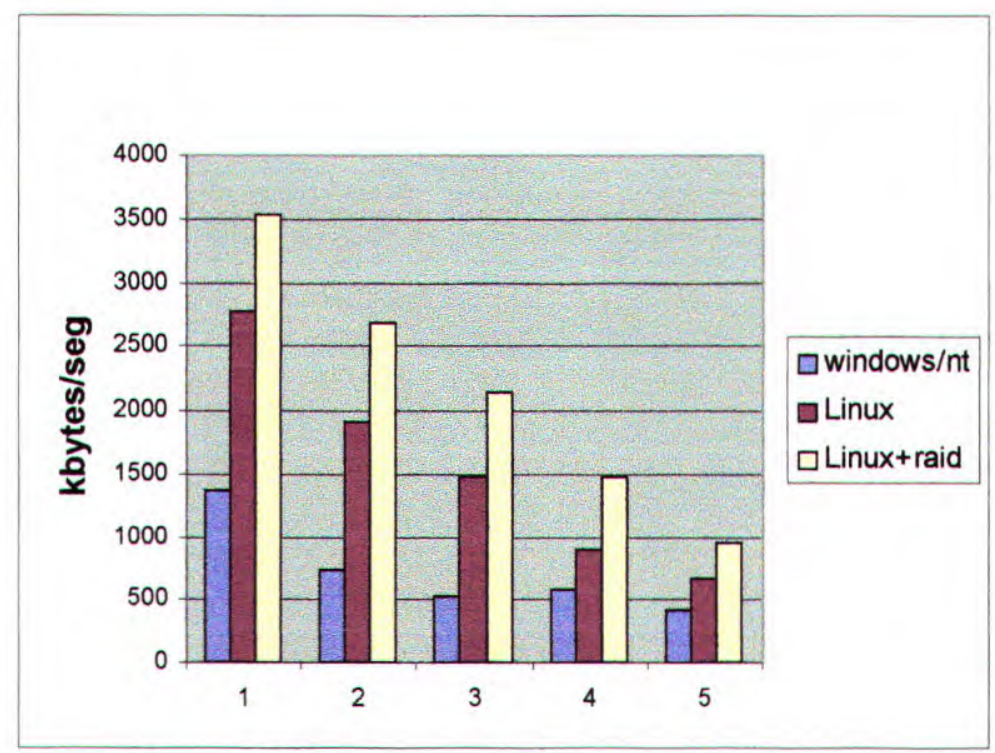

Figura 5 - Desempenho do servidor com sistemas operacionais diferentes. 
Conclui-se que o sistema operacional Windows/NT, em sua configuração padrão, apresenta um desempenho inferior ao sistema operacional Linux no atendimento a requisição locais de arquivos (tabela $1 \mathrm{e}$ figura 5). Outra constatação é que a utilização da tecnologia RAID (de forma local) no gerenciamento do sistema de arquivos obtém um desempenho superior em relação do sistema de arquivos tradicional (único disco).

\section{Desempenho do Sistema Operacional em Rede}

O teste anterior apontou um desempenho melhor do servidor de vídeo, em ambiente local, com a plataforma Linux. Como os sistemas operacionais em questäo possuem formas diferentes de gerenciar o envio de informações pela rede, buscou-se verificar se o Linux continuaria oferecendo um melhor serviço quando a transferência de arquivos ocorresse de forma remota.

Utilizaram-se duas configurações de rede diferentes. Em uma configuração o servidor e as estações clientes estão conectados através de uma rede Ethernet de $10 \mathrm{Mbps}$ (figura 0), na outra é utilizada uma rede FDDI de 100Mbps conectando o servidor e os clientes através de um Switch Ethernet de $10 \mathrm{Mbps}$ (figura 7). A configuração do servidor utilizada nesse teste foi a mesma configuração sem RAID do teste anterior.

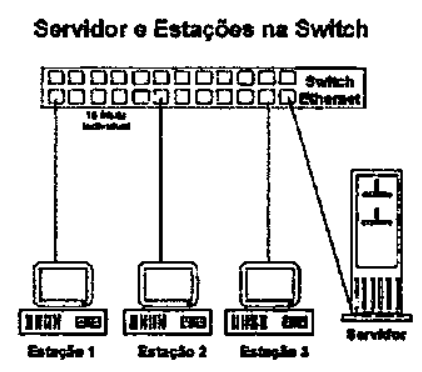

Figura 6 - Rede Ethernet para testes

\section{Servidor no Anel FDDI e Estaçőes na Switch}

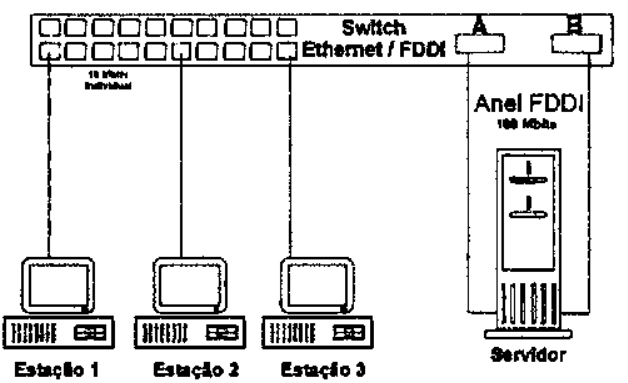

Figura 7 - Rede FDDI+Switch ethernet para testes

us zestutiauus unuuus uus usstes subre a rede Ethernet são mostrados na tabela 2 e na figura 8. Os resultados dos testes sobre a rede FDDI são mostrados na tabela 3 e a figura 9. A figura 10 compara 0 percentual de utilização da rede Ethernet entre os dois sistemas operacionais.

Tabela 2 - Desempenho sobre rede Ethernet.

\begin{tabular}{|c|c|c|}
\hline Teste & WindowsNT (kybtes/ seg) & Linux (kbytes/ seg) \\
\hline $\mathbf{1}$ & 783 & 1069 \\
\hline 2 & 524 & 569 \\
\hline 3 & 420 & 426 \\
\hline $\mathbf{3}$ & 553 & 568 \\
\hline $\mathbf{5}$ & 380 & 386 \\
\hline
\end{tabular}




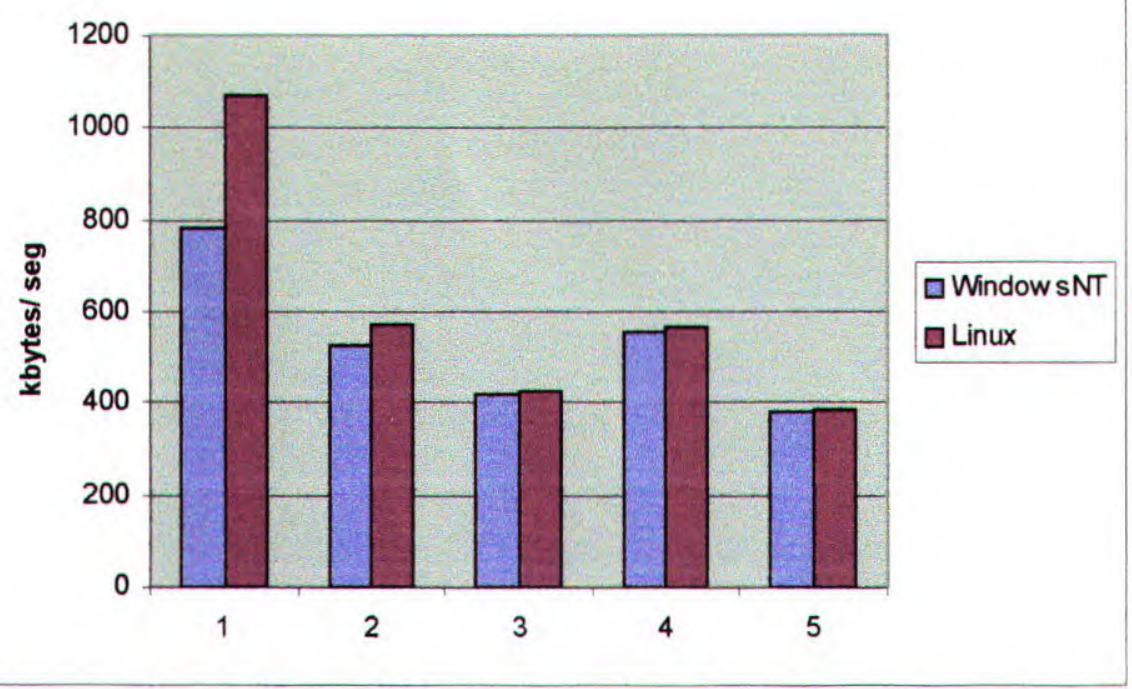

Figura 8 - Desempenho do S.O. - sistema de rede Ethernet

Tabela 3 - Desempenho sobre rede FDDI.

\begin{tabular}{|c|c|c|}
\hline Teste & WindowsNT (kybtes/ seg) & Linux (kbytes/ seg) \\
\hline $\mathbf{1}$ & 1039 & 1069 \\
\hline $\mathbf{2}$ & 1060 & 1075 \\
\hline $\mathbf{3}$ & 1000 & 1065 \\
\hline $\mathbf{4}$ & 986 & 1064 \\
\hline $\mathbf{5}$ & 779 & 1008 \\
\hline
\end{tabular}

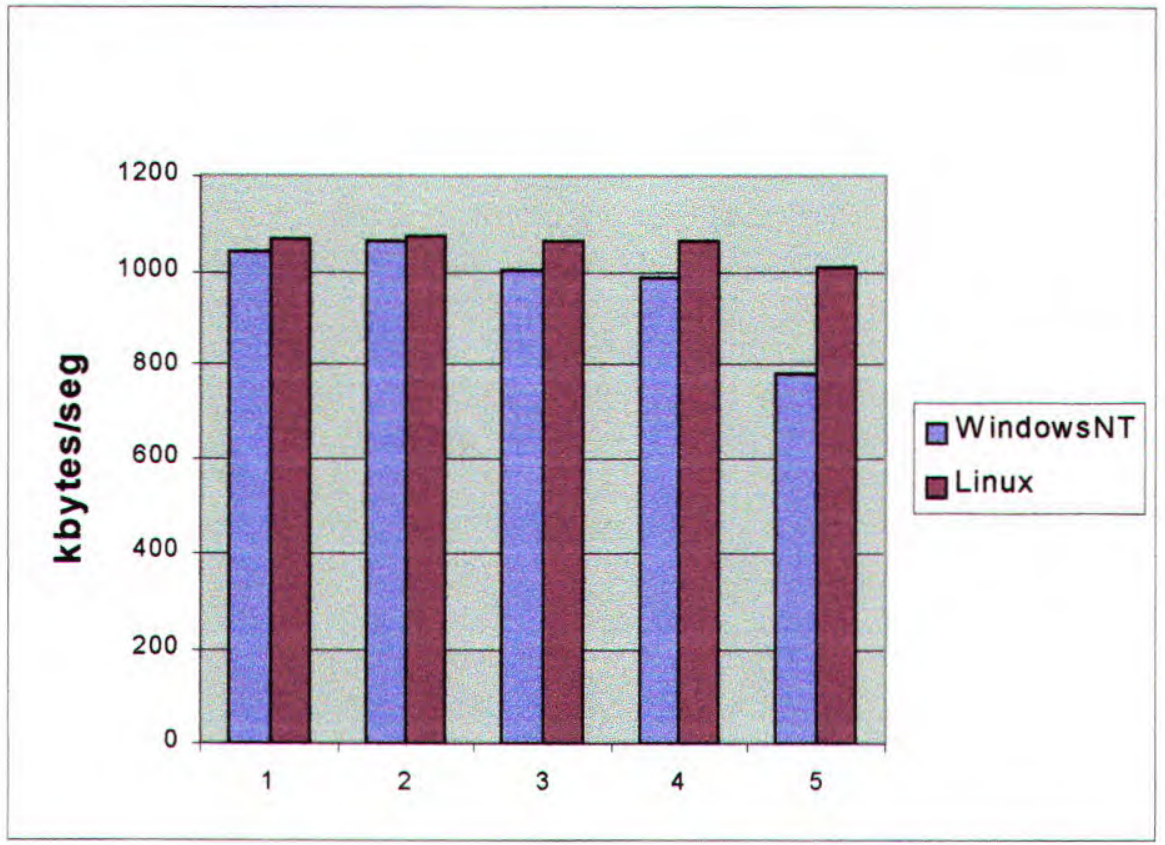

Figura 9 - Desempenho do S.O. - sistema de rede FDDI + Switch Ethernet. 


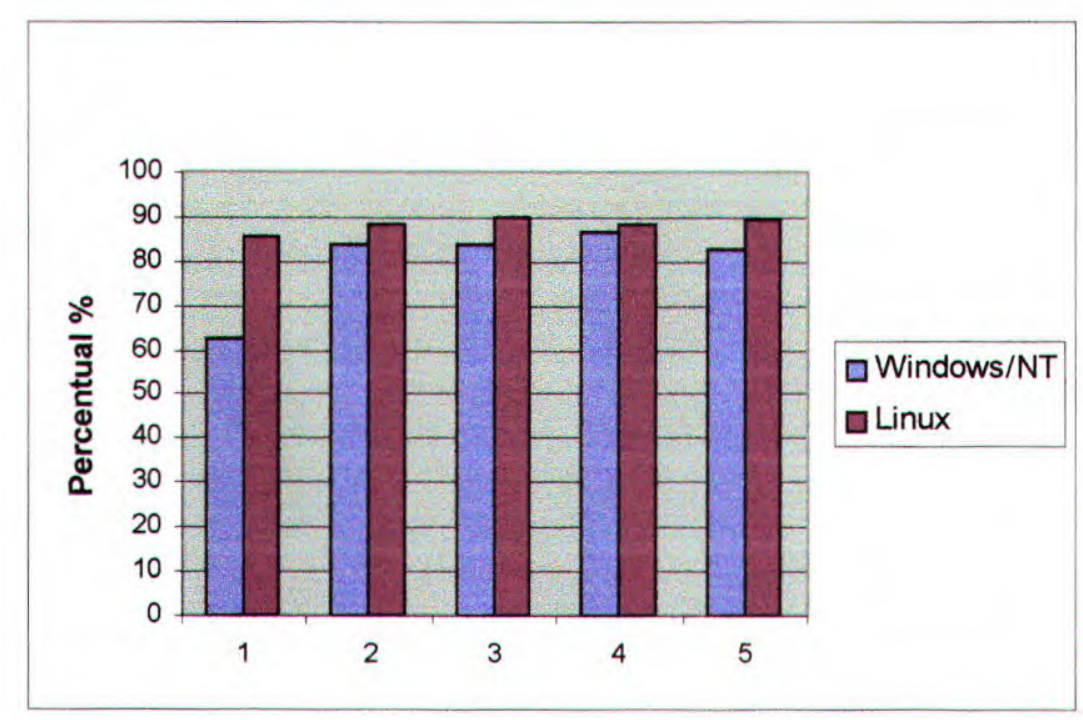

Figura 10 - Percentual de utilização da rede Ethernet.

$\mathrm{O}$ Windows/NT apresentou um desempenho inferior ao Linux na transferência dos arquivos nos dois casos analisados (Ethernet e FDDI).

Outra conclusão é que a rede Ethernet se torna um gargalo para um número médio de clientes (figura 8). Analisando a figura 10 podemos observar que no teste 1 , o gargalo é o sistema de rede do Windows/NT, já nos testes seguintes o gargalo é a rede Ethernet (10Mbps), já que a sua utilização chega a $90 \%$, que para a rede Ethernet é uma taxa alta. No sistema operacional Linux, o gargalo sempre é a rede.

$\mathrm{Na}$ figura 9 podemos concluir que o gargalo inicialmente é a rede Ethernet (10Mbps), porém para um número maior de clientes, o gargalo se torna o sistema de arquivo, concluímos também que gerenciamento de acesso ao disco do WindowsNT é menos eficiente que do Linux.

\subsection{Avaliação do Acesso Remoto ao Disco via Rede Ethernet}

Quando o sistema RAID é instalado em um computador, ele promove mudanças na forma de acesso e armazenamento dos dados, modificando o sistema de arquivos.

O objetivo desse teste foi comparar o desempenho do servidor de vídeo, sobre uma rede de computadores, ao se utilizar um sistema de arquivo tradicional (único disco) e utilizando o sistema de arquivo com a tecnologia Raid-0. Os testes foram realizados sobre o sistema operacional Linux. O servidor foi configurado com a controladora SCSI Adaptec 3985 (controladora de RAID) e o disco lógico RAID foi montado sobre os três discos rígidos SCSI quantum (1 de $2 \mathrm{~GB}$ e 2 de $4 \mathrm{~GB}$ ). Os resultados obtidos são mostrados na tabela 4 e na figura 11.

Tabela 4 - Desempenho do servidor sobre ethernet.

\begin{tabular}{|c|c|c|}
\hline Teste & Um único disco SCSI & Tecnologia RAID (kbytes/ \\
\hline 1 & 1064 & 1069 \\
\hline 2 & 579 & 569 \\
\hline 3 & 427 & 426 \\
\hline 4 & 559 & 568 \\
\hline 5 & 388 & 386 \\
\hline
\end{tabular}




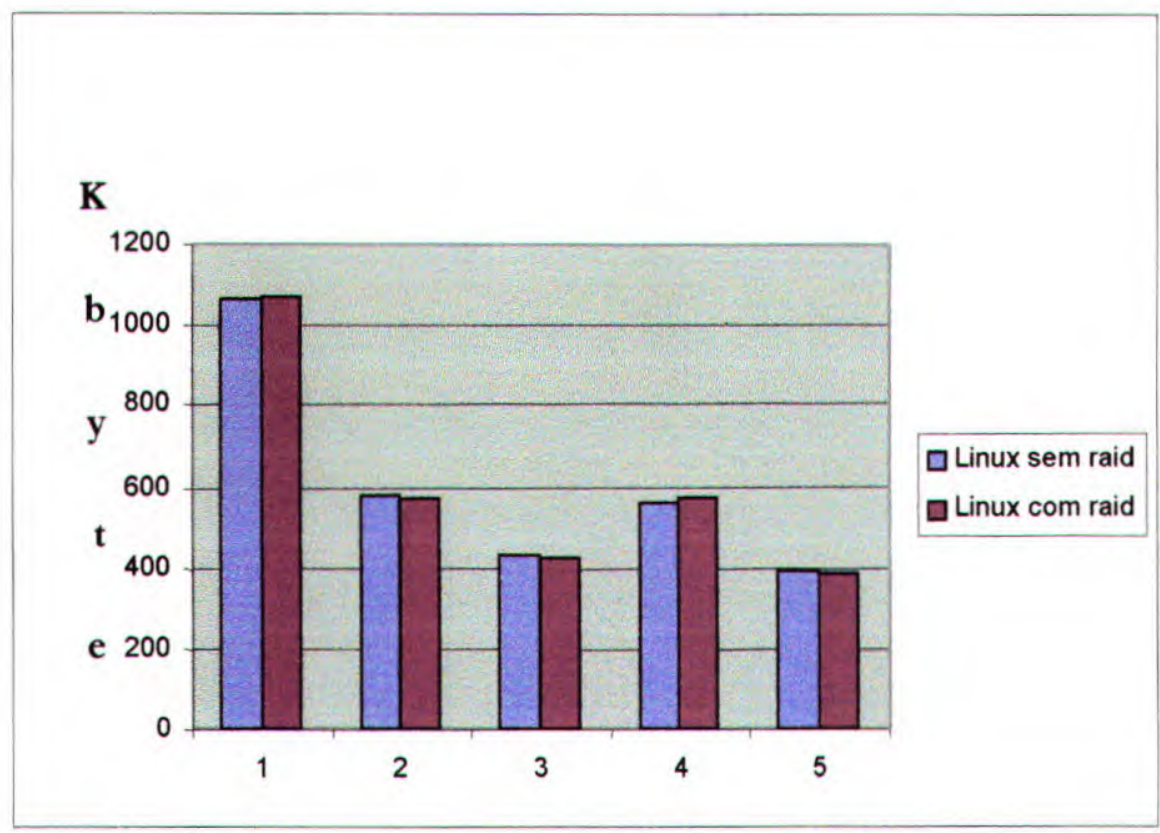

Figura 11 - Desempenho do Sistema de Arquivo sobre uma rede Ethernet (10Mbps).

Conclui-se que o gargalo do sistema é a rede Ethernet (10Mbps). Tanto o sistema de arquivo tradicional quanto no sistema de arquivo com tecnologia RAID apresentaram resultados semelhantes. A utilização da rede neste teste foi de aproximadamente $90 \%$, que é alta para a rede Ethernet (10Mbps).

\subsection{Avaliação do Acesso Remoto ao Disco via Rede FDDI}

Este teste visa medir o desempenho ao se utilizar um sistema de arquivo tradicional e utilizando o sistema de arquivo com a tecnologia Raid-0 sobre uma rede onde o servidor está conectado através de uma rede FDDI (100Mbps) e as estações estão conectados através de uma switch Ethernet (10Mbps). Os testes foram realizados sobre o Sistema Operacional Linux e com a controladora SCSI Adaptec 3985, o disco lógico RAID foi montado sobre os três discos rígidos SCSI quantum (1 de 2GB e 2 de 4GB), placa de rede digital FDDI DEFPA-AA. Os resultados obtidos são mostrados na tabela 5 e na figura 12.

Tabela 5 - Desempenho do servidor sobre rede FDDI.

\begin{tabular}{|c|c|c|}
\hline Teste & Um único disco SCSI & Tecnologia RAID (kbytes/ \\
\hline $\mathbf{1}$ & 1069 & 1078 \\
\hline $\mathbf{2}$ & 1075 & 1076 \\
\hline $\mathbf{3}$ & 1065 & 1063 \\
\hline $\mathbf{4}$ & 1064 & 1061 \\
\hline $\mathbf{5}$ & 1008 & 1067 \\
\hline
\end{tabular}

